Florida International University FIU Digital Commons

$3-27-2015$

\title{
Geographical Literacy, Attitudes, and Experiences of Freshman Students: A Qualitative Study at Florida International University
}

Daniela F. Ottati

dotta001@fiu.edu

DOI: $10.25148 /$ etd.FI15032148

Follow this and additional works at: https://digitalcommons.fiu.edu/etd

Part of the Curriculum and Instruction Commons, Elementary Education and Teaching Commons, Geographic Information Sciences Commons, Higher Education and Teaching Commons, Human Geography Commons, Junior High, Intermediate, Middle School Education and Teaching Commons, Physical and Environmental Geography Commons, and the Secondary Education and Teaching Commons

\section{Recommended Citation}

Ottati, Daniela F., "Geographical Literacy, Attitudes, and Experiences of Freshman Students: A Qualitative Study at Florida International University" (2015). FIU Electronic Theses and Dissertations. 1851.

https://digitalcommons.fiu.edu/etd/1851 


\section{FLORIDA INTERNATIONAL UNIVERSITY \\ Miami, Florida}

\section{GEOGRAPHICAL LITERACY, ATTITUDES, AND EXPERIENCES}

OF FRESHMAN STUDENTS: A QUALITATIVE STUDY

\section{AT FLORIDA INTERNATIONAL UNIVERSITY}

A dissertation submitted in partial fulfillment of the

requirements for the degree of

DOCTOR OF PHILOSOPHY

in

CURRICULUM AND INSTRUCTION

by

Daniela Fabiana Ottati Reperger

2015 
To: $\quad$ Dean Delia C. Garcia

College of Education

This dissertation, written by Daniela Fabiana Ottati Reperger, and entitled Geographical Literacy, Attitudes, and Experiences of Freshman Students: A Qualitative Study at Florida International University, having been approved in respect to style and intellectual content, is referred to you for judgment.

We have read this dissertation and recommend that it be approved.

$\begin{array}{r}\text { Sarah Mathews } \\ \hline \text { Aixa Pérez-Prado } \\ \hline \text { Jeffrey Onsted } \\ \hline \text { Hilary Landorf, Major Professor }\end{array}$

Date of Defense: March 27, 2015

The dissertation of Daniela Fabiana Ottati Reperger is approved.

Dean Delia C. Garcia

College of Education

Dean Lakshmi N. Reddi

University Graduate School

Florida International University, 2015 


\section{DEDICATION}

I dedicate this dissertation to my parents, who instilled in me a love for teaching and learning. I also dedicate my work to the inspiring educators that over the years I crossed paths with in Uruguay, the United States, and Italy. Gracias. Thank you. Grazie. 


\section{ACKNOWLEDGMENTS}

Being grateful is one of the many qualities my family has taught me. The Ph.D. journey is one where collaboration is necessary and I have been extremely lucky to count with exceptional individuals, who have offered me their expertise and guidance.

I want to thank my parents Jorge and Susana, and my brothers Jorge and Fernando for their constant support and for allowing me to follow a motto I believe in: John Cotto Dana’s “who dares to teach must never cease to learn.” I am thankful to my native Uruguay for providing me with a well-rounded instruction, and for believing in the power of education and granting free access to it at the primary, secondary, and tertiary levels. My long-time friend and future medical field professional Micaela was crucial in giving me the extra push I needed when I was contemplating when to begin my doctoral program. I want to thank FIU for being such a wonderful institution to study and work at. I enrolled as a freshman in 2005 and almost 10 years and four degrees later I can say that we grew together. I have taken memorable courses with admirable professors, held numerous leadership positions, and met great individuals along the way.

I would like to thank Dr. David Park, Mrs. Regina Miller, and Mrs. Dianne Valdivia for recommending me for admission to the doctoral program. Dr. Linda SpearsBunton was the first individual I contacted when I applied. She believed in me since that very first email and if I am where I am today it is thanks to the opportunity she gave me. At the College of Education's Office of Graduate Studies I found two amazing allies: Ms. Caprila Almeida and Ms. Katie Pereyra. Two dedicated professionals who would explain in detail every deadline and every requirement. Their guidance and reminders allowed me to stay on track and pushed me into the right direction at all times. 
I could not have asked for a better group of individuals to be in my dissertation committee. Every conversation with Dr. Hilary Landorf, my major professor, renewed my enthusiasm. Working with such brilliant, organized, and dedicated professional has allowed me to complete challenging tasks in a very smooth manner. Dr. Sarah Mathews provided me with a key piece of advice: to relate all of my assignments to my dissertation topic. This allowed me to have plenty of information read by the time I started working on my proposal. Dr. Aixa Perez-Prado was crucial at the proposal stage as she grasped the essence of my proposed work. She was able to articulate exactly what was going through my mind. I thank Dr. Jeffrey Onsted's willingness to help an education major with a passion for geography. It was a pleasure to work with such admirable geographer, who helped me determine what instrument to use for the quantitative component.

Two other individuals have been of immense help: Dr. Linda Bliss and Dr. Mido Chang. They have taken the time to provide me with valuable feedback that has improved the quality of my work. I appreciated Dr. Bliss' in-depth analyses of my writing and Dr. Chang's feedback on Phase I of my study.

I gratefully acknowledge Drs. Benjamin Smith and Milan Kubiatko for providing feedback on my survey. I thank Dr. Charlie Andrews, who granted me access to one of his courses, where I conducted the pilot. I want to acknowledge Dr. Abdelhamid Meziani, Chair of the FIU Department of Mathematics \& Statistics, and to Professors Elizabeth Nicoli-Suco and Phillppe Rukimbira for allowing me to collect data in their Finite Math sections. Last, but not least, I would like to thank the wonderful freshman students who participated in my study. They took the time to complete my survey and participate in the interviews. Without their collaboration, this study would not have been possible! 


\title{
ABSTRACT OF THE DISSERTATION \\ GEOGRAPHICAL LITERACY, ATTITUDES, AND EXPERIENCES \\ OF FRESHMAN STUDENTS: A QUALITATIVE STUDY \\ AT FLORIDA INTERNATIONAL UNIVERSITY
}

\author{
by \\ Daniela Fabiana Ottati Reperger \\ Florida International University, 2015 \\ Miami, Florida \\ Professor Hilary Landorf, Major Professor
}

The purpose of the study was to explore the geography literacy, attitudes and experiences of Florida International University (FIU) freshman students scoring at the low and high ends of a geography literacy survey. The Geography Literacy and ABC Models formed the conceptual framework. Participants were freshman students enrolled in the Finite Math course at FIU. Since it is assumed that students who perform poorly on geography assessments do not have an interest in the subject, testing and interviewing students allowed the researcher to explore the assumption.

In Phase I, participants completed the Geography Literacy Survey (GLS) with items taken from the 2010 NAEP Geography Subject Area Assessment. The low 35\% and high 20\% performers were invited for Phase II, which consisted of semi-structured interviews. A total of 187 students participated in Phase I and 12 in Phase II.

The primary research question asked was what are the geography attitudes and experiences of freshman students scoring at the low and high ends of a geographical 
literacy survey? The students had positive attitudes regardless of how they performed on the GLS.

The study included a quantitative sub-question regarding the performance of the students on the GLS. The students' performance on the GLS was equivalent to the performance of $12^{\text {th }}$ grade students from the NAEP Assessment. There were three qualitative sub-questions from which the following themes were identified: the students' definition of geography is limited, students recall more out of school experiences with geography, and students find geography valuable. In addition, there were five emergent themes: there is a concern regarding a lack of geographical knowledge, rote memorization of geographical content is overemphasized, geographical concepts are related to other subjects, taking the high school level AP Human Geography course is powerful, and there is a need for real-world applications of geographical knowledge.

The researcher offered as suggestions for practice to reposition geography in our schools to avoid misunderstandings, highlight its interconnectedness to other fields, connect the material to real world events/daily decision-making, make research projects meaningful, partner with local geographers, and offer a mandatory geography courses at all educational levels. 


\section{TABLE OF CONTENTS}

CHAPTER

PAGE

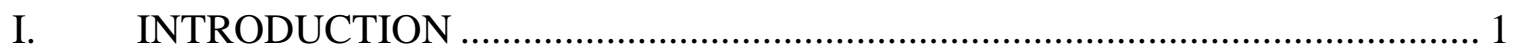

Current State of Geography Education ............................................................. 1

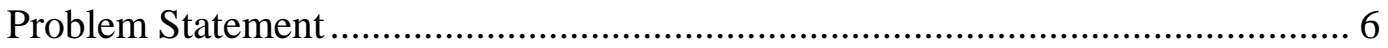

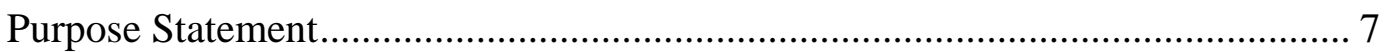

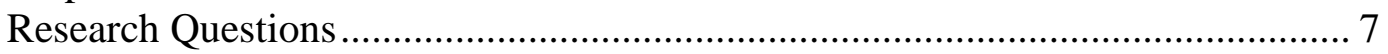

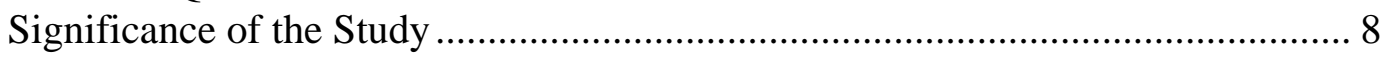

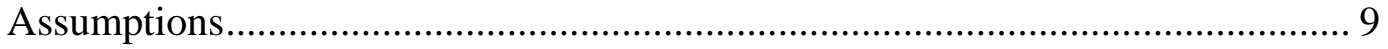

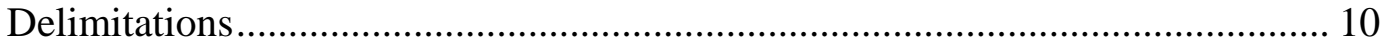

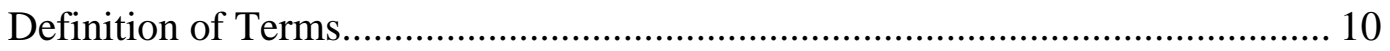

Conceptual Frameworks ........................................................................... 11

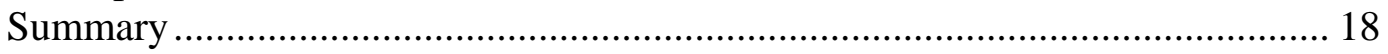

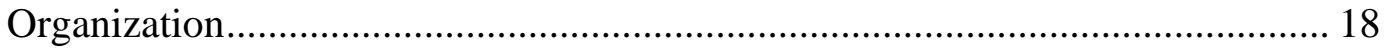

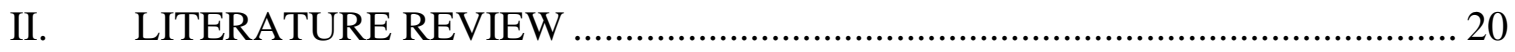

Brief Past and Present of Geography in U.S. Higher Education ......................... 20

Challenges in Geography Education............................................................... 21

Why Geography and Geography Education Research Matter............................. 23

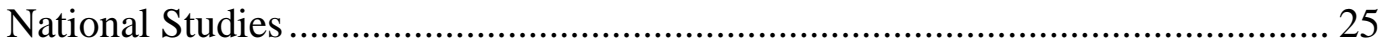

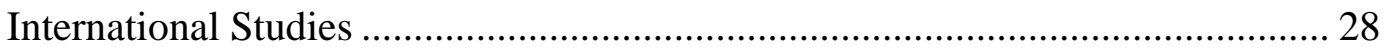

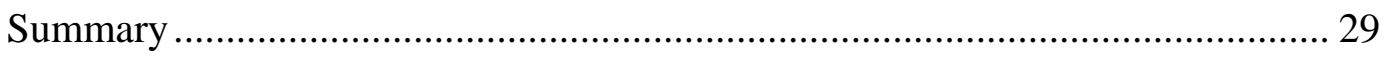

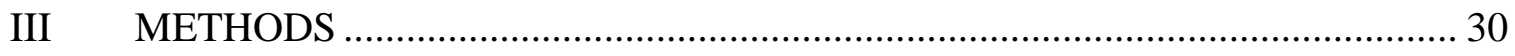

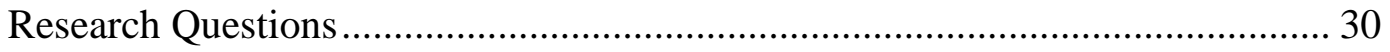

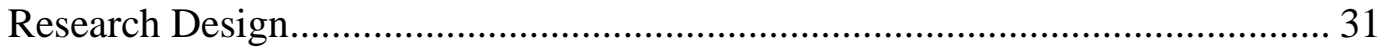

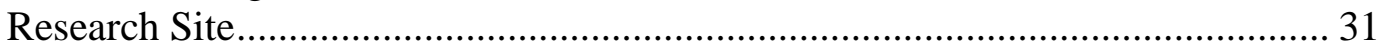

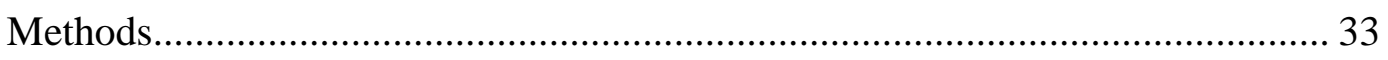

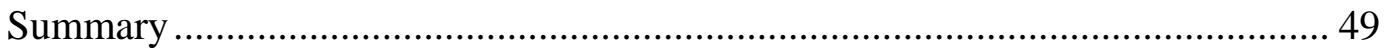

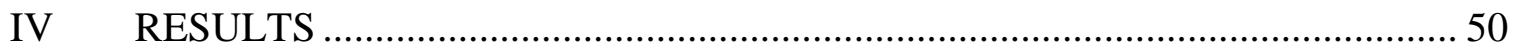

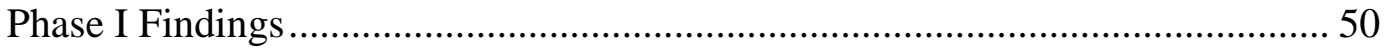

Phase II Findings........................................................................................ 53

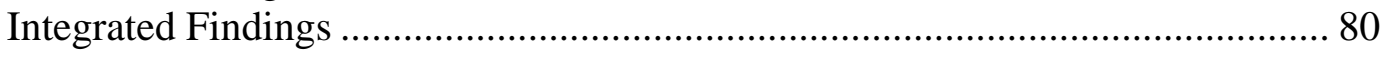

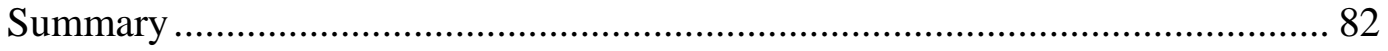

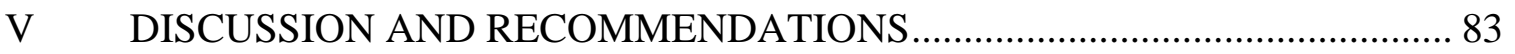

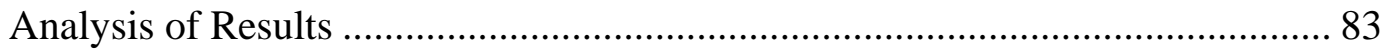

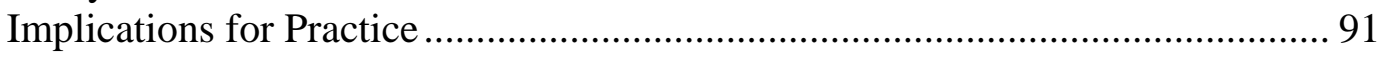

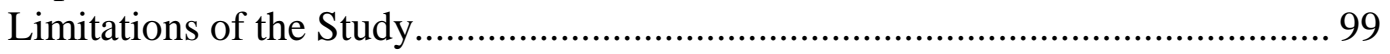

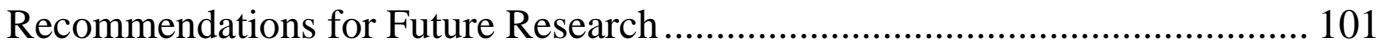

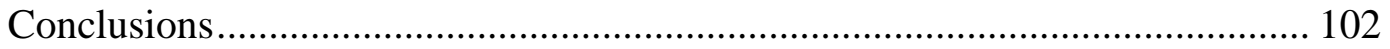




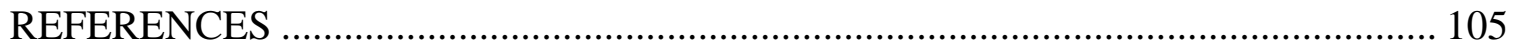

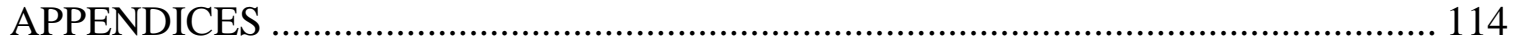

VITA 


\section{ABBREVIATIONS AND ACRONYMS}

$\begin{array}{ll}\text { ABC } & \text { Affect, Behavior and Cognition } \\ \text { FIU } & \text { Florida International University } \\ \text { GIS } & \text { Geography Education National Implementation Project } \\ \text { GLS } & \text { Geography Literary Survey } \\ \text { GPS } & \text { Global Positioning System } \\ \text { MMC } & \text { Modesto Maidique Campus } \\ \text { NAEP } & \text { National Assessment of Educational Progress } \\ \text { NCSS } & \text { National Council for the Social Studies } \\ \text { NGS } & \text { National Geographic Society } \\ \text { TGIF } & \text { Teaching Geography is Fundamental }\end{array}$




\section{CHAPTER I \\ INTRODUCTION}

In an increasingly complex, troubled and closely intertwined world community of cultures and nations, Americans simply do not know much about our global neighbors (or, for that matter, about ourselves in a geographic sense). We have little understanding of, or feeling for, other lands and peoples. We are largely ignorant of their ways of living, environments and natural resources, human capabilities, and cultural attainments. We also know little about their similarities and differences, their hopes and dreams, or their problems and needs. Perhaps of greatest importance, we fail to understand how closely linked and important we have become to one another. How can Americans possibly expect to maintain a position of respect and leadership in a world of cultures and nations about which we know-and seemingly care-so little? (Gritzner, 2003, p. 90)

\section{Current State of Geography Education}

In this statement, Dr. Charles Gritzner, a distinguished Professor and Graduate Coordinator of Geography at South Dakota State University (Department: Geography, n.d.), highlights the concern of numerous teachers and individuals regarding the present state of geography education in the United States. Despite ongoing efforts by educators and organizations to promote geographical literacy in the nation, studies suggest that the performance of American students in geographical assessments is still lower than their international counterparts. Research studies conducted at the national level, such as the Geographic Literacy Study (National Geographic Education Foundation, 2006) have echoed Dr. Gritzner’s view. 
According to the results of the 2006 Geographic Literacy Study, conducted by National Geographic-Roper Public Affairs on a sample of 510 United States individuals, "most young adults between the ages of 18 and 24 demonstrate a limited understanding of the world, and they place insufficient importance on the basic geographic skills that might enhance their knowledge” (National Geographic Education Foundation, 2006, p. 6). Results from the study's past edition, in the year 2002, were no different, and there was little to no improvement from the 1988 survey (National Geographic Education Foundation, 2002). These findings come from a nation where, in most cases, geography education takes a minor role in the social studies curriculum (Gritzner, 2003).

Among the alarming findings of the 2006 survey were that $50 \%$ of the participants believed it is not absolutely necessary to know the location of countries in the news. Their performance on the survey was aligned with this belief as $63 \%$ were not able to find Iraq on a Middle East map, despite the news coverage of the 2003 U.S. invasion, and 75\% could not find Indonesia on a map even after images of the tsunami and its devastation were all over the news in 2005. Young adults also struggled with national knowledge; for example Mississippi could not be located by 50\% of the participants on a map, in spite of the media coverage of the 2005 hurricane, and only 50\% were able to identify New York State on a map. Participants believed English was the most widely spoken language in the world and $60 \%$ did not speak a foreign language fluently. Furthermore, almost $50 \%$ thought it is not absolutely necessary to be able to speak a foreign language and only 20\% possessed a passport (National Geographic Education Foundation, 2006). Along with attitudes, maps skills and the relation between geographical knowledge and current events, students were also tested on their 
geographical skills. It was found that despite some functional skills, a good percentage of young Americans lack the basic practical skills necessary for safety and employment in today's world. For example:

- One-third (34\%) would go in the wrong direction in the event of an evacuation; and

- As many as one-third (32\%) would miss a conference call scheduled with colleagues in another time zone (National Geographic Education Foundation, 2006).

The National Geographic Education Foundation (2006) pointed out that "these results suggest that young people in the United States, the most recent graduates of our educational system, are unprepared for an increasingly global future” (p. 7).

Shortly after the study's report was released the results were highlighted in the media. Several news reporters agreed that "far too many [students] lack even the most basic skills for navigating the international economy or understanding the relationships among people and places that provide critical context for world events" (Study: Geography Greek, 2006, para, 4). National Geographic also emphasized that “young Americans are alarmingly ignorant of the relationships between places that give context to world events” (Young Americans Still Lack, 2006, para. 5). At that time, National Geographic president John Fahey, now chairman of the National Geographic Society (NGS), added that "geographic illiteracy impacts our economic well-being, our relationships with other nations and the environment, and isolates us from the world" (Young Americans shaky, 2006, para. 3). 
Geographic illiteracy in schools is a disturbing trend, but not a recent one. The struggle is not only present at institutions of higher education; it has its roots as early as in elementary school. For this reason the National Council for the Social Studies (NCSS) as well as the NGS have promoted the Teaching Geography is Fundamental (TGIF) Act, which would "ensure federal support for geography comparable to the eight other core academic subjects identified by the No Child Left Behind” (Daly, 2008, par. 1). It is important to highlight that TGIF was also introduced in the 109th, 110th, 111th, and 112th Congresses (with no success), and that geography is the only No Child Left Behind core academic subject that has never received any federal funding (Education Foundation Policy Initiative, n.d.), both of which suggests little national support for geography education reform efforts. In addition, the National Geographic Network of Alliances for Geographic Education has partnered university faculty members with K-12 educators in order to support geographic literacy across different states (About Us - Network of Alliances for Geographic Education, 2012).

The lack of geographical literacy is as problematic as its lack of instruction because "at some point, America decided that providing kids with a geography education didn’t matter” (Sparks, 2008, para. 1). Another major issue is that geography education has often been limited to having students memorize the names of states and their capitals, recite definitions, or color maps, all of which are now discredited methods of instruction (Stallworth, \& Braun, 2000). Even the father of American geography, William Morris Davis, worked intensely back in the 1890s in order to rescue geography from relying too much on factual information (Martin, 2005). 
Even though there are components of geography to which students are rarely exposed, not even the basic concepts are mastered. The two facts that create tension concerning geography education are that students tend to only associate the subject with the memorization of locations and facts (a crude definition of geography) and secondly that geography is about more than memorizing what is where (absolute location).

According to Savage and Armstrong (2000), a good geography lesson is one that focuses on having students thinking geographically. In order to do so, students need to start developing observational skills that will prompt them to ask questions about the world that surrounds them. Thus, geography might contribute to the "imagination of alternatives and concrete demonstrations of other ways of living in a society” (Massey, 2009, p. 137). In addition, Blij (2012) has urged the nation as a democratic one to be responsible and not to lessen the amount of coverage of international news. According to Blij, "geographic illiteracy poses a huge risk to America’s national security” (p. xii) since "there is ample evidence that inadequate geographic comprehension contributes significantly to flawed policy making” (p. xii).

The poor instruction is accompanied by a lack of time allotted for geographyrelated instruction. Nowadays “students aren’t learning subjects such as geography and history as teachers spend more time on math and reading to accommodate standardized tests” said Roger M. Downs, a concerned Pennsylvania State University geography professor (Hechinger, 2011, para. 3).

Curriculum-makers are failing to understand that depriving students of geographical knowledge will also deny them understanding of other disciplines: 
Geographic knowledge provides a foundation for studying history, economics, political science, architecture, environmental science, demography, geology, and more. In fact, geographic knowledge correlates with other positive traits, such as having a higher level of education, traveling overseas, and following current events. (Sparks, 2008, para. 4)

The results of the 2006 Geographic Literacy Study should not be a surprise considering that "less than half of high school graduates in the United States take a standalone geography course in either middle school or high school” (National Geographic Education Foundation, n.d., para. 3).

\section{Problem Statement}

As national studies and scholars have repeatedly indicated, young students in the United States are less geographically literate than those in other industrialized nations (Carano \& Berson, 2007). In the 2002 edition of the National Geographic-Roper study, the participating nations were Canada, France, Germany, Great Britain, Italy, Japan, Mexico, Sweden, and the United States. Out of these nine participating nations, the United States placed second to last in geographical literacy (RoperASW, 2002). Consequently these sorts of findings have led to scholars labeling American students as geographically illiterate (Segall \& Helfenbein, 2008).

In addition, the majority of the studies have concentrated on students' geographical skills and abilities and little emphasis has been given to students' attitudes toward geography and experiences with the discipline. This has led to a limited holistic understanding of geography education as it stands today since these other dimensions of geography education were not examined. 


\section{Purpose Statement}

The purpose of this qualitative study was to explore the geography attitudes and experiences of freshman students at Florida International University who scored at the low and high ends of a geographical literacy survey (Phase I). The use of extreme sampling for Phase II allowed for an exploration of the attitudes and experiences of students among the highest 20\% and lowest 35\% scorers on the geographical literacy survey. FIU was selected as the research site due to the diversity of its learners, its respect for diversity and the dignity of the individual, and its effort to prepare students to become global citizens. This qualitative study explored the geography attitudes and experiences of freshman students who scored at the low and high ends of a geographical literacy survey at a 4-year institution of higher education.

\section{Research Questions}

The primary research question for the study was what are the geography attitudes and experiences of freshman students scoring at the low and high ends of a geographical literacy survey?

The study’s research sub-questions were:

1. How do freshman students perform on the Geographical Literacy Survey (GLS)?

2. How do students define geography?

3. How do students describe their in and out of school experiences with geography?

4. How do students describe the value of geography to their lives, fields of study and careers? 


\section{Significance of the Study}

"It's no secret that Americans know next to nothing about geography" (Edelson, 2009, para. 4).

Besides this general notion, it is commonly believed that those students who are the least geographically literate are also those who think geography is not important, but that is only a popular assumption. Testing the geographical literacy of students and exploring their attitudes and experiences about geography provides the field relevant new insight.

The results of this study could be of use to educators, administrators, and researchers who (a) teach at FIU or at a similar institution and/or (b) have an interest in geography education, and students’ geography literacy, attitudes, and experiences.

Besides providing a greater understanding of students’ experiences and attitudes towards geography, the study can better inform geography and/or undergraduate studies departments as to what type of geography-oriented course offering may be appealing to college students in order to prevent further student alienation from the subject. Therefore, faculty members and college administrators may use the research findings for the purposes of creating a geography course for the undergraduate population that will be tailored to the students' needs. The study can be of significance as well to professionals and researchers in the educational arena who will have new insight into freshman students’ experiences and attitudes toward geography. 


\section{Assumptions}

The main three assumptions behind this study were:

\section{Geography education should continue playing a role in the U.S. educational} systems.

In spite of its limited instruction, geography has managed to survive and should continue having a presence in the American educational systems. Dr. Kerski, ESRI Education Industry Curriculum Development Manager, strongly believes in the importance of having geography in the curriculum. He states:

Geography enables students to understand their world locally to globally, make wise decisions about the planet and its resources, and become critical thinkers...Geography grapples with the key issues of our timeenergy, water, biodiversity, climate, natural hazards, population, and much more. (Kerski, 2011, para. 1)

\section{There is a need to further explore students' attitudes toward geography and experiences with the discipline.}

Studies on attitudes and experiences are limited since studies on students’ aptitudes have dominated the geography education literature. Since it is commonly assumed that students who are the least geographically literate are also those who think geography is not important, testing the geographical literacy of students and exploring their attitudes and experiences about geography can provide the field relevant insight. In addition, considering that attitudes "influence...decisions, guide...behavior, and impact what...[people]...selectively remember” (Pickens, 2005, p.47-48), students’ attitudes toward geography deserved special attention. 


\section{Participants provide honest responses to both the survey and interview questions.}

Confidentiality was preserved and students knew they could withdraw from the study at any point with no ramifications. Therefore it is assumed that the answers and responses provided by students were honest.

\section{Delimitations}

This study was delimited to FIU freshman students enrolled in three face-to-face sections of Finite Math (MGF 1106) in fall 2014, who had not taken a geography course during their post-secondary studies or were not enrolled that semester in a geography class. Students who were enrolled in these sections, but who were not in their freshman year, were excluded from the study.

\section{Definition of Terms}

The following terms were central to this study:

Attitude. A judgment developed on the ABC model (discussed in the following section), which is composed of affect, behavior, and cognition. The affective response is an emotional response that expresses an individual's degree of preference for an entity. The behavioral intention is a verbal indication or typical behavioral tendency of an individual. The cognitive response is a cognitive evaluation of the entity that constitutes an individual's beliefs about the object.

Extreme ends of the GLS. For the purposes of this study, the extreme ends of the geographical literacy survey were the highest $20 \%$ and lowest $35 \%$ survey performers.

Freshman students. FIU students who were enrolled in three face-to-face sections of the MGF 1106 course Finite Math, of first year status, and who had not taken a geography course during their post-secondary studies. 
Geographical literacy. Individuals are geographically literate when they possess geographic perspectives, geographic knowledge and geographic skills (Geography for Life, 2014). The concept of geographical literacy was discussed as early as in the 1970s (Manson \& Vuicich, 1977).

Geography. There are several formal definitions of the study of geography, but for the purposes of this study "Geography is the study of what is where, why there, and why care?...in regards to the various physical and human features, conditions, and interactions on Earth's surface” (Gritzner, 2002, p. 39). The what includes all features of Earth's surface that occur in spatial distribution; the where consists of the concepts of location, distribution, pattern, area, region, accessibility, and remoteness; the why there is composed of agents, processes, interrelationships, and lastly the why care is comprised of the importance, relevance, action and reaction (Gritzner, 2002).

K-12. Refers to the sum of primary and secondary education.

Phase I. Screening quantitative phase of the study, which consisted of the administration of the Geography Literacy Survey (GLS).

Phase II. Qualitative phase of the study, which consisted of in-depth interviews.

\section{Conceptual Frameworks}

Bogdan and Biklen (2003) stated that the use of the word theory is much more associated with the term paradigm which is a

loose collection of logically held together assumptions, concepts, or propositions that orient thinking and research. When we refer to a theoretical orientation or theoretical perspective, we are talking about a way of looking at the world, the assumptions people have about what is important. (p. 33) 
Two models oriented thinking and research in the study: the Geographical Literacy Model and the ABC Model, discussed in the following section.

\section{Geographical Literacy Model}

The National Geography Standards, Geography for Life, were created in an attempt to provide guidance to the instruction of geography at the national level. The document Geography for Life was originally published in 1994 by the Geography Education National Implementation Project (GENIP) and revised in its second edition in the year 2012. The GENIP is a "consortium of geographic associations committed to improving the status and quality of geography education in the United States” (What is GENIP?, n.d.). The consortium is formed by the Association of American Geographers, the American Geographical Society, the National Council for Geographic Education, and the National Geographic Society (What is GENIP?, n.d.).

Geography for Life includes three major components which together represent what it means to be geographically literate. In order to be geographically literate, students need to have acquired geographic perspectives, geographic knowledge and geographic skills. National Geographic has referred to this concept as geo-literacy (Micalizio, Kessler, \& Crooks, n.d.).

Geographic perspectives. Geographic perspectives asks students to learn to approach the world from spatial perspective (where something occurs) and ecological perspective (how living organisms interact with the environment) and to "comprehend that Earth is composed of living and nonliving elements interacting in complex webs of relationships within nature and between nature and societies” (Geography for Life: National Geography Standards, 1994, p. 57). Some of the terms used to describe this 
perspective are "distribution, place, processes, location, relationships, movement, clusters, accessibility, patterns, connections, [and] change” (The Geographic Perspective, n.d.).

Geographic knowledge. The subject content matter students should learn is divided into six essential elements with a total of 18 standards (listed further in this section).

Geographic skills. Geographic skills asks students to become actively engaged in doing geography by drawing upon their critical thinking skills (Geography for Life, 2014). The five skills are asking geographic questions, acquiring geographic information, organizing geographic information, analyzing geographic information and answering geographic questions (Geography for life: National geography standards, 1994).

Geographic skills are used

when we make decisions important to our well-being - where to buy or rent a home; where to get a job; how to get to work or to a friend's house; where to shop, vacation, or go to school. All of these decisions involve the ability to acquire, arrange, and use geographic information. (Geography for Life: National Geography Standards, 1994, p. 41)

According to the National Council for Geographic Education, "if students learn only geography content, they may score well on fact-based tests, but will not be able to reason geographically in new and different situations. If students focus on skills alone without understanding geographic perspectives, they may not be able to correctly formulate a geographic question to investigate” (Geography for Life, 2014). A geographic perspective also enables students "to better understand the past and present 
and to prepare for the future" (Howarth \& Mountain, 2004, p. 262). Geography for Life: National Geography Standards (1994) provided a very clear explanation as to why relying on geographical facts alone does not constitute geographical understanding: An isolated geographic fact does not constitute geographic understanding. For example, to know that Mount Everest is the highest peak in the world is not understanding geography until that isolated fact is put into a variety of spatial contexts. Geographic understanding requires we know not only the location of Mount Everest but why it is the highest peak in the world. We must understand the physical processes that were responsible for its creation and evolution. We must understand why its location in the Himalayas has impacts on the Indian subcontinent in terms of access to water and downstream flooding, political security and territorial conflict, and transportation passes and barriers. (p. 21) Geography literacy is necessary since geography allows individuals to answer questions about where things are and how and why they got there. In addition, it allows individuals to understand the relationships between people, places, and environments (Geography for Life: National Geography Standards, 1994). Most importantly, it is fundamental to teach to students the real-life applications of such rich knowledge: At the everyday level, for example, a geographically informed person can appreciate the locational dynamics of street vendors and pedestrian traffic or fastfood outlets and automobile traffic; the routing strategies of school buses in urban areas and of backpackers in wilderness areas; the land-use strategies of farmers and of real estate developers. (Geography for Life: National Geography Standards, 1994, p. 29) 
In order to assist schools with increasing geographic literacy, 18 national standards were developed and adopted in the United States. These standards are encompassed in six essential elements: The World in Spatial Terms, Places and Regions, Physical Systems, Human Systems, Environment and Society, and The Uses of Geography (National Geography Standards, n.d.). Howarth and Mountain (2004) have declared that "students need geographic knowledge to understand the world and their relationship to it” (p. 262). These standards and essential elements constitute the Geographic Knowledge component of the Geographical Literacy Model. The six essential elements with their corresponding standards are listed below:

\section{The World in Spatial Terms}

1. How to use maps and other geographic representations, tools, and technologies to acquire, process, and report information from a spatial perspective

2. How to use mental maps to organize information about people, places, and environments in a spatial context

3. How to analyze the spatial organization of people, places, and environments on earth's surface

\section{Places and Regions}

4. The physical and human characteristics of places

5. That people create regions to interpret earth's complexity

6. How culture and experience influence people's perceptions of places and regions 


\section{Physical Systems}

7. The physical processes that shape the patterns of earth's surface

8. The characteristics and spatial distribution of ecosystems on earth's surface

\section{Human Systems}

9. The characteristics, distribution, and migration of human populations on earth's surface

10. The characteristics, distribution, and complexity of earth's cultural mosaics

11. The patterns and networks of economic interdependence on earth's surface

12. The processes, patterns, and functions of human settlement

13. How the forces of cooperation and conflict among people influence the division and control of earth's surface

\section{Environment and Society}

14. How human actions modify the physical environment

15. How physical systems affect human systems

16. The changes that occur in the meaning, use, distribution, and importance of resources

\section{The Uses of Geography}

17. How to apply geography to interpret the past

18. How to apply geography to interpret the present and plan for the future (National Geography Standard Index, n.d.) 
These elements lead to a strong basis of geographic knowledge, which is one of the three components of geographical literacy. The list above indicates there is more to geography than locating nations and memorizing capitals. Those misconceptions that narrow the geography spectrum come from the lack of exposure to the other layers of the discipline and poorly trained social studies/geography teachers (Gao, 2011; Gilsbach, 1997; Holstrom, 1994; Mohan, 2009; Wolfe, 2002) who have themselves acquired limited subject matter knowledge (Earle, 2008; Rogers, 1997). The challenge for today’s educators is to facilitate student acquisition of geographic knowledge, perspectives and skills since "being literate in geography is essential if students are to leave school equipped to earn a decent living, enjoy the richness of life, and participate responsibly in local, national, and international affairs" (Geography for Life: National Geography Standards, 1994, p. 9). This model will be central to the study in conjunction with the ABC Model explained below.

\section{ABC Model}

The ABC tripartite method proposed by Rosenberg and Hovland (1960) consists of affect, behavior, and cognition. These three components come together to make a judgment regarding an individual's attitude. In the case of this study, the model was used in order to explore the attitudes towards geography the freshman students participating in Phase II (interviews) have. The affective response is an emotional response that expresses an individual's degree of preference for an entity (e.g., "I like geography”). The behavioral intention is a verbal indication or typical behavioral tendency of an individual (e.g., "I will avoid taking a geography course"). The cognitive response is a cognitive 
evaluation of the entity that constitutes an individual's beliefs about the object (e.g., "I believe geography is useless").

It was important to undertake a study about students' attitudes about geography because the literature has concentrated in assessing students' geographical knowledge without placing enough emphasis on all the insight that students' attitudes towards and experiences with the discipline can reveal. Since it is commonly assumed that those students who are the least geographically literate are also those who think geography is not important, testing the geographical literacy of students and exploring their attitudes and experiences about geography can provide relevant insight to the field.

\section{Summary}

This chapter introduced the current challenges in geography education and the need for further exploration of students' attitudes toward geography. The study focused on the geography attitudes and experiences of FIU freshman students' scoring at the low and high ends of a geography literacy survey and it will be of use to educators and administrators at FIU and similar institutions of higher education. The final section discussed the study's assumptions and delimitations, defined the key terms, and introduced the conceptual frameworks.

\section{Organization}

The rest of the paper is organized in the following manner. Chapter II consists of the literature review of students' attitudes toward geography as well as relevant information pertaining to research on geography education. Chapter III describes the design of the study. The chapter also lists reasons as to why FIU served as the research site. Chapter IV presents the results from the data analysis. Chapter V contains a 
summary of the study, analysis of results, implications for practice, limitations of the study, recommendations for future research, and conclusion. 


\section{CHAPTER II}

\section{LITERATURE REVIEW}

\section{Brief Past and Present of Geography in U.S. Higher Education}

As early as 1851 the American Geographical Society, an organization of

professional geographers, had been established in New York City (Johnston, 1997).

Geography formally began in the United States as a university discipline around the turn

of the twentieth century (Martin, 2005). By then, geography was a respected subject

(Getis, Getis, \& Fellmann, 2008). This started changing around 1948, the year in which

one of the most influential universities in the United States, Harvard, closed its

geography department (Smith, 1987, as cited in Murphy, 2007). Even before Harvard’s

closing, William Morris Davis, the father of American geography, worried about a lack

of mature geography in higher education that would support the geography taught in

schools (Gaile \& Willmott, 1989).

In addition, by 1967 geography had started to be labeled as a soft discipline which

lacked rigor and there were issues justifying its role in universities (Livingstone, 1992).

By the 1970s, 32 university geography departments had disappeared (Johnston, 1997).

The reasons behind geography's constant challenge to position itself in U.S. institutions of higher education during the first half of the twentieth century "are complex, and have yet to be adequately explained or synthesized” (Martin, 2005, p. 3).

In more recent years, “geography has been folded into a larger unit with some loss of influence or standing” (Martin, 2005, p. 7), but the number of new programs is rising as well as the number of faculty and students enrolled in geography programs (Martin, 2005). According to Murphy (2007), in the eyes of international scholars, geography at 
the tertiary level is influential, but "viewed from a domestic perspective, however, geography’s position in higher education looks less strong” (p. 1).

The discipline is not as strong as other sibling subjects such as history and some institutions do not even have geography programs (Murphy, 2007). In the case of Florida, out of the 12 universities that comprise its State University System, only seven offer geography programs (Florida Atlantic University, Florida International University,

Florida State University, University of Florida, University of North Florida, University of South Florida, and the University of West Florida).

\section{Challenges in Geography Education}

It is often challenging for geographers to convey to non-geographers what the discipline entails. Gritzner (2002) believes that "geography suffers immeasurably from its vague and fuzzy image...[since]...practitioners, have failed miserably to convey the nature, utility, and excitement of our discipline to non-geographers” (p. 38). Gritzner (2002) adds that he has compiled nearly 200 definitions of geography from different geographic sources. Most Americans are unaware of the nature and scope of the discipline and associate it simply with facts and location (National Research Council, 1997). However knowing where things are located is just one of the steps needed in order to arrive at a complete understanding as geographers also focus on the interactions of people with each other and their environment (Getis, Getis, \& Fellmann, 2008).

An additional challenge is the general lack of instruction. The fact that geography standards exist does not necessarily mean they will be taught. While states have adopted the geography curriculum standards based on the Geography for Life document, most students in the United States will not have had enough explicit geography instruction to 
meet all of these standards unless they enroll in a college undergraduate program (Geography for Life, 2014). Although future geographers may have several programs to choose from nationwide, non-geography majors may not acquire the geographical perspectives, knowledge and skills that would lead them to be geographically literate. To make it even more challenging for the discipline, geography, under No Child Left Behind, "remains the only core subject for which dedicated funding has not been provided” (Downs, 2011, p. 40). The 2010 National Assessment of Educational Progress (NAEP) Geography Subject Area examination, for example, indicates that there was a slight decline in the performance of twelfth graders as compared to the previous test administration, which occurred in 2001 (Downs, 2011). In addition, "geography is not commonly taught as a separate subject in American secondary schools” (Jones, 2006). This issue was discussed more in depth by Downs (2011):

Geography is taught as part of social studies in grades $\mathrm{K}-4$ and that curricular arrangement often extends into grades 5-6. Geography typically appears in grades 7 or 8 as a stand-alone course under the guise of a world cultures label. In high school, geography is rarely taught as a stand-alone course and at best it is infused with another subject. (pp. 39-40) In the 2006 Geographic Literacy Study by National Geographic-Roper Public Affairs, it was reported that "half (48\%) of 18- to 24-year-olds...[said]...they had a class devoted entirely to geography at least once between the sixth grade and...[twelfth grade]. As many (49\%) did not” (National Geographic Education Foundation, 2006).

Given that in some cases "a student often takes just a single geography course during their entire educational career” (Jones, 2006, p. 7), Sommers (2007) and Jones 
(2006) believe it is essential for students to be exposed to a well-taught, interesting, and relevant geography course during college since it can influence their view toward the discipline as a whole. Johnston (1997) provides a thought-provoking comment regarding the marginalization of geography in schools and colleges, "It is inconceivable to go through school or college without required courses in history, but few of us graduate with some exposure to modern geography” (p. ix).

\section{Why Geography and Geography Education Research Matter}

Geography is an essential discipline that should be part of everyone’s lives. Getis, Getis, and Fellmann (2008) highlight three main reasons as to why the discipline is useful to society:

1. Geography is the only discipline that explores the diversity of physical and cultural phenomena from place to place.

2. Having a grasp of the subject will be essential in understanding the national and international issues that we hear and see on the news.

3. The field offers numerous job opportunities.

In addition, Hanson (1997) has highlighted several geographical ideas, such as the map, weather map, and Geographic Information Systems (GIS), that have contributed immensely to shaping the world we live in today. Geography serves to see "unforeseen linkages, between climate change and historical events, between natural phenomena and political development, between environment and behavior, that are unmatched in other fields” (Johnston, 1997, p. xiii).

Some of these linkages are never made by educators. Geography plays a big role in history, but the connection is rarely acknowledged. Scholars should emphasize the 
importance of both disciplines to one another (Gritzner, 2002). According to East (1965), "in studying the inescapable physical setting of history, the geographer...examines one of the strands from which history itself is woven” (p. 2-3). Gritzner (2003) adds that "to persons possessing a poorly developed mental map, historical events occurred in a spatial vacuum. History and geography remain spatially unlinked and unrelated, severely limiting the significance of one to the other” (p. 90).

Geography is necessary in order to understand society in general as well as our communities and neighborhoods. It is clear how geography has relevance to numerous critical issues that society faces today (National Research Council, 1997). In a time of global challenges, students need to receive an education that provides them a societywide perspective on several issues including, but not limited to:

illness, hunger, and poverty; environmental damage and unsustainable use of natural resources; violent conflict rooted in cultural, ethnic, and religious difference... the spread of gang activity to suburban and rural communities, the increasing frequency of property-damaging floods and wildfires, steadily rising commute times, and the lack of access to fresh meat and produce in impoverished urban communities. (Edelson, 2008, p. 3)

Research in geography education offers endless topics of relevance for research. According to Lambert (2010), it is “self-evident that GER [geography education research] does not easily measure up, in quantity if not quality, to the sustained, fully funded research that is undertaken in science, technology, engineering and mathematics, for example, or in supposedly generic educational themes such as assessment and school leadership” (p. 84). Research in geography education is necessary in order to explore the 
dynamics of how geography contributes to education. In addition, Segall and Helfenbein (2008) call for increased research on geography education and acknowledge that "research is also needed to better understand how institutional geography education impacts students' geographic understandings and engagements outside of school and vice versa” (p. 272).

\section{National Studies}

The literature on geography attitudes of college students in the United States is very limited. Since the study's population is of freshman students and the studies at the tertiary level are not numerous, articles on high school student's attitudes toward the subject were also included in this review.

The lack of research on the topic in general was addressed by Brook (1977). Due to this fact, she administered a questionnaire in order to explore the general attitudes toward geography held by social studies ninth and tenth grade students, as well as social science education students at the University of Georgia. In the questionnaire, 97 students were asked to record their personal information, to rank geography among other subjects, to conceptualize geography as well as to record their attitudes toward the discipline. The results indicate that students liked geography more as one of the social studies subjects, but not when compared to other subjects. Educational level, gender, and students' individual conceptualizations of geography were examined as influences on attitude, but the findings suggested there were no significant differences in attitudes among those groups. Brook (1977) reflected on the study by concluding that determinants of attitude had to be more complex than what she anticipated them to be. Among the weaknesses of the study was that in ranking subjects including geography, students ranked subjects for 
which they might not have ever taken a course. This could have led to a ranking of known subjects rather than a ranking based on their attitudes. In addition, the report was too brief and detailed information on each section of the study was not provided. The strengths came from the consultation of geographers regarding questionnaire items' content validity, even though social studies educators should have been in the panel as well in order to make sure students would understand the vocabulary employed.

Bowlick and Kolden (2013) investigated, through a case study, attitudes of University of Idaho students towards geography's role in their daily lives as well as the relevance of the discipline to their careers or academics. These non-geography majors were already enrolled in the elective geography courses of Introduction to Physical Geography and Human Geography. A total of 265 students completed the pre-course survey, administered during the first week of the semester, while 82 participated in the post-course one, which was given prior to final exams. The results suggest that, following completion of a geography course, students generally thought geography played a bigger role in their lives, was more relevant to their academic and future careers, and perceived their own geographic skill to be greater. According to Bowlick and Kolden (2013), geography courses such as the ones in their case study can increase student appreciation of geography. The main limitation of the study noted by the researchers was the smaller number of post-test participants.

Hubbard and Stoddard (1979) argued that "almost since its introduction into American high schools and colleges, geography has been plagued with the problem of justifying its existence as a bona fide academic discipline” (p. 188). Since there is no distinct definition of what the subject and its purpose are, it is a struggle to convey it to 
non-geographers. In addition, they discussed the misconceptions that students have due to the emphasis placed on location by stating that "students should be made aware that geography is a discipline that attempts to explain the location of various phenomena by asking the question why there? rather than only where?” (p. 191). The purpose of their study was to evaluate the “images” (p. 199) that 694 students from 12 different high schools across the state Nebraska had of geography. All these high schools taught geography to their students. Students completed a survey composed of 30 items. The findings suggested that in general students believed that geography involved more than memorizing the names of places, that it was more than simply drawing maps, and that it helped them understand current events. In addition, they saw it as a useful subject that should be part of a high school's curriculum. According to Hubbard and Stoddard (1979), even though the high school students from their study had a positive view on geography, the misconceptions they encountered at the college level may be among students who did not take a geography course in high school. They suggest this topic as a possibility for future research.

Lastly, McTeer (1979) conducted a study on the geography attitudes of high school senior students from several high schools in the state of Georgia. When asked which one of the social sciences they liked least, the majority of the students listed geography. Even though the study's methods as well as the results were briefly explained in this report, the researcher did provide extra information he obtained by informally asking students, teachers, and administrators why geography was not liked. The three reasons he identified were:

1. There is too much emphasis on rote memorization. 
2. Geography courses are assigned to teachers who do not master the content and have a negative attitude because they were forced to teach geography.

3. Social science teachers lack academic preparation.

There are several findings that suggest the subject is one of the least liked at the elementary level as well. Sack and Petersen surveyed elementary Texan students' attitudes toward geography in the years 1983 and 1993. In both studies, students rated geography as the least favorite subject (Sack \& Petersen, 1998). In addition, in the NAEP 2001 test, only 15\% of the students chose geography as one of their favorite subjects (Sack \& Petersen, 1998).

\section{International Studies}

The international literature on geography attitudes suggests, as opposed to the American studies, that students either have a positive or neutral attitude toward the subject.

The attitudes toward geography lessons of 200 high school students in Turkey, measured using a Geography Lesson Attitude Scale, suggested that students had very positive attitudes toward geography (Ozdemir, 2012). About 84\% of the students loved geography, 70\% thought that geography lessons were necessary and important for everybody, $61 \%$ thought that geography lessons were useful in daily life, and $70 \%$ that geography lessons allow them to make inferences about natural events (Ozdemir, 2012).

Tomal (2010) was also interested in the attitudes of Turkish students. The results parallel Ozdemir's study since they suggested that students view geography favorably. Students ranked geography fourth among their favorite courses. Tomal took the research one step further and through answers to open-ended questions found that students are 
most likely to be interested in a lesson if they think highly of the teacher delivering it. Lastly, Biddulph and Adey (2004) found that two thirds of English students in the eighth grade who were interviewed thought geography was a useful subject.

Kubiatko, Janko and Mrazkova (2012) found slightly different results in their study of Czech high school students' attitudes towards geography after using a Geography Attitudes Questionnaire. The findings suggested that students have a relatively neutral attitude toward the subject. The researchers listed teacher unpreparedness to teach the subject and excess of rote memorization as possible reasons as to why the students’ attitudes were neutral.

\section{Summary}

Based on a synthesis of the current literature, high school and college students' attitudes toward geography were explored through various international and national studies, which have predominately used quantitative methods. Students who participated in the studies had already been exposed to geography or social studies courses.

Among the areas that are yet to be analyzed are the geography attitudes and experiences of freshman students who were not recently enrolled in a geography-related course. Another gap identified during this review is the need for a qualitative approach toward investigating this topic, which was what McTeer (1979) informally attempted to do by conducting informal interviews. By placing more emphasis on the insight that students' attitudes and experiences with the discipline can provide, the researcher can better understand if those students who are the least geographically literate are also those who think geography is not important, as it is commonly assumed. 


\section{CHAPTER III}

\section{METHODS}

The purpose of this study was to explore the geography attitudes and experiences of FIU freshman students scoring at the low and high ends of a geography literacy survey. The results of the GLS (Phase I) as well as in-depth qualitative interviews (Phase II) served as the main components of the study.

First, the GLS was administered to freshman students (Phase I). Then, the researcher conducted in-depth interviews of selected students (Phase II). Phase I utilized a criterion sample (FIU freshman students enrolled in selected sections of the Finite Math course MGF 1106 who had not taken a postsecondary geography course), whereas Phase II employed extreme case sampling (students who scored at the low 35\% and high 20\% ends of the survey).

This chapter details the methods and procedures utilized in conducting this research and answering the research questions. This chapter is organized in the following manner: research questions, research design, research site, participants, integrity measures, data management, as well as instrumentation, data collection, and data analysis.

\section{Research Questions}

The following was the principal research question of the study:

What are the geography attitudes and experiences of freshman students scoring at the low and high ends of a geographical literacy survey?

The following were the study’s research sub-questions.

1. How do freshman students perform on the Geographical Literacy Survey 
(GLS)?

2. How do students define geography?

3. How do students describe their in and out of school experiences with geography?

4. How do students describe the value of geography to their lives, fields of study and careers?

\section{Research Design}

Creswell (2009) sees research designs as “plans and the procedures for research that span the decisions from broad assumptions to detailed methods of data collection and analysis” (p. 3). Heck (2006) adds that research design "is concerned with the assumptions underlying the manner in which the study is constructed to pursue inquiry about the phenomenon” and “determines whether the research question can be answered adequately through the manner in which the data was collected” (p. 377). In addition, Johnson and Christensen (2004) see research design as the guiding strategy that will answer research questions.

The data collection method for this qualitative study was interviews. The survey data (from Phase I) provided the foundation for the collection of interview data (Phase II). By using the survey as a screening tool, the study explored through interviews the geography attitudes and experiences of low and high geographical literacy survey performers.

\section{Research Site}

The study was conducted at FIU, a public 4-year tertiary institution, established in 1965, whose main campus is located in Miami, Florida: 
Florida International University is an urban, multi-campus, public research university serving its students and the diverse population of South Florida...[It is] committed to high-quality teaching, state-of-the-art research and creative activity, and collaborative engagement with...local and global communities (Vision \& Mission, n.d.).

FIU's diversity of learners was one of the reasons why this institution was selected for this study. FIU, with approximately 50,000 students (About Us, n.d.), has a diverse student population makeup. Sixty-one percent of its students are Hispanic, 15\% White non-Hispanic, 13\% Black, and 11\% from other minority groups (About Us, n.d.). In addition, FIU aims to prepare students to understand and appreciate others through one of its core values: respect for diversity and the dignity of the individual (Vision \& Mission, n.d.). Lastly, FIU has among its goals to prepare students to become global citizens. According to Global Learning for Global Citizenship, which is FIU's Quality Enhancement Plan (QEP):

This multi-year initiative is the university's roadmap for enabling students to act as engaged global citizens. Through an integrated global learning curriculum and co-curriculum, all FIU undergraduates have multiple opportunities to develop global awareness, a global perspective, and an attitude of global engagement. (Global Learning, n.d.)

Other considerations were the researcher's knowledge of the institution and ease of communication with FIU's administration and faculty members. 


\section{Methods}

Using the GLS as a screening tool for determining possible interview participants allowed the researcher to explore the attitudes and experiences of freshman students belonging to two extreme groups of geographical literacy proficiency. The GLS was used to select participants and provide a context for the qualitative analysis. Onwuegbuzie and Collins (2007) call it a nested relationship, where "the sample members selected for one phase of the study represent a subset of those participants chosen for the other facet of the investigation” (p. 292). In the study, the Phase II interviewees represented a subset of the pool of GLS participants from Phase I.

\section{Population}

The population consisted of FIU students enrolled in three face-to-face sections of the Fall 2014 course MGF 1106, Finite Math, which is a core-curriculum course at FIU. This particular course was chosen since it has a large concentration of freshman students enrolled in it. The sections selected by the researcher were the three largest sections offered for this course during the Fall 2014 term at FIU-MMC.

\section{Sample}

Criterion sample allowed the researcher to choose individuals "because they represent one or more criteria” (Onwuegbuzie \& Collins, 2007, p. 286). A criterion sampling technique was used for the quantitative screening Phase I of the study since only students who met specified criteria were eligible to participate. In the study, only students of freshman status who had not taken a geography course during their postsecondary studies were eligible to participate. This criterion was developed after reviewing the literature, which suggested that most students who participated in research 
studies were enrolled in geography-related courses. Therefore, it was relevant to have as participants students who reflected the typical freshman student in the United States, which is a student with very limited academic exposure to the subject.

Students of freshman status were chosen over sophomores, juniors, and seniors since they are fresh from high school and can provide insight from their high, middle, and elementary school years. The age range of freshman students is also very close to that of the twelfth grade students who participated in the 2010 Geography NAEP Assessment that the GLS is based on. In addition, "the average freshman college student is among the most geographically lost of all” (Fuller, 2012, p. 3). These reasons helped the researcher select freshman students over other undergraduate classifications.

It is important to note that students of sophomore, junior or senior status enrolled in the selected sections of Finite Math were not eligible to take the GLS nor were those freshman students who had taken/were taking a geography course during their postsecondary studies.

\section{Instrumentation}

Phase I. Gall, Gall and Borg (2003) define surveys as "the use of questionnaires...to collect data about the characteristics, experiences, knowledge, or opinions of a sample or a population” (p. 638). Briggs and Coleman (2007) add that surveys are the appropriate approach to use when data are needed from a large number of individuals. The objective of the survey in the study was to assess freshman students' geographical literacy (research sub-question \#1) in order to be able to obtain participants for Phase II of the study. 
The students' geographical literacy was measured by using the GLS, a researcherdeveloped multiple-choice instrument of 23 items (APPENDIX B). Part A of the GLS contained 10 items measuring geographical literacy while Part B consisted of demographic questions (sex, race, ethnicity) and questions regarding the background of the participants (academic major, foreign languages spoken, grades 6-12 school location, geography courses taken in grades 6-12, perceived geographical skills, favorite social studies subject, interest in international news coverage, international travel experience, living abroad experience, and study abroad experience).

The items from Part A of the GLS were compiled from a database of 23 multiple choice questions from the 12th grade NAEP 2010 Geography Assessment (National Center for Education Statistics, 2010). This instrument seemed the most appropriate for this research since the questions were designed for twelfth graders, an age group very close to this study's target population of freshman students.

In addition, the NAEP is "the nation's largest continuing and nationally representative assessment of what students know and can do in core subjects” (NAEP Geography - More About NAEP Geography, 2012). The NAEP was contacted and authorization to use the assessment items was given to the researcher provided those were cited (Sherran Osborne, personal communication, January 15, 2014).

The ten NAEP questions selected belonged to different levels of difficulty (easy, medium, hard), content area (space \& place; environment \& society; spatial dynamics \& connections) as well as cognitive levels (knowing, understanding, applying). As discussed in the previous chapter, students need to possess geographic perspectives, knowledge and skills in order to be geographically literate. The selected questions 
required students to make use of the aforementioned components of the geographical literacy model.

Phase II. Kvale (2007) has noted that "interviews are one of the major approaches in collecting data in qualitative research" since they aim at "understanding the world from the subjects’ point of view” (p. xv). Rubin and Rubin (1995) see interviews as approaches to learning that allow researchers to understand the experiences of the people they meet. Qualitative interviewing is a "way of finding out what others feel and think about their worlds” (p. 1). Lastly, Seidman (1991) adds that a researcher conducts interviews when he/she is interested in other people's stories since telling stories is a way of knowing and of symbolizing experiences through language. Through the interviews, the researcher obtained rich information regarding the interviewees’ geographical attitudes and experiences.

The interview questions were written by the researcher who compiled them as part of the interview guide (which can be seen in APPENDIX C). For the interviews, the main-branches-of-a-tree interview structure was followed; there were three (qualitative) research sub-questions that had several interview questions each (Rubin \& Rubin, 2012). This method assured that each sub-research question was addressed. Through the interview guide questions and other questions that emerged, the researcher explored the geographical attitudes and experiences of freshman students scoring at the low and high ends of the GLS.

Pilot Study. According to van Teijlingen and Hundley (2002), pilot studies are crucial since they are "mini versions of a full-scale study" that "increase the likelihood of success” (p. 33) in the main study. A pilot study was conducted using a group of 16 
freshman students enrolled in a 2014 Summer B section of the First Year Experience (SLS 1501) course, which is a core-curriculum course at FIU composed of freshman students.

The pilot study was conducted in order to uncover potential logistical problems in the data collection process as well as to test the GLS. The day the surveys were completed the researcher entered the data in SPSS and created a composite variable with the total score of Part A of the GLS. This allowed the researcher to rank the students' performances. Due to the small initial sample, the researcher invited all students for follow-up interviews (Phase II), instead of taking a percentage of the high/low scorers.

The interview guide and interview process were also piloted with four students who replied to the email invitation and agreed to be interviewed. There were no potential logistical problems encountered while conducting the two phases of the pilot study. Modifications were made to the GLS after performing the pilot study. In addition, conducting pilot interviews allowed the researcher to add several questions to the interview guide.

Instrument Development. As a result of the pilot study, improvements were made to the GLS and interview guide. An asterisk was added next to the word abroad on GLS items 21-23. The asterisk notes abroad is referring to "outside of the U.S.”. This addition was made after a student asked what the word abroad referred to. In addition, two Part A geography knowledge items on the GLS were replaced after the results suggested these items were too difficult for the students. This decision was made in order to improve the internal validity of the survey and was supported by one member of the panel of experts on geography who reviewed the instrument items for construct validity 
purposes. In regards to reliability, coefficient alpha was not $>.7$ for items $1-10$ (geographical knowledge), but the small sample size (16) has to be taken into consideration as well as the difficult items that were identified and removed for the GLS' final version. Additions were made to the interview guide as each of the three sections of the guide was expanded with additional interview questions.

\section{Data Collection}

Phase I. Data on geographical literacy were collected using the GLS. The researcher contacted via email the Chairperson of the Department of Mathematics \& Statistics Department who forwarded the data collection request to the instructors of the three large MGF 1106 sections the researcher had selected. The course instructors replied back via email in order to set-up a date when the researcher could collect the data at FIU’s MMC located in Miami, Florida.

Students were provided a printed packet which contained the IRB-approved consent form (which can be seen in APPENDIX A), a contact page asking for students' names, cell phone numbers and email addresses, and the GLS. The information provided in the consent form included the purpose of the study, what students were asked to do, risk and benefits, confidentiality, voluntary participation, and researcher's contact information (Institutional Review Board Consent Form Sample, n.d.).

Each packet also contained a unique participant identification code. The researcher reminded students that she was the only individual with access to both the GLSs and the page containing participants' personal information. In conclusion, confidentiality was guaranteed, but anonymity was guaranteed only at the conclusion of 
the research study since the students' contact information was needed in order to possibly reach them for Phase II.

Since the goal of the study was not to arrive at a generalization, the number of surveys collected was smaller than in studies that have generalizability as an objective. Considering that the main goal of the GLS was to be used for screening purposes, the initial sample size was of 200 participants.

Phase II. The source of data collection consisted of individual semi-structured interviews. An interview guide was used during each interview, but depending on the comments made by the interviewees, the researcher asked additional questions.

The researcher used extreme sampling, seeking individuals at the extremes of the phenomenon under study (McGovern, 2001). The students invited for the qualitative phase (Phase II) scored in the high 20\% end and low 35\% end of the GLS. The initial intention was to invite those from the extreme $20 \%$ ends, but due to the lack of responses from the low-scoring students, the percentage had to be increased to 35 in order to be able to conduct the interviews.

In regards to how many interviews to conduct, Guest, Bunce, and Johnson (2006) suggested to conduct a minimum of 12 interviews since saturation typically occurs within the first 12 interviews. In the study, six interviews on each end (low and high scorers) were conducted.

Selected students from Phase I were contacted via email by the researcher who requested interviews. As an incentive, participating interviewees were offered an FIU Panther Dining lunch voucher, valued at \$8.50, which they could use at any dining location on FIU's two main campuses. Those wishing to participate responded to the 
email in order to set-up a time and location at a university common area at FIU. The locations selected at MMC were the Bookstore’s Café and the Green Library.

Before beginning the interview, the researcher asked students for their permission to record the interview with a digital sound recorder. All students agreed to have the interviews recorded. The researcher had the interview guide handy. When necessary, member checking was performed while the interviews were being conducted in order to better make sense of the data. During the interview, the researcher restated and or summarized information to question the interviewee and improve accuracy.

The interviews were semi-structured, and designed to explore participants' thoughts, feelings and behaviors about geography, as well as their experiences with the subject. The interview process was guided by open-ended questions that assisted the goal of exploring the students' experiences and attitudes toward the discipline.

During the interviews, the researcher also had a document with the geography standards and their essential elements, as listed in Chapter I, which was used to prompt the interviewees for additional insight. This document was shown to the students at the end of the interview. Students were explained that those were the national geography standards and stated what students were supposed to learn. Interviewees were told to read the 18 standards and talk about the ones that "spoke" to them.

Some interviewees decided to make comments on each one of the standards while others only made comments on some. Among the comments made by the interviewees when reviewing the standards were experiences they remembered, if they were taught the standard or not, and if they associated the standard with geography. 


\section{Data Analysis}

Phase I. Data from the GLS was entered in SPSS in order to assist in the selection of Phase II participants and to answer research sub-question 1: How do freshman students perform on the Geographical Literacy Survey (GLS)?

The creation of a composite variable with GLS Part A items (1-10) allowed the researcher to identify scorers at the high $20 \%$ and low 35\% ends of the GLS. The composite variable ranked the students' scores from lower to higher. These students became eligible to participate in the qualitative Phase II. As previously mentioned, codes were used in SPSS to identify survey participants and the researcher was the only individual to have the ability to match the code with the students' real names and contact information.

In order to answer the research sub-question and be able to report demographic and background information on the GLS participants, the researcher analyzed frequency outputs that were obtained by using SPSS.

Phase II. According to Merriam (1988), “data analysis is the process of making sense out of one’s data” (p. 127). Taylor and Bogdan (1984) elaborate by suggesting that the goal of data analysis is "to come up with reasonable conclusions and generalizations based on the preponderance of the data” (p. 139). Data collected from the interviews was transcribed by the researcher into Word documents (one of the transcribed interviews can be seen in APPENDIX D). The researcher transcribed all 12 interviews from the digital audio recordings.

Even though several researchers encourage doing interviewing and analysis

simultaneously, Seidman (1991) suggests separating them. He encourages finishing with 
all interviewing before doing any in-depth analysis in order to "avoid imposing meaning from one participant's interviews on the next” (p. 86). Seidman's advice was followed for Phase II of this study.

The large amount of text that was produced through the interviews was condensed to what was most important. According to Seidman, the data has to be reduced “inductively rather than deductively" (p. 89), which means the researcher sees what emerges from the text. Seidman (1991) noted that even though the researcher comes with an open attitude, "no interviewer can enter into the study of an interview as a clean slate” (p. 89). Therefore, after inductively analyzing the transcripts in order to discover what themes emerged from the findings, the researcher analyzed the transcripts deductively by using sub-questions 2-4:

2. How do students define geography?

3. How do students describe their (in and out of school) experiences with geography?

4. How do students describe the value of geography to their lives, fields of study and careers?

To determine what was relevant, important or interesting, the researcher made judgments of what was significant. This included content that was related to geography, social studies, global education, foreign languages, foreign nations, as well as students’ attitudes, and experiences towards the discipline of geography. Reducing the data by marking what was important allowed the researcher to develop themes (Seidman, 1991). Themes were created by “organizing excerpts from the transcripts into categories” (Seidman, 1991, p. 99) and then searching for patterns and connections among them. 


\section{Data Management}

Phase I and Phase II data, including consent forms, surveys and interview transcripts, were organized and stored in a locked cabinet at the researcher's home office. In addition, all electronic files were organized and stored in the researcher's passwordprotected personal laptop. These digital files were backed up on an external hard drive. The laptop and the hard drive were always with the researcher in her home office. Once the data were analyzed, pseudonyms were used to protect interviewees’ identities throughout the paper.

\section{Integrity Measures}

Phase I. The integrity measures of validity and reliability are discussed in this section. The Assessment Division of the National Center for Education Statistics under

the U.S. Department of Education has not yet released the technical data pertaining to the integrity measures of the 2010 NAEP Geography Subject Area Assessment. The researcher was informed that the release of this data might take an additional year (S. Osborne, personal communication, September 16, 2014).

Validity. Even though validity measures for the 2010 NAEP Geography Subject Area Assessment were not available, there was very detailed information regarding how the test instrument was developed:

NCES [National Center for Education Statistics] calls on many constituents to guide the process and review the assessment. The NAEP contractor begins this process by developing more than twice the number of needed items. This item pool is then subjected to: 
- an internal contractor review with content experts, teachers, experts on political sensitivity and on bias;

- pilot tests with small groups of students and targeted cognitive labs; and, - under NCES guidance, refinement of items and scoring rubrics.

Then a standing committees of content experts, state and local education agency representatives, teachers, parents, and representatives of professional associations reviews the items. Each standing committee considers:

- the appropriateness of the items for the particular grade;

- the representative nature of the item set;

- the match of the items with the framework and test specifications; and

- the quality of items and scoring rubrics.

This is followed by a state item review where further feedback is provided. Items are then revised and submitted to the Governing Board assessment development committee for approval prior to field testing.

The field test is used to finalize the testing instrument. Items are revised based on student data, and the item set is once again subjected to review following the same procedure described above. Then, a final set of test items is assembled for NCES and the Governing Board review and approval. (NAEP Item Development Process, 2007)

According to Salkind (2010), through content validation methods, researchers assess the quality of survey items. Construct validity of the instrument was established by having experts analyze the GLS, a standard method for assessing content validity (Salkind, 2010). In order to do so, the GLS was emailed to three geography professors 
and their insight was taken into consideration in order to make the necessary revisions to the survey.

The panel of experts consisted of Dr. Jeffrey Onsted, Associate Professor of Environmental Studies, International Relations, and Geography at FIU, Dr. Benjamin Smith, Assistant Professor of Geography at FIU, and Dr. Milan Kubiatko, Assistant Professor at the Institute for Research at Masaryk University in Brno (Czech Republic), who has extensively explored European students' attitudes and perceptions towards geography (as noted on Chapter II). Thanks to Dr. Smith’s feedback two items from the initial GLS version were replaced with other two multiple choice items from the NAEP Assessment. The first item was a very difficult item that asked students to identify the profile of a continent, which was replaced with an item that asked students to understand differences between native and official languages. The second one was an item about irrigation that was similar to another item on the GLS related to water; this item was replaced with one where students were required to locate the Mississippi River from a cross-section of the U.S.

In regards to external validity, the GLS was not designed to allow for generalization to the entire U.S. freshman population since the survey (Phase I) was used primarily as a screening tool for Phase II.

Reliability. Even though reliability measures for the 2010 NAEP Geography Subject Area Assessment were not available, the researcher measured the internal consistency reliability using Cronbach's alpha coefficient. Coefficient alpha is “one of the most important and pervasive statistics in research involving test construction and use (Cortina, 1993, p. 98). Cronbach's Alpha was chosen as the test to perform since for 
dichotomous items it is mathematically equivalent to the Kuder Richardson Formula 20, which calculates the internal consistency reliability of dichotomous items (Statistical Computations, 2009). The reliability analysis of the 10 items from Part A of the GLS revealed a low Cronbach’s Alpha of .487.

Considering that reliability of a test is in part a function of its length, the low alpha coefficient may be due to the fact that Part A of the GLS contained only 10 items. It is important to emphasize that these 10 items were extracted from the NAEP Geography Subject Area Assessment, which is carried by the National Assessment of Education Statistics. Therefore, even though the reliability measures were not available, the assessment can be trusted to have its items highly correlated.

Phase II. The concepts of credibility, transparency and consistency are described in this section.

Credibility. Qualitative research describes the world as participants experience it. In qualitative studies there are multiple not fixed or agreed upon realities that reflect a particular point and a specific context (Merriam, 2002). Therefore, in this study the intention was to better understand what the selected interviewees' geographical attitudes and experiences were. The goal was to interpret the points of view of the high and low GLS performers.

Erickson (1986) sees that generalizability is an "inappropriate goal for interpretative research... The search is not for abstract universals arrived at by statistical generalizations from a sample to a population, but for concrete universals” (p. 130). Merriam (1998) adds that qualitative work is conducted "because the researcher wishes to 
understand the particular in depth, not to find out what is generally true of many” (p. 208).

The results of the study can be of value to institutions other than FIU, but its usefulness should be left to the consumer (Merriam, 1998). Thick, rich descriptions of the research process (Merriam, 1998) were provided in order for consumers to have detailed and abundant information to decide for themselves whether or not the study can be beneficial to their fields.

Rubin and Rubin (1995) note that "researchers judge the credibility of qualitative work by its transparency, consistency-coherence, and communicability” (p. 85). These three standards are discussed next.

Transparency. According to Rubin and Rubin (1995), transparency "means that a reader of a qualitative research report is able to see the basic processes of data collection" (p. 85). A transparent report allows consumers to evaluate the strengths, weaknesses, and biases of the study (Rubin \& Rubin, 1995). Since the "primary instrument of data collection and analysis in qualitative studies” (Merriam, 1998, p. 203) is the researcher, a careful process of data collection and analysis facilitates enhancing the transparency of the emergent data.

Strategies used were attention to data collection and recording as well as maintaining organized records of transcripts and interview digital files. In addition, and as recommended by Maxwell (2005), verbatim transcripts from the interviews were developed by the researcher. This assisted the researcher in accurately capturing the interviewees’ responses. 
Merriam (2002) stated that biases have to be identified so they can be monitored. In regards to the topic of geography, and based on the researcher's experience as a teacher who had among her assignments to teach social studies, and her interest in the discipline, she was well aware that there is a tendency to marginalize and misunderstand the subject, as noted throughout Chapter I. Therefore, the researcher did not allow that bias to interfere with the interviews conducted. Questions were asked in a manner that allowed interviewees to answer them freely regardless of what the researcher believed or anticipated they would respond. Identifying biases allowed the researcher to keep them under control when conducting the interviews, and to avoid shaping the interviewees' answers. Being transparent "encourages the researcher to stay close to his or her data in writing up a report” (Rubin \& Rubin, 1995, p. 87).

Consistency. A consistent final report is one where "the researcher checked out ideas and responses that appeared to be inconsistent” (Rubin \& Rubin, 1995, p. 87). A related concept is coherence of themes, which means that the researcher "can offer explanations for why apparent contradictions in the themes occurred and what the contradictions mean” (Rubin \& Rubin, 1995, p. 87). Examining inconsistencies is beneficial to the researcher since "the reader is more likely to believe that the interviewees are responding openly” (Rubin \& Rubin, 1995, p. 90). Through a careful revision of the interview findings, the researcher explained contradictions. For example, one of the interviewees did not associate a human geography course to geography. The researcher explained why this student's view was not aligned with the one of the other students who took the course. 
Communicability. It is important for researchers to conduct "research that is designed to garner lots of evidence; that is vivid, detailed and transparent; that is careful and well documented; that is coherent and consistent is going to be convincing” (Rubin \& Rubin, 1995, p. 91). The research presented should feel real to the consumers of the report. In order for this research to feel real, the researcher made sure it was detailed, full of evidence, and with vivid text (Rubin \& Rubin, 1995).

\section{Summary}

The present chapter introduced the approach used in the study over its two phases. Phase I consisted of administering the GLS and identifying students scoring at its low and high ends. Phase II used in-depth interviews with selected students from Phase I. The findings, detailed in the next chapter, allowed the researcher to explore the geography attitudes and experiences of FIU freshman students scoring at the low and high ends of the GLS. 


\section{CHAPTER IV}

\section{RESULTS}

The purpose of this study was to explore the geography attitudes and experiences of freshman students scoring at the low and high ends of a geographical literacy survey. In order to do so, the study was divided into two components, the GLS (Phase I) and in-

depth interviews (Phase II). The results at each one of these phases are reported in this chapter.

\section{Phase I Findings}

A total of 200 MGF 1106 (Finite Math) students completed the GLS. Some of the 200 completed surveys contained missing data. Since the missing data were limited to a small number of cases, the researcher opted to exclude those surveys from the statistical analyses, making the number of total analyzed surveys via SPSS to be 187. According to Howell (2012), the approach employed for this study, listwise deletion, is "by far the most common approach to [treat] missing data” (para. 12).

The GLS was a researcher-developed multiple-choice instrument of 23 items. Part A of the GLS contained 10 geographical literacy items while Part B consisted of 13 demographic and background information variables. The demographic data were used for a general contextual description of who participated in the screening Phase I.

Out of the 187 participants, 72\% were women, 28\% men, 60\% White, 14\% Black, 10\% Other, $8 \%$ Multiracial and the remaining $8 \%$ was composed of Asian, Native Hawaiian, and other combinations since the students were able to check all the options that applied to them. 
Sixty-nine percent of the students were Hispanic and 31\% non-Hispanic. Thirtysix percent were from FIU's College of Arts and Sciences, 32\% from the College of Nursing and Health Sciences, 8\% were Undecided, 5\% from the School of Hospitality \& Tourism Management, 4\% from the College of Education, 3\% from the College of Public Health \& Social Work, 3\% from the School of Journalism \& Mass Communication, 3\% from the College of Business, 3\% from the School of Architecture + The Arts, and the remaining 3\% were from other colleges/schools.

Ninety-four percent completed more than half of their K-12 education in the United States, and $43 \%$ chose history as the favorite social studies subject. Fifty-nine percent spoke two languages and $42 \%$ followed international news at least once a week. Twenty-nine percent reported having taken two geography-related courses in their K-12 education and $49 \%$ believed themselves to have good geography skills. Lastly, 36\% had traveled abroad 1-3 times, 75\% had never lived abroad, and 98\% had never studied abroad.

Research sub-question 1 was: How do freshman students perform on the Geographical Literacy Survey (GLS)? A composite variable with the total GLS score (maximum 10 items correct, minimum 0) showed the students' performances on Part A of the GLS (items \#1-10). The average raw score was 6.9 correct items out of 10 . The frequencies of the raw scores are shown in Table 1. 


\begin{tabular}{ll} 
Table 1 \\
Frequencies & of GLS Raw Scores \\
\hline Score & Frequency \\
\hline 2 & 2 \\
3 & 4 \\
4 & 13 \\
5 & 14 \\
6 & 36 \\
7 & 43 \\
8 & 32 \\
9 & 29 \\
10 & 12 \\
\hline Total & 187 \\
\hline
\end{tabular}

The freshman students' mean performance of $69 \%$ on Part A of the GLS was equivalent to the mean performance of the 12th grade students from the 2010 NAEP Geography Subject Area Assessment on the same 10 items which was 68\%. This comparative data is provided since the items from Part A of the GLS were taken directly from the 2010 NAEP Geography Subject Area Assessment. It was not among the goals of this study to make an in-depth comparison to the original NAEP assessment. In addition, such comparison could not have been adequately made due to the variability between the conditions of the two studies such as population, sample, location, instrument, and time. 


\section{Phase II Findings}

The low 35\% and high 20\% GLS performers were invited for Phase II. A total of 12 students participated in the Phase II interviews. Six were from the low end of the GLS and 6 from the high end of the survey as seen in Table 2, which provides pseudonyms. As suggested in Chapter III, data saturation is usually reached after conducting 12 interviews. After conducting 6 interviews on each end the researcher reached data saturation in this study. In the case that data saturation was not achieved at that point, the researcher would have invited one more interviewee on each end, and repeat that process until data saturation was reached.

Even though Chapter II suggests that students’ attitudes toward geography do not differ due to gender, all 12 interviewees in this study, as it can be seen in Table 2, were females. This can be understood considering that 72\% of the GLS respondents were females.

Table 2

Interviewees from Phase II

From low end of GLS (low 35\% performers)
From high end of GLS

(high 20\% performers)
Jimena

Ana

Elena

Deborah

Ashley

Fabiola

\section{Caroline}

Viviana

Carmen

Naomi

Natalia

Diana 
In the following paragraphs a brief background of each participant is provided, beginning with the interviewees from the low end of the GLS.

- Jimena is a Brazilian-born student who came to the U.S at the age of five, becoming the first one in her family to graduate from high school, and also the first one to go to college. The majority of Jimena's family is in Brazil and she frequently communicates with them in Portuguese. Jimena also understands Spanish. She wants to study Social Work and might double-major in Health Sciences.

- Ana is from Colombia as is her entire family. She speaks English and Spanish and has lived in the Miami area as well as in Vero Beach. Her major is Political Science.

- Venezuelan born and raised Elena moved to the United States five years ago. Her entire family is from Venezuela. She speaks English, Spanish and a little Portuguese. She is majoring in Psychology.

- Deborah, a Psychology major, was born in Florida as was the rest of her family. She has lived from Lake Worth to the Boynton/Delray area. She is learning Spanish and Creole.

- Ashley, a Hospitality Management major, was born in Jordan, but moved to Palestine when she was one-year-old. She initially moved to Orlando and then to Broward County when she was four. She wants to become fluent in Arabic and many other languages.

- Fabiola, a double major in English and Spanish, was born and raised in Venezuela and moved to Weston when she was 13. She is bilingual 
(English/Spanish), and wishes to learn several other languages.

The remaining six students were from the high end of the GLS:

- Caroline is from Palm Beach County and introduced herself as "half-Spanish and half-American”. She is bilingual in Spanish/English, has knowledge of French and is currently learning Portuguese. Caroline’s field is Nutrition.

- Viviana comes from a Colombian family, but was born in the United States. She speaks Spanish and English and believes she will be studying Nursing.

- Carmen, an anthropology major, was born and raised in Florida and was homeschooled almost her entire K-12 career. Her parents are from Puerto Rico and she is bilingual in English and Spanish. She would like to study Italian.

- Naomi is from Miami and her mother is from Costa Rica. She speaks English, Spanish and a little Portuguese. Her major is Hospitality Management.

- Natalia was born in Perú and came to the United States when she was seven. She speaks Spanish and English and wants to study Criminal Justice.

- Diana was born in Miami. Her mother is from Nicaragua and her father from El Salvador. She is bilingual (English/Spanish) and may continue studying Italian in the future. Her field of study is Nursing.

Emergent themes. After the 12 transcripts were inductively analyzed five themes emerged:

- Concern regarding a lack of geographical knowledge

- Rote memorization of geographical content is overemphasized

- Geographical concepts are related to other subjects 
- Taking the high school level AP Human Geography course is powerful

- There is a need for real-world applications of geographical knowledge

Concern regarding a lack of geographical knowledge. Students expressed concern regarding their lack of geographical knowledge and that of other people around them. First of all, students struggled when asked to recall the geographical concepts they had learned. Jimena remembered her overall geography experience in elementary school: “in terms of geography I didn't learn much, except the continents, or the states, the little song of the 50 states.” In middle school she “didn’t learn that much” after her teacher had to leave due to pregnancy and had a substitute teach her. Jimena remembers that "it was never somebody actually teaching” after her teacher left.

Deborah recalled that in elementary school she "just colored maps." She had a similar experience to Jimena's with her teacher not being engaged: "the only geography course I took [in middle school], I didn't learn much 'cause she [geography teacher] wasn’t really into it” and “she really never taught it.” Deborah’s experience in high school was no different: “we didn’t learn much 'cause in his [geography teacher] class we would just talk 'cause he didn't want to be one of those strict teachers.” Overall, Deborah wished to have acquired more knowledge:

I haven't really learned anything and then you realize when people ask you where a certain place is you sitting there dumb because you don't really know where it is..."What's going on over there?” "Over where? What are you talking about?"

Ashley shared that after middle school, “you don’t really stress geography” and was highly concerned at people’s lack of knowledge:

Sometimes you think it's common knowledge like to know that there's seven continents, but people can't even name those. Or people can't even you know just name like simple things like where South America is or I 
don't know 'cause “oh my God, that's so fifth grade.” Even though we are not taking a lot of geography courses like there's just some things that you think you should know, but when you hear other people don't, you're like wow...

Fabiola sees the need to expose students to more geography:

[It is important for] people have a better knowledge of how the world is generally 'cause I mean I know if I ask my brother to point at -I don't know- Thailand in the map he would be lost and he is in 10th grade right now so I feel like it's important to find your place and know where you are and have a general idea of where everything is.... it does have to be emphasized a lot more 'cause I mean it really is upsetting to think that there's people in this university that don't know like they are so, they think...that Africa is a country, "what are you talking about?"

Elena believes that having geographical knowledge should be a basic skill and stated: “I don't even know where Minnesota is. The states of the United States? I don't know where they are. Like I wish I knew where they were, but I don’t.” Caroline expressed her concern regarding the lack of geographical knowledge she has seen in others:

A lot of people don't really know, a lot of young people don't really know how far a mile is or a kilometer compared to a mile and that's something really important especially when you go to another country and everything is on kilometers, everything is metric... a lot of people don't even know what all of America looks like, the 50 states, they don't know that Alaska is actually up north and is not on a little square at the bottom of the map... A lot of people have been talking about study abroad and it's like you can go to all these places and a lot of people don't really know where they are or like what to do there.

Viviana stated that “some people don't know what's going on in the other side of the world" and "some people never heard of known countries and...everybody should be familiar with...the most generic and...general topics of geography.”

Naomi added that “you can ask someone 'oh what's the capital of this state?' and they have no idea or you ask them this country and they would be 'what is that? Asia or Africa?' [laughs] they are really confused so I think it’s kinda important.” 
When discussing the importance of using geographical knowledge when having

conversations about current events, Naomi stated:

Sometimes you might be talking and they would tell you all about it and "oh my God, this issue is going on and it's so important and I feel so strongly about it" and then you might ask them a question like ok "what's happening around it that you think may be influencing that?” and they are like “oh, I don’t know!” I think it just makes them sound a little bit ignorant just because they don't take the extra step of trying to find out more or less what exactly is going on so they might think "oh yes this is terrible and this is happening”, but you don't know what's going on around it, the circumstances...

Diana also stressed the importance of having knowledge when discussing what

happens in the world:

I know people get mixed up and rant, they have no idea what it is, they have no idea what's it about, they just spit out names and pretend they know what that is. Like I said in order to better yourself you need to know about others. It really puts a person in an ignorant position when they start speaking about things they don't know about like Iran, Iraq, this is here, this is not there.

When asked about the role geography will have in the future, Natalia added:

I don't know, because how it's going... people don't really realize it and don't take interest in the course or anything 'cause they don't know anything about it. Maybe if they get informed on it and it's more than just a map then yeah I think it would be interesting 'cause a lot of people I know are interested about culture and that has a lot to do with geography so... I think that if people were more informed on it, they will be more interested.

Ana used a friend in order to illustrate how people do not know about geography:

One example is: my friend picked to go to FSU and she hates the cold so she's hating it, but she didn't really prepare to look into it or prepared to put common sense, but I guess I take it for granted it's common sense because if you have never taken a geography course in your life you wouldn’t really know.

Carmen believes social studies is not emphasized enough in our schools:

Right now education K-12 isn't as good since we don't emphasize history and geography as much, then the kids they won't take interest in that, if they'd been shown or talked about more of that, I guess they'd be more interested. 
Rote memorization of geographical content is overemphasized. When talking

about their experiences with geography, students repeatedly mentioned they had to memorize facts and locations all the time.

Jimena recalls learning geography was factual and about memorization: "very factual, we are doing this for this quiz... at the time I didn't see how important it was... it was just a lot of memorization. It was kind of repetitive, maybe if the whole middle school course wasn't about memorization, then it would have been a little bit more interesting.”

Ana also remembered being asked to "memorize random facts" and that the approach used in her geography classes was "more of a let’s memorize this and that." Elena echoed that experience: "we used to just learn it [geographical material] for the test. Read the book, memorize it and just take the test...it was just read the book and take the test. That was it. There wasn't much else to it.”

Deborah recalls memorization activities that were not that helpful: "I remember we just colored maps to help us memorize where the states were even though we did that for two days and it didn't really help us." Ashley stated that she has forgotten most of the material she was asked to memorize:

When I was taking the course it was like, let's just memorize this, but I have forgotten most of what I learned so if you don't keep it up I mean, you are gonna lose what you learn, that information in general it's good to have so...

Caroline summarized her experiences as one where "it was all memorization,” a view that Viviana ("It was more about memorizing and taking the tests”) and Naomi shared ("It was mainly just memorizing”). 
Natalia reflected on her geography instruction and stated that geography was easy for her: “because I’m good at memorizing things so I passed all my tests. I just didn’t learn anything out of them. I just memorized it for that test.”

Diana mentioned how standardized geography instruction is: "these are the rules, you have to memorize them, that's it. Nobody goes out and explores really what it's about.” When reflecting on her elementary years, Diana noted: "It was useless. Pretty much memorizing the capitals, that is the one thing that I grabbed from there.” Many of her teachers overemphasized the memorization of material: “[previous teachers] were all based on memorization like I said, cut and copy, nothing new, nothing to actually experience and to immerse yourself in.”

Naomi overcame the issue of having to constantly memorize facts by always relating the content to real-life:

It was mainly just memorizing, but I didn't really like doing that. When I do something, I think I might as well learn it if I'm going through the effort so I would go ahead take a little extra time, like ok, this is here and then I tried to connect it to like a fun fact or something going on in the news... if I would have treated it like "oh, it’s just another class" memorizing information right now that I will forget at the end of the semester then I think I would have definitely wasted my time and I wouldn't really have cared

Geographical concepts are related to other subjects. Students do not associate many geographical concepts to geography and attribute them to other subjects. When reviewing the essential elements of geography, Elena recognized many concepts, but not from geography instruction: "The physical systems I remember more from Earth Space Science not from geography. For the human systems I think more of history than geography.” 
Deborah learned about how culture and experience influence people's perceptions of places and regions through another course: "I learned a lot about culture in high school, this teacher, he wasn't even supposed to be teaching that course, he was teaching English, but he was all into geography and people’s cultures.”

Fabiola recognized many of the essential elements of geography through other subjects. Concepts such as organization of people, places, and environments ("I think I saw the kinda idea of organization of space in art”), the regions people create to interpret Earth's complexity and how culture and experience influence people's perception of places and regions ("we've been talking about in my sociology class right now"), the characteristics and spatial distribution of ecosystems ("a little we might have mentioned when we talked about ecosystems in biology”), the process, patterns, and functions of human settlement ("maybe a little bit talking about Native Americans") and how forces of cooperation and conflict among people influence the division and control of Earth's surface (“a little bit in history”).

Viviana learned about the physical processes that shape the patterns of Earth's surface ("not really in geography, but more in earth space science"), about the characteristics and spatial distribution of ecosystems on Earth's surface ("also on biology”), about the characteristics, distribution, and migration of human populations on Earth's surface ("mostly in history classes") and about the process, patterns, and functions of human settlement (“in basically all our history classes”).

Naomi was taught about the characteristics and spatial distribution of ecosystems on Earth's surface in a science course: "I'm actually learning that right now in environment class.” 
Natalia indicated that through science she learned about the physical processes that shape the patterns of Earth's surface ("that might have been more earth space just 'cause the teacher started going off track a little bit”), and about the characteristics and spatial distribution of ecosystems on Earth's surface ("I think that was more earth science than anything”).

Naomi related to history how forces of cooperation and conflict among people influence the division and control of Earth's surface:

Ok, that one I think would have to be more historical just like the division of the surface, just because that's when more borders were established like "ok, this is happening between us, this is our land, this doesn't belong to you" so I think that does cause conflicts 'cause if you take it back to the peace acts and the treaties it causes a lot of wars just because they claimed "oh, this is ours" so that would definitely influence later on

\section{Taking the high school level AP Human Geography course is powerful.}

Advanced placement allows students to take college-level courses while being enrolled in high school: 'Through more than 30 courses, each culminating in a rigorous exam, AP provides willing and academically prepared students with the opportunity to earn college credit, advanced placement, or both” (Human Geography Course Description, 2013). The purpose of the course is to

introduce students to the systematic study of patterns and processes that have shaped human understanding, use, and alteration of Earth’s surface. Students learn to employ spatial concepts and landscape analysis to examine human socioeconomic organization and its environmental consequences. They also learn about the methods and tools geographers use in their research and applications. (Human Geography Course Description, 2013) 
In most cases, students who took or were familiar with the Advanced Placement Human Geography course in high school, gained an awareness of human geography.

Elena did not take the course, but being aware of its existence in high school added the human dimension to her understanding of geography:

It wasn't until freshman year here that there was an AP course in Human Geography and a lot of people took it 'cause it was like easy AP, but from what I hear from it, you learn that human aspect of geography and so I didn't know there was such thing until four years ago

Viviana mentioned that besides maps and countries, geography also deals with people thanks to having taken the course: "I studied human geography...in sophomore year so I guess is also about culture and...diversity around the world.”

For Natalia taking the course marked a before and after in her understanding of geography:

It was... I thought it was gonna be a lot different than what I thought it was gonna be. I thought it was gonna be boring, I was gonna learn just about like a map and where things are located and that's about it, and I thought that's what's all it's gonna be, and it turned out to be not about that, it turned out to be about how places are correlated to the people and turned out to be more about the people in the places. I learned that I did like learning about the maps anyways because I liked knowing where the countries and the places and everything is, but I also liked learning about the people in the places and how it affects them and how they affect the place and the terrain.

Viviana shared her thoughts and those of her classmates before taking the Human Geography course: “...when I first came into the geography class I was not prepared for it, I guess, you can say that... Everybody was like -I remember before the human geography- everybody is like 'Human geography? What do you mean?’” Jimena and Caroline took the course, but still struggled associating the human aspect to their own definitions of geography. Jimena took the course, but did not relate 
the content to what geography means to her and did not mention this course when asked about the geography courses she had taken during her K-12 education: "I did take in high school though human geography, but it wasn’t really about geography, you know it was about the different cultures, but it didn't have to do with like the maps and stuff like that.”

Caroline also took the course and had some difficulties associating culture with geography: "In high school I took Human Geography so that obviously had a lot to do with geography, but it had more to do with people and the way they affect the states around them.”

There is a need for real-world applications of geographical knowledge. Students want to understand the usefulness of the geographical concepts and skills they learn as well as how that information can be applied to everyday life.

When taking a look at the essential elements of geography, Jimena stated: "I think the use of geography is important but I don’t think it was stressed enough.” Ashley did not learn it at school: "that's probably something that I do on my own.”

Elena does not see the relation: "I don’t really see it being applied to my life or... I just don’t see it.” Deborah shared Elena’s view: “I learned nothing about that [applying geography to interpret the present and plan for the future].” Fabiola was very direct with her answer: “They teach you how to read a map, but there’s not much past there.” Diana echoed that view: "here we are, one thing people really don't think about” [how to apply geography]. 
Caroline added: “I don’t really think we learned how to apply geography to interpret the past in history, to know where things were, and I don’t think to plan for the future either. That's important. It's usually left out.”

Viviana added: “For the future, we really didn’t talk about how to use geography to predict what would happen, know things for the future.” Natalia believes that taking courses that relate geography to traveling and to local events would be helpful:

....if it's like a study abroad program and it's also teaching you about the geography of the places that you are going you get, you have a more realistic and firsthand experience and it would make it more interesting 'cause you are in a different place so if it's more hands on and if you see that it can be applied to everything around you...

...if it affects the community, the people around where we're living in, I think that would be appealing because they [students] would realize the problem, they would be more aware of the problem and they would realize more of the details of it and you would come with a better solution because you are much more aware of it...

Diana stated that her World Geography high school course would have been much more interesting if she had learned how the information can be applied: "Connecting [the material] to real, to present time [would have made the course more exciting].”

Themes from research questions. Besides the aforementioned emergent themes, the study's sub-questions 2-4 pertained to the qualitative component of the study:

2. How do students define geography?

3. How do students describe their in and out of school experiences with geography?

4. How do students describe the value of geography to their lives, fields of study and careers? 
The following section provides the three themes identified from the qualitative research sub-questions.

Student's definition of geography is limited. The first qualitative research subquestion was "how do students define geography?”

Jimena, Ana, Caroline, Viviana, Natalia, Elena, Naomi, Carmen, Ashley and Fabiola defined the subject as a discipline governed by maps and location. As Fabiola expressed when asked to define the subject, "You are going to be looking at maps, and you are going to be studying a lot of maps, and a lot of different things about maps.” Carmen added, "Geography is basically [pauses] where all the countries are I guess.” Ashley also made a connection to history and the current events of a certain location by expressing that geography is the study of "what goes on in certain areas, and the history that affected that area.”

Elena also linked the subject with nature ("the basic knowledge of the nature or what not, what type of tree is that, and what's that part of the river”) and Deborah with physical features ("Well, you are gonna learn about some mountain places, some oceans”).

In her response, Diana mentioned that did not see ties to humans "More like environment, not people, never people. I was never taught that and I never associated it with that. It was not until later that I finally -like now- [laughs] that I finally opened up my mind, yeah different people, different environments, exactly.”

Natalia tied geography with cultures: "I guess geography, they teach you about the cultures of different places, different regions." 
Students describe richer out of school experiences with geography. The second qualitative research sub-question was "how do students describe their in and out of school experiences with geography?” Students remembered concepts learned and tasks performed, and special projects conducted. For their outside of school experiences, they described watching TV shows, reading books, playing online games, using the GPS and Google Maps/Earth, looking at imagery, traveling, and talking to others.

Students recalled concepts learned and tasks performed in their geography courses throughout their K-12 education. Jimena remembered some of the topics covered and the tasks she had to do:

I remember having to fill out a map, having to learn like the fifty states of the United States and having to locate them on the map... and I remember learning the difference between a valley, a stream, a river and having those definitions, and learning about the different natural disasters like earthquakes, hurricanes...

I remember learning [in human geography] about the different types of maps, the map makers, not specifically about geography, where things are on the map, I remember also learning about the definitions of worldview, learning just the different cultures mainly.

Caroline also recalled her experiences with both physical and human geography:

Yes, we always took social studies class in elementary school and we would learn about like America and how the theory of Pangaea and stuff like that and then I high school I took Human Geography so that obviously had a lot to do with geography, but it had more to do with people and the way they affect the states around them.

Ana, Diana, Naomi and Carmen also recalled concepts they learned, which dealt with map skills:

I remember some concepts, like I remember the hurricane thing and I remember... learning the state capitals... they gave us like a map of the world and we had to memorize the capitals and populations, that's why maps is the first thing that comes to my mind. (Ana) 
The capitals, I remember learning the capitals, having to memorize them. Remembering all the lakes, all the oceans surrounding us, the continents and the surrounding countries. (Diana)

...in middle school they had us learn all the countries in the world and we had to locate them on the map and we were tested on that. (Naomi)

When I was a lot younger she [mother, who was in charge of the homeschooling] got a globe and she would make me memorize and she would ask me where's a certain country and she wouldn't let me see the globe and I had to tell her what continent, what countries were surrounding it and stuff like that. I think that's about it. (Carmen)

Venezuelan- born Elena remembers learning about the geography of her native country:

I learned...the geography of my country so...the savannas...we are...next to the Amazon so it's a lot of jungle... But for some reason I remember rivers a lot, like deltas and all that, I remember...the specific type of trees

The students recalled special projects they were asked to do in their courses,

mainly related to a specific country they had to research:

I remember vaguely in one of my classes in middle school we had a project where we would have, we made a passport and we had to pick a country that we went to and we learned things about the county and the climate, and what you would wear and things like that and at the end of the week you would present where you went and stuff like that, but I don't remember. I think the passport was better than just trying to memorize random facts. (Ana)

In middle school we had to do projects about different countries so like every group had to do a project about a different country and had to do a board explaining a lot of facts about the country and then they had to dress up like the country and then they had a diorama, something really big. (Caroline)

We used to do projects on countries, like pick your favorite country and study it and say your favorite things about it, like the food and stuff like that, but that's about it I think. We just had one project from what I remember. (Viviana)

In elementary definitely, we had our little notebooks and we would learn about a new country or we'd have, every week we'd be assigned a different country so like every time I think of geography I usually think of Uzbekistan because it was usually my assigned country all the time for some reason and I would be like 
"yeah, I know all about it! I know this, this and this”. I felt like accomplished when I was little so... (Naomi)

...earlier in my years they made us research about one specific place and I had Colombia and I learned that the capital was Bogotá back then and I thought that was cool because I got to research a country that I didn't know before so I got to learn more about a different place oh and in middle school they also made us do research on another country, I think I had Turkey that time, but I got to learn more about just where it's located, I got to learn about it and see about the people and population. (Natalia)

Ashley's project was also about a country, but it required the students to plan an

entire vacation at that destination:

Yeah I had to do a research project on the state of Oklahoma of its existence, when it came to be, where it is and then I had to print out like the shape of it and then like and I also did a research project on Australia and the I kinda had to make a vacation within Australia so I had to tell where I was staying, where the area is, what I did for fun and that kind of thing, and I got to know Australia 'cause nobody really thinks about Australia so I got to expand on my knowledge (Ashley)

Diana recalled a project she had to do regarding climate change:

We had to do our own globe per say of what the climate would be expected after greenhouse gasses, but it was more of like science and geography, but she [teacher] made it specific so that we could contour our own globe as to how it would look I think it was 25 years later and yes it was kinda of an utopian kinda of globe that she wanted us to do.

The students also described outside of school experiences they had or have with geography. One of them was watching documentaries or shows on TV that covered geographical information. Caroline and Carmen mentioned documentaries on channels such as National Geographic, Animal Planet, Discovery Channel and the History Channel:

I think National Geographic is really interesting and those shows on like Animal Planet or Discovery Channel are really interesting and they talk about different places, well Animal Planet definitely talks about different places. (Caroline) 
I watched a lot of them when I was younger... documentaries on History Channel, National Geographic regarding archeology or environmental science. Like stuff about anthropologists going to stay with indigenous tribes in the Amazon or they would go to different countries and interact with the people, learned more about the culture though that. (Carmen)

Jimena, Ashley, Fabiola, Viviana and Diana recalled shows that range from

survival of the fittest to house hunting in international locations:

What I really like is when TV shows they do like an expedition to a certain place, the top of a really high mountain or like survival you know, survival of the fittest I guess, then you learn a lot of the specifics, maybe the geography of that place, (Jimena)

I watch the food shows and I forgot what's it called, it's like he goes around the world and tries different things so you get an idea of where he is, what they eat, what is there, norm, 'cause here it's a lot different than if you go to Asia or like.... (Ashley)

Yeah, mostly just looking up online, I watch a lot of House Hunters International which shows you kind of what houses are like and it shows you kinda the landscape of course, lots of Google boredom time, yeah I guess that's mostly it, just online. (Fabiola)

My mom watches the, my mom likes those types of shows and I watch them with here like different culinary cuisine too like I think it's important to look at the world and travel a lot, 'cause you never know what's out there, 'cause you are always on the same place. (Viviana)

OK, just thinking about this right now there was this show that used to be "Can you name that state?" and they would give you like a whole background on the state and the gentleman used to run through everything important about it and then at home...(Diana)

Reading books have also provided students experiences with geography:

When I'm reading books if I learn about a place that I don't know where it is, I'd look it up you know. Then I would go to Google and be all over the place. I don't watch much TV or go into magazines period so like it's only when I'm reading a book that I'm interested then I go on Google look it up, to look at some pictures, to teach myself about that place. (Deborah)

I think I read in books as well about geography, but I don't remember exactly. (Carmen) 
I read books sometimes, I read when I have spare time and that does take you to different places ‘cause if it's based, I don't know, in Italy or a South American country it may not be precise, but it gives you the idea of what's around it and I think that's cool. (Natalia)

Elena and Fabiola shared experiences they had playing online games that asked them to put into practice their geographical skills:

'Cause there's a game online that is "Find the Airport" and then it basically puts you in a random place, in a random city and you need to find the airport. So I would be thrown somewhere on the Middle Eastern and I had to move around in Google Maps until I found the airport. I saw it online and then I just opened the link. (Elena)

A lot of it comes from this Facebook game there was a while ago and you had to put like countries with like the capitals or the flags with the countries so I did that a lot out of boredom also in Venezuela everything that is South America I know it because of when I was in Venezuela they taught a lot of you know the capitals in South America, this is how the entire landscape works, yeah. (Fabiola)

Students expressed how much they rely nowadays on technology and the GPS:

I think it is [important to know how to read maps] even though it's a dying art because people over rely on the GPS and so nobody probably knows how to read a map. (Ashley)

I don't even know how to view a map, like I use the GPS and I'm horrible at directions and everything about it so like I use the GPS a lot. (Viviana)

I definitely use GPS. (Caroline)

Besides the GPS, students have numerous experiences with Google Maps and

Google Earth:

Yes, 'cause I'm not good with directions. Ok, so you want me to go where? Yes, that's what I usually do, I use Google Maps, use my GPS, I ask somebody to take me to the place first before I go so I can learn the surroundings. (Deborah)

I used to go on Google Earth a lot 'cause I found it interesting how the whole world is displayed there and you can see in detail everything and I also use Google Maps too basically 'cause I'm horrible at directions so like I use those type of applications a lot. (Viviana) 
Yeah, I did that when we went to Europe, I looked around London, I do this thing in which I try to find my house in Venezuela without remembering my address so I just have to kinda remember what the streets look like and yeah...(Fabiola)

I live in Miami so I can’t go anywhere without my Google Maps. (Ana)

Yeah, if it's somewhere that I haven't been before and I have the address I would look it up before I go so I kinda have an idea and just memorize the route. Sometimes [I would use Google Maps' street view feature] if I am not familiar with the area (Carmen)

I use it because since I haven't been to Brazil in a long time and I was like "oh I want to see the place where I grew up" so I use that, or I want to see what Paris looks like just to kill the curiosity when I have some free time. (Jimena)

Yeah, sometimes like I used to go on Google Maps to map out a way when I wasn't driving for my dad, 'cause he asked me to do it, I used it sometimes just to basically just walk around the little places and virtual things, just to walk around it and see what's there and everything...I used to go from here to New York virtually and then I switched it to Europe 'cause I found it interesting how it's different... (Natalia)

I use Google Maps especially since I have been looking for apartments and I necessarily need to know the name to find out you know more about the place. I just use Google Earth to look at it or just general fun. (Diana)

Imagery has provided students with reasons to seek more information about

places around the word:

Yes, there are some pictures that I am like "OMG, I have to go there today". Pictures help you identify a place so that whenever you see a picture of Lady Liberty you are going to be like NY you know. So they definitely help you identify a place. (Jimena)

When I see like interesting locations that I would like to travel so I like to look at it and see, like I was walking down and I saw a magazine with a really pretty beach so I kinda looked to see where it was. Costa Rica. I wanna go. (Ana)

It happens to me all the time, yeah. I saw this picture of this place, of this national park in Croatia and I saw the picture "oh, I'm gonna go there!” 'cause there's like this river, it doesn't look like a river, it looks like waterfalls and all that and it looks like it's in the middle of a rainforest, but it's not, it's in Croatia, it's in the Mediterranean. (Carmen) 
I have like a few Instagram accounts that I follow like of different places around the world and it would be a really pretty place and I would also be like "uuuhh, where's that?” I would start looking it up and I would be like "oh, ok". Where's that? Where's this? I would just compare them... (Naomi)

I just took a course on music appreciation and there's a lot of pictures of like these buildings, and I was like "I wonder where’s that!" and it was in Vienna, Austria and I never considered that country to visit and now I would love to visit. (Viviana)

Traveling has provided students with opportunities to experience geography:

I got the opportunity since I was a little girl to travel to places so I got to appreciate not only the cultures that changes from the different places that you go but also the landscapes that I find personally beautiful. Like when I went to Holland two years ago it was just like amazing when you see the river above the ground level, it just helps you understand, here in Miami it’s just flat, and humidity and the beach, and that's it. Those are the three things, but once you leave there's just much more to a place than what you see, so I appreciate, and when I flew by Colombia, just beautiful mountains, it's nice, it's nice. (Elena)

Yeah or like I ask them [friends] I'd say where's it and then I'll do a whole search on it, oh that's really awesome. Me and my roommates we have this list of adventures on our refrigerator 'cause we live in Lakeview and so basically we are trying to go around like to everything that's been popular. Like we've been to Wynwood, the art place, and just to see the different, in Miami there's a bunch of different cultures anyways so to get to know the area... (Ashley)

I've gone on a road trip throughout the U.S. and seen all the monuments and national parks. (Carmen)

Yeah, I mean just traveling like a few hours north you will see you know there's a lot more trees, a lot more nature, for example just even an hour off you go into the Everglades and that's a completely different ecosystem from here and you would just learn so much more. (Naomi)

...not too recently- I was going to go on vacation and so I had to make a whole not a whole report kinda thing- but just to explain it to my family so I went online, I looked up pictures, I picked out like a whole -what's it called- like a whole itinerary and I had to learn what was the map we were gonna use in the place, so it was pretty cool, I had fun with that, but other than that I don't think I have ever used anything geography... (Diana)

I remember when I, my family traveled a lot so when we would go on road trips my dad has a map like before we even had the whole GPS thing, I just remember 
the car rides, big maps, and stopping on the side of the road, so I think it's important just in case anything happens and you're lost. (Ashley)

Lastly, students who participated in the interviews mentioned that a big source of

insight is talking to others who are from a different country or area:

...my best friend, she was born in Spain, and then she moved to Germany and then she moved here so we just always ask her about how is it over there and then even here just like you know we are mostly Hispanics, but still you are from Colombia, what's in Colombia? I like to know and learn about...(Elena)

In here I haven't met that many people, but I plan to learn more about where they are from. (Deborah)

Yeah, for sure, especially here when you meet people and they have an accent, you are right away, where are you from? You're guessing in the back of your head. (Ashley)

Definitely I do, I love hearing about different, people from different ethnicities and different cultures, it's fun, we are very diverse. (Fabiola)

Yes, even when someone has a different accent I might wonder where they are from, like I met this, during summer I met this girl and she had kind of an African accent and I wondered where she was from and I asked her "where are you from?" and she said "I'm from West Africa" I forgot the exact country, the exact stat or whatever, but yeah, she would say things are so different and it was pretty cool meeting her. (Viviana)

Yeah. I always do 'cause I'm curious to know about the different lifestyles compared to like here, like the different aspects of their culture, I think that's cool. What's the difference between their home and where they are residing? (Carmen)

...just the cultures themselves are so different and I find it like I definitely find it interesting just because it's very different from what I'm used to especially since all the girls were very similar in my high school, which is just completely different, when I got her. (Naomi)

All the time, oh my gosh because it's so different in different... Even like here in the United States is so different like if someone comes from New Jersey or something is a lot different from being in Miami or New York so I try to ask people "oh, so what do they have? What's it like" 'cause I know, I also started getting into it when I traveled from Perú to here because it was such a difference to see so much green 'cause there where I was it was just desert so I started 
getting into that 'cause I know there are differences between places so I think I really like that. (Natalia)

I like how they differ from me. I want to put myself in their shoes and understand how that would make sense to them because we are going to be different and I understand that, but how does that difference make you better or worse or different how does that work? Not to be judgmental, but how does your life work because of where you were? (Diana)

Students find geography valuable to their daily lives and fields of study. The last qualitative research sub-question was "how do students describe the value of geography to their lives, fields of study and careers?”

I realized it [the importance of geography] back then in high school when I was learning. I didn't think about it at first 'cause I don't really enjoy maps, I’m not good at it at times, but I realized it afterwards, after I got to learn more about it, I realized it's as important as other subjects and it really just affects everything... it affects a lot of people in ways you didn't know so yes, it is important. (Natalia)

...what it's affecting us the most it's what's happening today and geography is today. (Jimena)

Students described that geography is valuable to daily life because it helps in the decision-making process of where to live, and because it is necessary when engaging in conversations regarding current events. Students also mentioned ways in which geography is related to their fields of study as well as the interest they would have in a course that tied their future careers with geography.

Students find geography to be useful when determining where to live:

Yeah, it’s definitely very important, I mean having lived in Venezuela where there's lots of mountains when you buy a house you have to make sure you're buying a house that's either well built or that is not gonna collapse on you at any point with the rain 'cause it happens a lot for you to have floods and a lot of houses would be lost so I definitely experienced the need of knowing geography. (Fabiola)

I mean geography for me was really important in Bright Futures [scholarship] 'cause I had to stay within Florida. (Natalia) 
Now when it comes to homes for your likes and dislikes, to keep a peaceful house in order to keep your likes and dislikes in order, to know where you're gonna settle, what type of environment you're looking for, what is the culture that surrounds it, the culture has a lot to do with the geography. Bayside is a lot more hustling and hustling because of the marina, because of the port, because it's right next to the coast, exactly. If you buy an apartment near there, you have to expect that. If you pick an apartment in Kendall, is extremely quiet, there's gonna be no bus routes, there's gonna be nothing so you need to know about that.

When it comes specifically to living, it can most definitely help you...So if you're buying an apartment you need to know how far one thing is from the other and usually you're going to school, you're going to work. So if you don't really take into consideration how far one thing is from the other, you can most definitely be ruining your daily schedule...

I had accepted a job without knowing how far it would be from my house and I ride a little scooter. I think I was 15. My little scooter doesn't go that fast. And the job was in Dadeland and I had no idea. I was like yeah, I'll get there in 30 minutes, don't worry about it. And I was supposed to come in at 8, I left the house at 7 with my little scooter. I got there at 9:30. Yeah, I didn't keep that job [laughs]. That was pretty much it so most definitely affects your transit and your piece of mind. If you have no idea of where you're standing, you are going to ruin your daily schedule. (Diana)

It's important for your daily decision making because we use it every day regardless of whether you know it or not. Like I have to use it every day if I'm gonna go somewhere. Like I live almost an hour away so I have to know what's going on down there, how's the weather going. (Deborah)

I live 45 minutes away and I don't want to do all that traffic and even if it's two times a week [to come to the university] like I just see, I've seen people struggle and just the environment and that's just extra stress and so if you are thinking about it, it is geography 'cause it's the environment that you want to be in or you don't want to be in. (Ashley)

I also did take into account how far the university was referred to my house because I didn't want to move so I didn't have to commute so I did take that into consideration. (Natalia)

Geographical knowledge was found relevant when having conversations with

others about what is happening in the world:

It's very important 'cause just just like to know like let's say a conversation and people go “aha aha aha” it’s probably because they don't know and then like you 
probably stop talking to them because like a lot of people like good intellectual conversations. (Ashley)

I think it's important yeah, I mean you can't talk about Israel or the conflict there without talking about where it is and everything that's around it and everything that's between it. (Fabiola)

Yeah, like some people don't know what's going on in the other side of the world, and then the media also manipulates it so I think it's important to know where that area is and understanding more of where they are coming from. (Viviana)

I definitely think it's important 'cause sometimes you might be talking and they would tell you all about it and "oh my God, this issue is going on and it's so important and I feel so strongly about it" and then you might ask them a question like ok "what's happening around it that you think may be influencing that?" and they are like "oh, I don't know!” I think it just makes them sound a little bit ignorant just because they don't take the extra step of trying to find out more or less what exactly is going on so they might think "oh yes this is terrible and this is happening”, but you don't know what's going on around it, the circumstances, you don't know what's influencing [it]... (Naomi)

I think it would be better for them to be well informed because if you know the geography or the relation that one place has to another and why they are fighting and all of that it is history, but like the geography is also really important because a lot of times they fight over territory and that's geography of course and if they don't know about that they are not really as aware of the issue as they should be to have an opinion that could affect how that happens or the news, yeah, if they don't really know about it, like it's not as well for them because they don't really understand that basic problem that they have... (Natalia)

Students believe geography is related to many fields of study:

...you are going to meet all kinds of people wherever you go or even if you know example science, there's going to be researchers everywhere and say you choose a particular species there can be that kind of species across the world, you don't know that, hospitality, you are going to be dealing with different clients, engineering, there's different types of architecture, things you need to take into perspective such as the natural disasters in the area, it's just something that wherever you go you should know more or less the land 'cause at the end of the day it’s definitely gonna influence how you live. (Naomi)

...'cause I guess geography is used in a bunch of different professions maybe in little ways, lot ways, like from just I guess it's good to know, you may never know when you need it. (Carmen) 
Ashley and Naomi shared how they see geography being related to their field:

My major is hospitality management so it's completely different, but with hospitality yeah, I could end up traveling one day 'cause I wanna be a manager of a hotel and it's good to have all that under your belt and to understand where people come from. If I work in France one day, know their culture, their language, it's better for you. (Ashley)

Definitely, hospitality I think is very open, you are gonna be dealing with a lot of internationals, there is for example, over the summer I worked a lot, I had an internship, it was dealing with event planning and event décor so I dealt sometimes with people who wanted to do destination weddings so there were people you know from California, there was another girl from New York and they were all like, we want to come and do it at Miami, Eden Roc, or we are going to go to the InterContinental and you just have to be prepared to work with different kinds of people, not "oh, we are only going to work with these", there's a lot of people that are going to be involved, you know, there's so many different things in that field... (Naomi)

Diana and Viviana shared the connections they found between geography and

their field, nursing:

I guess hospitals will always be around and there should be hospitals in certain areas of the world, like there are some places where there are no hospitals for like miles, and we need a hospital in everyone's convenience and I think in the future they should build more hospitals and I guess that's how it relates. (Viviana)

Yes, most definitely now with everything happening with the Ebola crisis, yeah it has a lot to do. Depending on where I settle in life it would affect my income of work, my general income, because if let's say I move to I don't know I move to rural Kentucky, my options of work would be limited than where something, yes it's tragic, somewhere with more experiences available in Africa or I move to I don't know, let's say Washington DC. Let's say, testing, research, places with universities, I'm gonna have more jobs than just rural Kentucky, yeah [laughs]. (Diana)

Elena, Fabiola, Caroline, Natalia and Ana also shared the link they found between geography and their respective fields:

Just different mentalities depending on each culture. Just it's more the mental aspect and the cultural aspect and just what you are used to those changes between psychology and geography. (Elena) 
I love writing, I feel like writing is part of everyone's kind of history and then you have writers like Horacio Quiroga that obviously wrote about the jungle and the rivers were in Uruguay or Heart of Darkness, which is a book that's set in the Congo and it talks, it also describes kind of the geography of the place, like, like it's an important aspect of what the people are like in a certain area, it's important to know the geography of a place. (Fabiola)

I think it's really important to see [the relation between geography and nutrition], because in every culture they eat differently and it's for different reasons so I think that's really important to understand. (Caroline)

Yes because I know that CIA deals a lot worldwide so you definitely have to know geography and its basics 'cause they send them out a lot on recruits or whatever and FBI deals a lot with here so mainly the United States, but they also need to know geography of the United States and like how things of other countries correlate with things here 'cause it could affect us here whatever is happening outside of the world so they need to know the culture, the way to speak to them so they need to be able to understand people, the culture there and how the geography is over there and how the geography is here to be able to be better at their jobs I guess...(Natalia)

...politicians have to appeal to the rest of the people and lots of different regions and different problems or different things for each city or state and they are gonna be different. Like for example when Katrina hit if you were a politician you kinda had to go for more like Medicare and stuff like that to help all the people in that situation, but if you really didn't know about that, you would have not hit those points. (Ana)

Having a course offering that could facilitate the task of showing how their future careers and geography relate was appealing to students:

I would look at the description, but I would only choose it if it actually involves what I wanna be after I get my psychology degree. (Elena)

Yeah I would be [interested]. I think I look at every course description, but I would look at that one too. (Deborah)

Course that tied [geography and my career]? Definitely, yes. (Naomi)

Yeah, it’s interesting. (Ana)

If there was courses like that? Yeah that would be [interesting], I would definitely look at the descriptions. (Ashley) 
Yeah, I would definitely be interested, especially if it had to do with writing. Any knowledge you can gain about anything can be tied into writing so you kinda become an expert of everything when you wanna be a writer. (Fabiola)

Table 3 shows the five emergent themes as well as the three themes from the three research sub questions.

Table 3

Themes from Phase II

Emergent Themes

Concern regarding a lack

of geographical knowledge

Rote memorization of geographical

content was overemphasized

Geographical concepts are

Related to other subjects
Themes from Sub questions

Student's definition of geography is limited

Students describe richer out of school experiences with geography

Students find geography valuable to their daily lives and fields of study

Taking the high school level AP Human

Geography course is powerful

There is a need for real-world applications of geographical knowledge

\section{Integrated Findings}

The study's primary research question was: What are the geography attitudes and experiences of freshman students scoring at the low and high ends of a geographical literacy survey? 
Students had similar experiences with geography that mainly consisted of having to memorize locations and definitions for an exam without understanding how the material related to real life. In some instances, students recalled having completed a research project they found more relevant than simply recalling material for a test. Students have had more experiences outside of school through TV shows, books, talking to others, traveling, and looking at images, among others.

Students' attitudes towards geography were positive regardless of the students' performance on the GLS. Students saw geography in a positive light since they described it as an important subject and geographical knowledge as necessary regardless of the overemphasized memorization exercises and lack of material they learned during their educational careers:

[Geography] is beneficial like I said with the current events and is just general knowledge that everybody should know, it's just helpful whether is large scale of small scale, in your everyday trying to get somewhere or maybe when you look at a map you see places you never learned of before you know like maybe you want to travel to somewhere Europe, Paris, there's a whole new world that if people could look on the map they could notice and gain interest to it. (Jimena)

[Geography is important] because every day now even more so we are like global and you need to know what the rest of the world looks like to find yourself in the world you are in. So you can't go to Egypt and expect mountains and like cold, it's like you have to know where you are. (Fabiola)

I think it [geography] helps a lot because I think we take for granted our geography that we are in and we don't really realize that in some places the climate or something would be different so the whole lifestyle would be different so if you ever wanna visit that country you might wanna know what conditions it's in so you can prepare yourself, you can't go to Alaska in shorts like people are here in Miami. (Ana)

[Geography] it's a cool course like and it's good to know at least where a city is, where a country is and just like the basic knowledge of the nature of what not, what type of tree is that, and what's that part of the river (Elena). 
It [geography] would help us understand exactly what, you know down here in Florida we grow oranges and stuff, it would help you learn what's grown on the other site of the States, tell you if there's mountains and that stuff and people don't really know much about the US when we live here because we don't learn that much about it so yeah...(Deborah)

[Geography is important] because if you know there are just a lot of references being made you don't wanna just limit yourself to one particular area 'cause I live in Florida doesn't mean I just would wanna know everything about Florida. It shows your intellectual growth if you know more about like everything else. (Ashley)

I think geography is important and you should know how the world is and like everything about it. (Viviana)

[It is important] because if I don't know about the world around me I wouldn't know how to interact with everybody else. (Diana)

You wouldn't think it at first, but it really is, like it affects a lot of things and it affects a lot of people in ways you didn't know so yes, it is important. (Natalia)

Regardless of their performance on the GLS, all 12 interviewees who participated in this study cared about geography and had similar experiences with the subject. The results of the study do not mirror the popular assumption that ties geographical lack of knowledge with a lack of interest.

\section{Summary}

This chapter reported the Phase I, Phase II and integrative findings of the study. The Phase I findings were obtained by calculating students' total GLS scores and analyzing GLS data on SPSS. For the Phase II findings, five emergent themes were presented while three more evolved from research sub-questions 2-4. Lastly, the chapter also provided the integrative findings, which helped assess students' attitudes toward geography depending on the end of the GLS they fell on. 


\section{CHAPTER V}

\section{DISCUSSION AND RECOMMENDATIONS}

The purpose of this study was to explore the geography attitudes and experiences of FIU freshman students scoring at the low and high ends of a geography literacy survey. The results of the GLS (Phase I) as well as in-depth qualitative interviews (Phase II) served as the main components of the study.

\section{Analysis of Results}

\section{Linkages to Conceptual Frameworks}

As discussed in Chapter I, the study had two underlying conceptual frameworks: the ABC Model and the Geographical Literacy Model. The tripartite ABC attitudinal model consists of affect, behavior, and cognition. The affective response is an emotional response that expresses an individual's degree of preference for an entity. The behavioral intention is a verbal indication or typical behavioral tendency of an individual. The cognitive response is a cognitive evaluation of the entity that constitutes an individual's beliefs about the object. The Geographical Literacy Model states that in order to be geographically literate, students need to have acquired geographic perspectives (approaching the world from spatial and ecological perspectives), geographic knowledge (six essential elements with a total of 18 standards) and geographic skills (becoming actively engaged in doing geography by drawing upon critical thinking skills).

In regards to the $\mathrm{ABC}$ Model, the coming together of students' emotional responses, actions, and thoughts regarding their experiences with geography described a positive attitude toward the subject regardless of whether the student scored at the low or 
high end of the GLS. Despite the excessive memorization, lack of teachers' motivation to teach the subject, and not understanding how the material related to daily life, students felt the subject was important and necessary, regardless of their thoughts back in middle/high school when they may have labeled the subject as boring and not as exciting as other disciplines.

It is important to note that even though the students had a positive attitude and described geography as a valuable subject, their limited definition of the discipline may be preventing them from understanding how much more valuable the subject actually is. For example, if a student believes geography is valuable because it is necessary to know where places are located, then that student is finding value in only one aspect of the discipline. If the student had a greater understanding of the subject, then geography's usefulness could be more evident in the eyes of the student.

In regards to the Geographical Literacy Model, students had much greater exposure to geographic knowledge as content than the other two components of geographical literacy. Of note is that students learned many geographical concepts in fields other than geography. Therefore students actually knew more geographical concepts than they believed, but did not associate them as being related to geography. This observation will be discussed later in this section.

Students did have some exposure to geographical skills as exemplified by how geography has been helpful to them in making decisions such as where to live. Geographic perspectives is the one component students lacked the most. This is a critical component since it provides students a framework in order to understand the people and places in our world. 


\section{Phase II (Emergent Themes)}

There were five emergent themes from the qualitative component. The first one was a concern regarding a lack of geographical knowledge. This was a very revealing result since conducting the study allowed for the exploration of whether students' geographical performances went hand in hand with their attitudes towards geography. People tend to assume that those students who struggle with geography do so because they simply do not care and do not believe geography is important and necessary. The students who participated in the study were concerned with both their own lack of geographical expertise and that of others who surround them. No matter how the students performed on the GLS, they had several concerns regarding how little geographical knowledge they had acquired and the limited knowledge they believe others have.

One recent example of a social media effort to geographically educate people happened during the Ebola crisis. Concern regarding the geographical illiteracy of our times prompted Twitter user Anthony England to develop and post on November 3rd, 2014 a map showing which African nations were affected by Ebola and which ones were not. He titled the map Ebola Map of Africa for the Geographically Challenged. His point was to illustrate that Africa is a continent and not a country and that people should not fear the entire continent and understand which nations were affected and which ones were not. England continued to post versions of the map during the days of the crisis.

The second emergent qualitative theme was that, for students, rote memorization of geographical content has been overemphasized. The concept of memorization to students worked as a synonym of uselessness. They recalled how they memorized facts, capitals, populations and locations for a test and forgot all about it afterwards. They saw 
those tasks as a waste of their time and the content as one that did not serve any purpose past the test-taking. Memorization is necessary, but if connections are not being made, then students will feel the course was useless and leave without an understanding of our complex world. Instead of over-relying on measuring students' ability to recall facts and name and locate places, Winfield (2008) suggests a move into a problem-based or issuebased geographic inquiry, which would allow students to apply their geographical skills, knowledge and perspectives. The New York Times published in an article titled All Over the Map: 10 Ways to Teach About Geography ways in which New York Times articles can be used in the classroom when teaching geography. The suggestions, which range from designing maps to analyzing border conflicts, relate to the National Geography Standards. According to the article, "teaching geographic literacy is essential if students are going to understand the challenges and opportunities of our complex world” (Marshall \& Gonchar, 2012, para. 1).

Another emergent concept from the qualitative data was that students related several geographical concepts to other subjects such as history, environmental science and earth space science. When the interviewees looked at the sheets with the geography standards, they recognized many concepts, but acknowledged that some had been learned though other disciplines. The interdisciplinary nature of education is no surprise and it is important that students are learning the concepts, but it is problematic that students do not associate geography as having a role in the many concepts they recall having learned in other subjects. This relates to students' limited and superficial definition of geography, which will be discussed later on in this section. That these students are not making the connections to geography is also problematic in terms of promoting and validating the 
usefulness of the subject. If students are not making the associations, then they will not understand how necessary geography is to comprehend current local and international events and many of our daily decision-making.

The fourth emergent theme was that taking the high school level AP Human Geography course is powerful. Taking this course provided students with an understanding that there is a branch of geography that deals with human populations and our planet. Students stated that before taking or hearing about this course they were not aware of the existence of this branch. The class gives students many opportunities to explore the relationships between humans and their environment. Geography education in the U.S. "benefited from AP Human Geography, and the geography community has an opportunity to encourage AP Human Geography students to build on their Advanced Placement (AP) experience in higher-level college geography courses and geography careers" (Paul et al., 2006, p. 99). The course is one of the fastest growing ones: "since its inception in 2001, the number of students taking AP Human Geography has grown considerably, from 97,762 in 2002 to 191,773 in 2012” (AP Central AP Human Geography Frequently Asked Questions, 2014). Even though this course has helped students expand their narrow definition of geography, school systems should not rely on an elective course to make up for what was not properly taught in the past. Instead, the course should expand students' understanding of human geography.

The last emergent theme was in regards to the need for real-world applications of geographical knowledge. This relates to the rote memorization theme as previously mentioned. If students are being asked to memorize material without understanding how the material is useful in real life, then they are less likely to attach meaning to it and 
retain it. As national geography standards 17 and 18 state, students need to understand how to apply geography to interpret the past, present, and plan for the future. In order to apply geography to interpret the past (standard 17), students should be able to:

- Describe the geographic context of famous events in US history using maps and narrative accounts (e.g., read accounts of Paul Revere's ride and follow the route on a map, compare the overland and water routes to California during the 1849 gold rush).

- Identify physical landforms that affected overland travel during the expansion of the United States (e.g., mountain ranges and passes, river crossings, deserts).

- Identify and describe the differences between the geographic contexts of Native American original settlement areas and the current tribal reservations in the United States. (National Geography Standard 17 National Geographic Education, n.d.) In order to apply geography to interpret the present and plan for the future (standard 18), students should be able to:

- Describe the geographic factors that would influence the decision on where to locate a new school in the local community (available land, proximity to student populations, proximity to dangerous roads or industries).

- Describe the services a city government needs to provide due to the specific geographic characteristics of the community (e.g., big snow removal equipment in lake-effect locations, frequent brake replacement for San Francisco streetcars, wind screens for tennis courts in Great Plains locations, evacuation plans in flood-prone areas). 
- Analyze a current environmental issue in the region (e.g., building or demolishing a dam, building or expansion of freeway system, creation of parks and open spaces, regulatory legislation on industry to prevent further air, water, and land pollution) and describe ways in which people and the environment interact to affect the issue positively and negatively. (National Geography Standard 18 National Geographic Education, n.d.)

One additional way in which teachers are helping students put into practice different concepts learned in the classroom is through educational games that use Google’s Street View feature. One of these games is called GeoGuessr, sponsored by the BBC News:

First, move around using your mouse and figure out where you are. Then click on the map in the lower right hand corner to place your marker (zoom in to increase your accuracy). When you're sure, click the “make a guess” button, and find out how close you were [to the actual location]! Once you've mastered the basics, set a time limit or challenge a friend. (How well do you know the world? Play Geoguessr to find out!, 2013)

Playing this game, as well as similar ones such as Locatestreet, allows users to take on an investigative role and find any clue from what can be seen on the street view (signs, soil, vegetation, crops, businesses, languages, climate, people, transportation, driving, landmarks) in order to help identify the randomly-generated location.

\section{Phase II (research sub-questions)}

The first qualitative sub-question asked How do students define geography? Students' definition of geography was very limited. How students define the discipline is 
very important since there is a societal misconception that geography is only about memorizing capitals and locating nations: "to most Americans, geography is about place names” (National Research Council, 1997, p. 2). The findings paralleled this statement; students defined geography in terms of what they were mostly exposed to at school: maps and location. Even though maps and location are undoubtedly crucial to geography, students struggled to see past that. There were a few mentions of geography's ties to the environment. The human aspect was almost nonexistent in student's definitions of the subject. Geography is a multi-faceted subject that has been misunderstood by society for too long.

The second sub-question was How do students describe their in and out of school experiences with geography? Students described richer out of school experiences with geography which had contributed to their knowledge base. The use of GPS, Google Maps, Google Earth and geography-related games as well as reading and talking to others has provided students with opportunities to do geography. There were less opportunities inside of the classroom as occasional projects on countries were more factual-based. One student described a class project she found to be valuable, which consisted of planning an entire vacation to her assigned country. That opportunity allowed the student to go beyond basic recall of facts by allowing her to connect the information to decision making.

The last sub-question was How do students describe the value of geography to their lives, fields of study and careers? Students found geography valuable to their daily lives and fields of study. Students described geography as an important discipline, found links between their fields of study/future careers and geography, though provided limited 
examples of how geography is useful in daily life. These examples included using geography to determine where to live and being geographical literate when discussing current events with others.

\section{Implications for Practice}

\section{Paradigm Shift}

The primary research question was What are the geography attitudes and experiences of freshman students scoring at the low and high ends of a geographical literacy survey? Through the analysis of the sub-question findings and the emergent themes, the complex concept of attitudes was the same regardless of which end of the GLS the student scored at. This provides an extremely helpful insight since this study suggests that the general assumption presented in Chapter I did not hold true for the interviewees. The students who were less geographically literate did have an interest in the subject and believed it to be valuable. Therefore, a shift in the general thinking has to take place so society can move away from “they struggle because they don’t care” to "what are the reasons why they struggle and what can we do about it so they can arrive at geographical literacy?”

The results should be relevant to all educators since they would benefit from incorporating a geographical perspective when teaching regardless of their subject area. This study should be of particular importance to social studies/geography educators at every level. The following are suggestions seeking to improve the current state of geography education in the nation. 


\section{Reposition geography in our schools to avoid further misunderstandings}

Geography has to be repositioned in the schools from a fact-driven subject to one that explores the interactions between people and places. Interviewees emphasized how much geography instruction relied on the memorization of facts and how the human branch was almost nonexistent in most of the students' early school years. The main two branches of geography (physical geography and human geography) should be effectively taught to students in the early grades (elementary level) and emphasized throughout their educational careers so they do not grow up with the misconception that geography is all about locating nations and memorizing capitals. If new generations are to appreciate and use geography in the exploration and understanding of the interrelation of humans and their environment, then the discipline's position in the schools and in society could and would improve. Daniel Edelson, Vice President for Education Programs at the National Geographic Society, shared this view that geography is misunderstood by recalling the reactions of his acquaintances after he accepted his position at the National Geographic Society:

Me: Well, the National Geographic Society has taken on the mission of geography education reform. My charge is to improve the quality and impact of geographic education in the United States.

Acquaintance [sarcastically]: Oh, that is important. I heard recently that the Chinese have gotten even farther ahead of us in map coloring.

Second acquaintance: No kidding. I believe that geography education should be a critical national priority. [Sly grin] We need more citizens who can name the capital of Iowa and list the major natural resources of Namibia...Geography is 
not, as its public image would suggest, about memorizing facts. Geography is something that you do. Geography is about explaining and predicting the events that occur on our planet. (Edelson, 2008)

This repositioning should consist of two components:

1. Giving geography a presence in educational institutions as stand-alone courses; and

2. the inclusion of higher order thinking skills and applications of geographical content to geography instruction

\section{Highlight the interconnectedness of geography to other fields and vice-versa}

Teachers should provide opportunities for students to see the interconnectedness of the discipline of geography to other fields such as history, economics, government, urban planning, environmental science, transportation, geology, anthropology, communication, epidemiology, marketing, agriculture, mathematics, and meteorology, among others. One of the qualitative emergent themes was that students did not associate many geographical concepts they had learned with geography. Both non-geography teachers and geography/social studies teachers should make geographical connections when necessary when covering topics that overlap other disciplines. An example from the interview data that relates to this interdisciplinary concern is the one about natural disasters. Over the interviews, students associated natural disasters to weather and climate, but initially did not see the ties to geography.

With the increased attention at the national level to STEM (Science, Technology, Engineering and Math) education, it could be highly beneficial for geography to tie itself to the STEM movement in order to show the different ways in which geography is 
present in the STEM fields. This would be an effective way of showing students the interconnectedness of the fields. National Geographic supports this view:

Geo-literacy is a natural fit with STEM education. Having a geo-literate populace is critical for maintaining economic competitiveness, quality of life, and national security in our modern, interconnected world. Likewise, STEM education focuses on supporting the development of high-quality science, technology, engineering, and math knowledge and skills for all students, in order to ensure society as a whole can continue to prosper in the 21st century technology-based economy (STEM Education, n.d.).

\section{Connect the material to real world events/daily decision-making}

Geography tends to be perceived superficially because of memorization. Incorporating current events and daily decision-making to lessons would demonstrate to students how the material they are learning is connected to what is happening in their surroundings. The New York Times had an article titled 50 Ways to Teach with Current Events (Gonchar, 2014) in which the 50 ways are broken down by category: reading and writing, speaking and listening, games and quizzes, photographs, illustrations, videos and infographics, design and creativity, making connections, and building skills. According to the article, students need to practice these skills in order to be informed about what's going on around the world. A need for real world applications of geographical concepts was a recurrent comment in the interviews.

\section{Make research projects meaningful by having students apply geography}

Students should be given opportunities to do geography. This can be accomplished by doing projects that are meaningful to them and incorporate all three 
components of geographical literacy: geographical perspectives, skills and knowledge. Therefore, the traditional projects on an assigned country where students provide basic facts about a nation are not sufficient. In the previous section, it was stated that one interviewee had to plan an entire vacation around an assigned country. That student found this class project to be more valuable than other projects that just required her to state simple facts (population, capital, etc.) regarding a country.

\section{Partner with local geographers}

According to Mohan (2009), "studies conclude that many geography teachers have little to no coursework in geography and many are not prepared to teach geography in the K-12 classrooms” (p. xiv). Teachers need to have a combination of formal (coursework, professional development, conferences) and informal education (travel, reading, consuming geography-related media) in geography. Mohan also highlighted the importance mentoring could play in teachers' self-efficacy in geography. Geographers and geography educators should work together.

Connecting teachers (whether face to face or online) with local geographers can help teachers show students what geographers do and what projects they are currently working on. Teachers would have the opportunity to interact with field experts, students would have a better understanding of the field, and geographers will be able to help improve the current state of geography in our school systems. There are programs that allow teachers to network with geographers. ESRI, a major supplier of GIS software, has a GeoMentor program, which allows teachers and students to network with GIS professionals in order to bring GIS into the classroom (The GeoMentor Program, n.d.). 
Rafiq Basaria, is one of the GIS professionals who registered in the system. He works as a GIS Analyst for Data Transfer Solutions in Orlando, Florida. When asked what motivated him to become a GeoLeader, Rafiq provided several reasons. He wants to help ignite the passion for educators to teach and students to learn, to help students realize that geography is important, and for them to be aware that the U.S. is known for having terrible geographical knowledge. He also wants students to know about GIS as a career option, to network students interested in GIS with his company through internships, to create interest in his community so its local university (University of Central Florida) could eventually offer a geography program, and to integrate students into Central Florida’s cohesive GIS community (R. Basaria, personal communication, November 12, 2014).

Crystal Phillips-Mustain, another GeoMentor who works as the Enterprise GIS Division Manager for the City of Palm Beach, Florida, has been mentoring others for many years as well as providing internship and volunteer opportunities. According to her, using GIS helps students understand the interconnectivity of our world since GIS has a unique ability to view issues with multi-disciplinary lens. She uses GIS to understand who, why, and where people are and their impacts to the environment and believes that students should be empowered to use GIS (C. Phillips-Mustain, personal communication, November 12, 2014).

\section{Offer a mandatory geography course in middle school, high school and college}

In some cases, students just take one geography course during their educational careers (Jones, 2006). Many students in the study pointed out that they had never taken a 
pure geography course or had only taken one. If students do not take geography courses during K-12, their unpreparedness for a college-level course will be evident.

Jo and Milson (2013) explored the perceptions of 260 high school geography teachers and 93 college professors on college readiness for geography. The results of their study suggest that geography educators perceive that their students are unprepared: ...challenges that were identified by teachers and professors across all goals included: (1) lack of prerequisite knowledge related to the topic; (2) lack of geographic and/or spatial thinking skills; (3) lack of higher-order, critical, and analytic thinking skills; (4) little knowledge of other places and unfamiliarity with world events; and (5) misconceptions and stereotypes related to the topic. Additionally, teachers and professors identified challenges that were specific to particular goals that indicate a lack of foundational knowledge among students in their courses. These challenges included lack of understanding or misconceptions of certain concepts, such as culture, region, political boundary, scale, state and nation, and interdependency; lack of skills to make connections between the local and the global and to execute a multiscale analysis to explore geographic problems; and little exposure to and experience with geospatial technologies. In addition to agreement on curricular goals, college readiness initiatives emphasize the need for students to develop proficiency with key academic knowledge and skills over the course of their primary and secondary education. Our findings indicate that neither secondary nor postsecondary geography educators perceive that their students are developing foundational geographic knowledge and skills in K-12 education. (p. 202) 
According to Fuller (2012), "geography is rarely taught in our primary and secondary schools" with the exception of "the occasional school or teacher trying to offer little geography” (p. 3). When this happens, geography is usually taught "without an organized curriculum and understanding of major concepts” (p. 3), which only allows educators to "offer little more than an exercise in pointless memorization" (p. 3). Fuller added that "the most alarming place for geographic ignorance...is the college classroom" (p. 3). Dr. Fuller, who has a Ph.D in geography, has had several experiences while teaching college students. One he recalls is students not being able to locate New Zealand on the map.

Dr. Fuller acknowledges that knowing the location is not higher-order knowledge. However he believes students need to start somewhere and knowing locations is an important start. Dr. Fuller, who has called freshman students the most geographically lost of all, added that "reaching this group needs to be accomplished well before the college years” (personal communication, December 3, 2014).

In order for geography to have a stronger presence in our schools it has to be mandatory at every level. Requiring that the American education system offers one mandatory geography course in middle school, one in high school, and one in college should be considered reasonable. In elementary school geography is part of the social studies umbrella, but stand-alone courses in geography for the other educational levels would help the discipline mark its presence.

If geography continues to be an elective (e.g. AP Human Geography), then students will not understand how fundamental it is to have geographical understanding. It is difficult to imagine going to school without ever taking English or Mathematics. Why 
is it accepted for students to go through school without a geography course? In 2010 the National Geographic Education Foundation included in its Geography Education in the United States report a map showing the state-level geography course requirements in middle and high school. Out of the 50 states, only three (Minnesota, Texas, and South Dakota) offered a mandatory course in both middle and high school. More than half of the states had no geography requirement at all, including the culturally diverse Florida, California and New York (Geography Education in the United States, n.d.). Furthermore, in late 2014, El Rancho Unified School District in California announced that, probably by the 2015-2016 school year, it will stop requiring its high school students to take geography and replace the course with one about diversity and inclusion.

Simply offering courses is not the solution. A combination of factors is needed in order to improve the current state of geography education. One major factor is having highly qualified geography teachers.

Teachers tend to teach how they were taught, a cycle that has proven detrimental for K-12 geography. To break this cycle of rote memorization of place locations, teachers need access to high-quality content in geography, access to classes and professional development that help teachers develop pedagogical content knowledge, and participate in mentoring programs with motivated, expert teachers. (Mohan, 2009, p. 153)

\section{Limitations of the Study}

Readers need to consider the presented results within the context of their limitations. The study had three main limitations. These limitations were (a) the unavailability of the 2010 NAEP Geography Subject Area Assessment integrity 
measures, (b) a low GLS Part A reliability coefficient, and (c) a lack of a more diversified sample. Each of these limitations is explained below.

The first limitation was the unavailability of the integrity measures of the 2010 NAEP Geography Subject Area Assessment on which this study’s GLS was based. The Assessment Division of the National Center for Education Statistics under the U.S. Department of Education has not yet released the technical data pertaining to the integrity measures of the 2010 NAEP Geography Subject Area Assessment. The researcher was informed that the release of this data might take an additional year (S. Osborne, personal communication, September 16, 2014).

Secondly, the reliability analysis of the 10 GLS Part A items revealed a Cronbach’s Alpha of .487 which was very low. The low alpha coefficient may be due to the fact that reliability of a test is in part a function of its length. Part A of the GLS, which was created by compiling selected items from the NAEP Geography Subject Area Exam, contained only 10 items.

Lastly, the researcher would have liked to have a more representative sample. Of the GLS respondents 72\% were females and all 12 interviewees were also females. A female majority is not representative of FIU's student population, which is more balanced (2013 Fact Book, 2013), but it was more representative to the study’s sample. In addition, a combined $68 \%$ of GLS respondents belonged to two university colleges: Arts \& Sciences, and Nursing \& Health Sciences. This was reflected in the interviews as the majority of the interviewees were from the College of Arts \& Sciences. 


\section{Recommendations for Future Research}

This study raised questions that could be explored through new avenues for study. Future research could focus on the teachers' side by exploring the geographical literacy, attitudes and experiences of social studies/geography teachers at the different educational levels (elementary, middle, and high school). This can result in much needed geography professional development sessions for those teachers who have not had a solid geography preparation themselves and want to become skilled geography educators.

In addition to exploring the geographical literacy, attitudes and experiences of social studies/geography teachers, it would be beneficial to interview and/or conduct focus groups with middle, high school, and college students in order to explore in-depth what type of geography course would be appealing to them. The present study suggested that students did not find in their past courses how the material they learned was useful. They also emphasized that there was too much memorization involved and that they would be interested in a geography-specific course that tied their field of study and geography. Therefore, course titles such as "Introduction to Geography” and "World Regional Geography” may alienate students from taking courses in the discipline. Exploring whether students would be interested in taking geography courses tied to current events or traveling, for example, may provide geography/social studies departments at the tertiary level with valuable insight.

In addition, a similar study could explore the geographical literacy, attitudes and experiences of freshman students who completed more than $50 \%$ of their K-12 education outside of the United States, which was not the case for the students who participated in this study. Lastly, a mixed methods study could perform an item analysis on the GLS in 
order to determine what component of the Geographical Literacy Model created problems or challenges for students.

\section{Conclusions}

This qualitative study explored the geography attitudes and experiences of freshman students at Florida International University who scored at the low and high ends of a geographical literacy survey. Due to the general assumption that those who perform poorly on geography assessments or posses little geographical knowledge do not care about geography and do not find the subject useful, this study aimed at testing the geographical knowledge of students and exploring their geography attitudes. The results obtained after testing participants (Phase I) and then conducting interviews (Phase II) allowed the researcher to suggest that students in the study found geography valuable regardless of their test performance.

The primary research question asked What are the geography attitudes and experiences of freshman students scoring at the low and high ends of a geographical literacy survey? The students had positive attitudes towards the subject even after acknowledging that there was there was too much memorization involved in learning geography, that they acquired limited knowledge, and that they did not learn how to apply the geographical knowledge.

There was a quantitative sub-question regarding the performance of the students on the GLS. The students' performance on the GLS was equivalent to the performance of the 12th grade students from the 2010 NAEP Geography Subject Area Assessment on the same 10 items. 
There were three qualitative sub-questions from which the following themes were identified: student's definition of geography is limited, students recall more out of school experiences with geography, and students find geography valuable. In addition, there were five themes that emerged from the data: there is a concern regarding a lack of geographical knowledge, rote memorization of geographical content is overemphasized, geographical concepts are related to other subjects, taking the high school level AP Human Geography course is powerful, and there is a need for real-world applications of geographical knowledge.

Among the recommendations for future research was to focus on social studies/geography teachers by exploring their geographical literacy, attitudes and experiences. This insight would provide relevant information regarding preservice teachers' preparation and inservice teachers' professional development opportunities, whether formal or informal. In addition, six recommendations for practice were stated: reposition geography in our schools to avoid further misunderstandings, highlight the interconnectedness of geography to other fields and vice-versa, connect the material to real world events/daily decision-making, make research projects meaningful by having students apply geography, partner with local geographers, and offer a mandatory geography course in middle school, high school and college.

As discussed in the introduction and exposed in the literature review, geographical illiteracy has come to dominate American students and geography education has taken a backseat in our educational systems. Exploring these issues through research studies may not improve the current state of geography education, but exposing these 
concerns and building on the work conducted by many others who are equally alarmed will certainly help keep the conversation alive. 


\section{REFERENCES}

2013 Fact Book. (2013). Office of Planning \& Institutional Research. Retrieved from http://opir.fiu.edu/FactBook2013/enrollment_2013.pdf

About us. (n.d.). Florida International University. Retrieved from http://fiu.edu/about-us/

About Us - Network of Alliances for Geographic Education. (2012). Retrieved from http://alliances.nationalgeographic.com/about

AP Central AP Human Geography frequently asked questions. (2014). Retrieved from http://apcentral.collegeboard.com/apc/members/courses/teachers_corner/ 220797.html

Biddulph, M., \& Adey, K. (2004). Pupil perceptions of effective teaching and subject relevance in history and geography at key stage 3. Research in Education 71(1): $1-8$.

Blij, H. J. (2012). Why geography matters: More than ever (2nd ed.). New York, NY: Oxford University Press.

Bogdan, R. C \& Biklen, S. K. (2003). Qualitative research for education: An introduction to theories and methods (4th ed.). New York, NY: Pearson Education group.

Bowlick, F. J., \& Kolden, C. A. (2013). Effects of an introductory geography course on student perceptions of geography at the University of Idaho. Journal of Geography in Higher Education, DOI:10.1080/03098265.2013.801068

Briggs, A., \& Coleman, M. (2007). Research methods in educational leadership and management (2nd ed.). Los Angeles, CA: Sage.

Brook, D. L. (1977). Students’ attitudes towards geography. Journal of Social Studies Research 1(2): 60-69.

Carano, K., \& Berson, M. (2007). Breaking stereotypes: Constructing geographic literacy and cultural awareness through technology. The Social Studies, 98(2), 65-69.

Cortina, J. (1993). What is coefficient alpha? An examination of theory and applications. Journal of Applied Psychology, 78(1), 98-104.

Creswell, J. W. (2009). Research design: Qualitative, quantitative, and mixed method approaches (3rd ed.). Thousand Oaks, CA.: Sage.

Daly, T. (2008). NCSS supports the Teaching Geography is Fundamental Act. National Council for the Social Studies. Retrieved, from http://www.socialstudies.org/node/242 
Department: Geography. (n.d.). South Dakota State University. Retrieved from http://catalog.sdstate.edu/preview_entity.php?catoid=1\&ent_oid=90\&returnto=1

Downs, R. (2011). The NAEP Geography Report 2010: What will we do next? Journal of Geography, 11, 39-40.

Earle, B. (2008). A phenomenographic analysis of elementary teacher candidates' conceptions of geography (Doctoral Dissertation). Retrieved from ProQuest Dissertations and Theses. UMI 3353655

East, W. G. (1965). The geography behind history. London, UK: Nelson.

Edelson, D. (2008). Repositioning geography education. National Geographic. Retrieved from http://education.nationalgeographic.com/media/file /Repositioning_Geography_Education.pdf

Edelson, D. (2009). Geographic Literacy in U.S. by 2025. ArcNews Online. Retrieved from http://www.esri.com/news/arcnews/spring09articles/geographicliteracy.html

Education Foundation Policy Initiative. (n.d.). National Geographic Education. Retrieved from http://education.nationalgeographic.com/education/program/policyinitiative/

Erickson, F. (1986). Qualitative methods in research on teaching. In M. C. Wittrock (Ed.), Handbook of research on teaching ( $3^{\text {rd }}$ ed.). New York, NY: Macmillan.

Fuller, G. (2012). The trivia lover's guide to the world: Geography for the lost and found. Lanham, MD: Rowman \& Littlefield.

Gaile, G. L., \& Willmott, C. J. (1989). Geography in America. Columbus, OH: Merrill Publishing Company.

Gall, M., Gall, J. \& Borg, W. (2003). Educational research: An introduction (7th ed.) New York, NY: Allyn \& Bacon.

Gao, Y. (2011). Secondary history/social studies teachers' self-efficacy regarding geography teaching. Retrieved from ProQuest Digital Dissertations and Theses. UMI 3487455

Geography Education in the United States. (n.d.). Retrieved from http://education.nationalgeographic.com/media/file/Geography_Education_in_the _United_States_.pdf

Geography for Life. (2014). National Council for Geographic Education. Retrieved from http://ncge.org/geography-for-life 
Geography for Life: National Geography Standards. (1994). Washington, D.C.: National Geographic Research \& Exploration.

Getis, A., Getis, J., \& Fellmann, J. (2008). Introduction to Geography (12 ed.). New York, NY: The McGraw-Hill Companies.

Gilsbach, M. (1997). Improvement needed: Preservice geography teacher education. The Social Studies, 88(1), 35.

Global Learning. (n.d.). Florida International University. Retrieved from https://goglobal.fiu.edu/about/

Gonchar, M. (2014, October 7). 50 ways to teach with current events. Retrieved from http://learning.blogs.nytimes.com/2014/10/07/50-ways-to-teach-currentevents/?_r=0

Gritzner, C. (2002).What is where, why there, and why care? Journal of Geography,101(1), 38-40.

Gritzner, C. (2003). Why geography? Journal of Geography, 102(2), 90-91.

Guest, G., Bunce, A., \& Johnson, L. (2006). How many interviews are enough? An experiment with data saturation and variability. Field Methods, 18, 59-82.

Hanson, S. (1997). Ten geographic ideas that changed the world. New Brunswick, NJ: Rutgers University Press.

Hechinger, J. (2011, July 19). U.S kids appear lost in latest study of geography knowledge. Bloomberg Business. Retrieved from http://www.bloomberg.com/news/articles/2011-07-19/u-s-kids-appear-lost-inlatest-study-of-geography-knowledge

Heck, R. (2011). Conceptualizing and conducting meaningful research studies in education, In C. Conrad \& R. Serlin (Eds). The Sage handbook for research in education: Engaging ideas and enriching inquiry ( $2^{\text {nd }}$ ed., pp. 199-219). Thousand Oaks, CA: Sage.

Holstrom, M. (1994). Evaluation of the geography component of K-12 teacher education in Santa Clara County, California (Thesis). Retrieved from ProQuest Dissertations and Theses. UMI 1359024

How well do you know the world? Play Geoguessr to find out! (2013, December 12).Retrieved from http://www.bbc.com/travel/feature/20131206-how-well-doyou-know-the-world-play-geoguessr-to-find-out 
Howarth, D. A., \& Mountain, K. R. (2004). Geography for life and standards-based education in the commonwealth of Kentucky. The Social Studies, 95(6), 261-265. Retrieved from http://ezproxy.fiu.edu/login?url=http://search.proquest.com/docview/274781688? accountid=10901

Howell, D. (2012, December 9). Treatment of Missing Data--Part 1. Statistical Home Page David C. Howell. Retrieved from http://www.uvm.edu/ dhowell/StatPages/M

Hubbard, R., \& Stoddard, R. (1979). High school students' images of geography: An exploratory analysis. Journal of Geography, 78(5), 188-194.

Human Geography course description. (2013). The College Board. Retrieved fromhttp://media.collegeboard.com/digitalServices/pdf/ap/ap-human-geographycourse-description.pdf

Institutional Review Board consent form sample. (n.d.). Cornell University. Retrieved from http://www.irb.cornell.edu/forms/sample.htm

Jo, I. \& Milson, A., J. (2013) College readiness for geography: Perceptions of high school teachers and college faculty, Journal of Geography, 112:5, 193-204. DOI: $10.1080 / 00221341.2012 .761718$

Johnston, R.J. (1997). Geography and geographers: Anglo-American human geographysince1945. London \& New York: Edward Arnold.

Johnson, B., \& Christensen, L. (2004). Educational research: Quantitative, qualitative, and mixed methods (2nd ed.). Boston, MA: Pearson Education.

Jones, M. C. (2006). High stakes teaching: The first course in geography. Journal of Geography, 105(2), 87-89.

Kerski, J. (2011). Why geography education matters. Retrieved fromhttp://www.esri.com/news/arcuser/0611/why-geography-educationmatters.html

Kubiatko, M., Janko, T., \& Mrazkova, K. (2012). Czech student attitudes towards Geography. Journal of Geography, 111(2), 67-75.

Kvale, S. (2007). Doing interviews. London: SAGE Publications.

Lambert, D. (2010). Geography education research and why it matters. International Research in Geographical and Environmental Education, 19(2), 83-86.

Livingstone, D. N. (1992). The geographical tradition: Episodes in the history of a contested discipline. Oxford, UK: Blackwell Publishers. 
Manson, G. \& Vuicich, G. (1977). Toward geographical literacy: Objectives for geographic education in the elementary school. New perspectives on geographic education: Putting theory into practice (pp. 191-209). Dubuque, Iowa: Kendall/Hunt.

Marshall, T., \& Gonchar, M. (2012, December 4). All over the map: 10 ways to teach about geography. Retrieved from http://learning.blogs.nytimes.com/2012/12/04/all-over-the-map-10-ways-to-teachabout-geography/?_r=2

Martin, G. J. (2005) All possible worlds: A history of geographical ideas, 4th ed. (Oxford and New York, NY: Oxford University Press).

Massey, D. (2009) Invention and hard work. In Pugh J (ed.) What is radical politics today? Basingstoke, UK: Palgrave Macmillan, 136-142

Maxwell, J. (2005). Qualitative research design: An interactive approach (2nd ed.) Applied social research methods series, 41. Thousand Oaks, CA: Sage Publications, Inc.

McGovern, D. P. (2001). Key topics in evidence-based medicine. Oxford, UK: BIOS Scientific Publishers.

McTeer, H. (1979). High school student's attitudes toward Geography. Journal of Geography, 78(2), 55-56.

Merriam, S. (1998). Qualitative research and case study applications in education. San Francisco, CA: Jossey -Bass.

Merriam, S. (2002). Qualitative research in practice: Examples for discussion and analysis. Jossey-Bass.

Micalizio, C., Kessler, B., \& Crooks, M. (n.d.). What is geography? National Geographic Education. Retrieved from http://education.nationalgeographic.com/education/media/whatgeography/?ar_a=1

Mohan, A. (2009). Teacher efficacy in geography: A mixed methods study of formal and informal teacher education (Doctoral Dissertation). Retrieved from ProQuest Dissertations and A mixed methods study of formal and informal teacher education Theses. UMI 3370155

Murphy, A. (2007). Geography's place in higher education in the United States. Journal of Geography in Higher Education 31(1): 121-141.

NAEP Geography - More about NAEP Geography. (2012, July 3). Retrieved from https://nces.ed.gov/nationsreportcard/geography/moreabout.aspx 
NAEP item development process. (2007, January 26). National Center for Education Statistics. Retrieved from http://nces.ed.gov/nationsreportcard/contracts/item_dev.aspx

National Center for Education Statistics. (2010). NAEP Geography Subject Area. Retrieved from http://nces.ed.gov/nationsreportcard/geography/

National Geographic Education Foundation. (2002). National Geographic - Roper 2002Global Geographic Literacy Survey. National Geographic. Retrieved from http://www.nationalgeographic.com/geosurvey2002/download/RoperSurvey.pdf

National Geographic Education Foundation. (2006). National Geographic - Roper Public Affairs 2006 Geographic Literacy Survey. National Geographic. Retrieved from http://www.nationalgeographic.com/roper2006/pdf/FINALReport2006GeogLitsur vey.pdf

National Geographic Education Foundation. (n.d.). Geography Education in the United States. National Geographic. Retrieved from http://education.nationalgeographic.com/media

National Geography Standard 17 National Geographic Education. (n.d.). Retrieved fromhttp://education.nationalgeographic.com/education/standards/nationalgeography-standards/17/?ar_a=1

National Geography Standard 18 National Geographic Education. (n.d.). Retrieved fromhttp://education.nationalgeographic.com/education/standards/nationalgeography-standards/18/?ar_a=1

National Geography Standard Index. (n.d.). National Geographic Education. Retrieved from http://education.nationalgeographic.com/education/standards/nationalgeography-standards/?ar_a=1

National Geography Standards. (n.d.). National Council for Geography Education. Retrieved from http://netforum.avectra.com/eWeb/DynamicPage.aspx?Site=Test One\&WebCode $=$ GeographyStandards

National Research Council (1997). Rediscovering geography. Washington DC: National Academy Press.

Onwuegbuzie, A. J., \& Collins, K. M. T. (2007). A typology of mixed methods sampling designs in social science research. The Qualitative Report, 12(2), 281-316.

Ozdemir, U. (2012). High school students' attitudes towards geography courses. World Applied Sciences Journal, 17(3), 340-346. 
Paul, G., Hildebrant, B., and Strauss, T. (2006). Advanced Placement Human Geography: The first five years. Journal of Geography, 105(3), 99-107. DOI: $10.1080 / 00221340608978671$

Pickens, J. (2005). Attitudes and perceptions. In N. Borkowski (Ed.), Organizational Behavior in Health Care ( $1^{\text {st }}$ ed.). Boston: Jones and Bartlett.

Rogers, L. (1997). An examination of elementary teachers' knowledge of geography and geographic education (Doctoral Dissertation). Retrieved from ProQuest Dissertations and Theses. UMI 9734529

RoperASW. (2002). National Geographic — Roper 2002 Global Geographic Literacy Survey. National Geographic. Retrieved from http://www.nationalgeographic.com/geosurvey2002/download/RoperSurvey.pdf

Rosenberg, M. J., \& Hovland, C. I. (1960). Cognitive, affective, and behavioral components of attitude. In C. I. Hovland and M. J. Rosenberg (Eds.), Attitude organization and change: An analysis of consistency among attitude components (p. 1-14). New Haven, CT: Yale University Press.

Rubin, H.J., \& Rubin. I.S. (1995). Qualitative interviewing: The art of hearing data. Thousand Oaks, CA: Sage.

Rubin, H.J., \& Rubin. I.S. (2012). Qualitative interviewing: The art of hearing data $\left(3^{\text {rd }}\right.$ ed.). Thousand Oaks, CA: Sage.

Sack, D., and J. F. Petersen. (1998). Children's attitudes toward geography: A Texas case study. Journal of Geography 97(3): 123-131.

Salkind, N. J. (2010). Encyclopedia of research design. Thousand Oaks, CA: Sage.

Savage, T. V. \& Armstrong, D. G. (2000). Effective teaching in elementary social studies.Upper Saddle River, NJ: Prentice-Hall, Inc.

Segall, A. and Helfenbein, R. (2008). Research on K-12 geography education. In Tyson, C. A., \& Levstik, L. S. (2008). Handbook of Research in Social Studies Education (259-283). New York, NY: Routledge.

Seidman, I. (1991). Interviewing as qualitative research: a guide for researchers in education and the social sciences. New York, NY: Teachers College Press.

Sommers, B. J. (1997). The freshman year experience and geography: Linking student retention and the introductory geography curriculum. Journal of Geography, 96(5), 243-249. 
Sparks, E. (2008, May 21). Don't know much about geography. The American. Retrieved from http://www.american.com/archive/2008/may-05-08/don2019t-know-muchabout-geography/

Stallworth, C. \& Braun, A. J., Jr. (2000). GIS programs: Geography tools for teachers and students. Social Education. 64 (3), 161-164.

Statistical computations. (2009). The CORR Procedure. Retrieved from http://www.okstate.edu/sas/v8/sashtml/proc/zompmeth.htm

STEM education. (n.d.). Retrieved from http://education.nationalgeographic.com/education/stem-education/?ar_a=1

Study: Geography Greek to young Americans. (2006, May 4). CNN. Retrieved from http://www.cnn.com/2006/EDUCATION/05/02

Taylor, S., \& Bodgan, R. (1984). Introduction to qualitative research methods (2nd ed.). New York, NY: Wiley.

Teijlingen, E. V., \& Hundley, V. (2002). The importance of pilot studies. Nursing Standard, 16(40), 33-36.

The geographic perspective. (n.d.). Retrieved from http://education.nationalgeographic.com/education/media/geographicperspective/?ar_a=1

The GeoMentor Program. (n.d.). Retrieved from http://edcommunity.esri.com/educational-roles/GeoMentors

Tomal, N. (2010). High school students' attitudes towards geography and the questions they wonder about. Scientific Research and Essays, 5(13), 729-1733.

Vision \& mission. (n.d.). Florida International University. Retrieved fromhttp://fiu.edu/about-us/vision-mission/index.html

What is GENIP? (n.d.). Geography Education National Implementation Project. Retrieved from http://genip.tamu.edu/

Winfield, A. G. (2008). Social studies and geography: beyond rote memorization. In R.H. Audet and L. K. Jordan (Eds.). Integrating Inquiry across the Curriculum. Thousand Oaks, CA: Corwin Press.

Wolfe, L. (2002). Geography inservice education programs, teacher beliefs and practices, and student outcomes (Doctoral Dissertation). Retrieved from ProQuest Dissertations and Theses. UMI 3050149 
Young Americans shaky on geographic smarts. (2006, May 2). NBC News. Retrieved from http://www.nbcnews.com/id/12591413/ns/us_news-education/t/youngamericans-shaky-geographic-smarts/\#.Uynw8Wbn-1t

Young Americans still lack basic global knowledge, National Geographic-Roper Survey Shows. (2006, May 5). National Geographic Society Press Room. Retrieved from http://press.nationalgeographic.com/2006/05/02/roper-geography-study/ 


\section{APPENDICES}




\section{Appendix A}

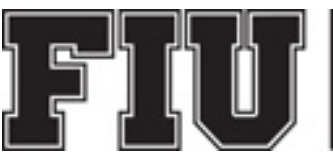

\section{FLORIDA}

INTERNATIONAL

UNIVERSITY

\section{ADULT CONSENT TO PARTICIPATE IN A RESEARCH STUDY}

Geographical Literacy, Attitudes, and Experiences of Freshman Students:

A Qualitative Study at Florida International University.

\section{PURPOSE OF THE STUDY}

You are being asked to participate in a research study. The purpose of this study is to explore the geography literacy, attitudes and experiences of FIU freshman students.

\section{NUMBER OF STUDY PARTICIPANTS}

If you decide to be in this study, you will be one of several FIU freshman students enrolled in the MGM 1106 Finite Math course [or a similar core curriculum course]. You should not previously have taken a geography course during college or be currently enrolled in one.

\section{DURATION OF THE STUDY}

The study has two phases. Phase I, a survey, will take approximately 8-10 minutes. If you are eligible and agree to participate in Phase II, an interview, it will take approximately 60 minutes. 


\section{PROCEDURES}

If you agree to be in the study, we will ask you to do the following things:

1. Complete a (8-10 minutes) survey, which consists of 10 multiple-choice geography knowledge questions as well as 13 demographic/background information items.

2. Provide your full name, working phone number and working email address, which will be used if you are eligible for Phase II of the research study.

3. Selected students will be asked to participate in Phase II, a (60-minute) interview regarding your attitudes towards geography.

\section{RISKS AND/OR DISCOMFORTS}

There are no risks associated with your participation and any inconvenience to you derives only from the amount of time taken to answer the survey and interview questions.

\section{BENEFITS}

There is no direct benefit to participants. However, it is hoped that your participation will allow researchers to better understand the geographical literacy, attitudes and experiences of freshman students.

\section{ALTERNATIVES}

There are no known alternatives available to you other than not taking part in this study.

\section{CONFIDENTIALITY}

The records of this study will be kept private and will be protected to the fullest extent provided by law. In any sort of report we might publish, we will not include any 
information that will make it possible to identify a subject. Research records will be stored securely and only the researcher team will have access to the records. However, your records may be reviewed for audit purposes by authorized University or other agents who will be bound by the same provisions of confidentiality.

If you decide to participate, you will asked to provide a working phone number and working email address in order to be contacted for Phase II if you are eligible. Students contacted for Part II of the study may choose not to participate. After conducting the interviews, all personal information obtained during Phase I will be destroyed by shredding and the deletion of digital files.

\section{COMPENSATION \& COSTS}

There is no compensation provided to the subjects who participate in Phase I. Those who participate in Phase II (interviews) will receive a FIU Panther Dining lunch voucher as a token of appreciation for their cooperation.

\section{RIGHT TO DECLINE OR WITHDRAW}

Your participation in this study is voluntary. You are free to participate in the study or withdraw your consent at any time during the study. Your withdrawal or lack of participation will not affect your relationship with Florida International University. The investigators reserve the right to remove you without your consent at such time that they feel it is in the best interest of the research. 


\section{RESEARCHER CONTACT INFORMATION}

If you have any questions about the purpose, procedures, or any other issues relating to this research study you may contact Daniela Ottati anytime at dotta001@fiu.edu.

\section{IRB CONTACT INFORMATION}

If you would like to talk with someone about your rights of being a subject in this research study or about ethical issues with this research study, you may contact the FIU Office of Research Integrity by phone at 305-348-2494 or by email at ori@fiu.edu.

\section{PARTICIPANT AGREEMENT}

I have read the information in this consent form and agree to participate in this study. I have had a chance to ask any questions I have about this study, and they have been answered for me. I understand that I am entitled to a copy of this form after it has been read and signed.

Signature of Participant

Date

Printed Name of Participant

Signature of Person Obtaining Consent

Date 


\section{Appendix B}

Please circle only one answer for each item.

\section{SECTION A: GEOGRAPHICAL KNOWLEDGE}

1. The graph below shows the states with the largest number of Hispanic people in their population. Based on the graph, the probable place of origin for the largest number of Hispanic people in the Unites States is

TEN STATES WITH THE LARGEST HISPANIC ORIGIN POPULATION:

1990 (in thousands)

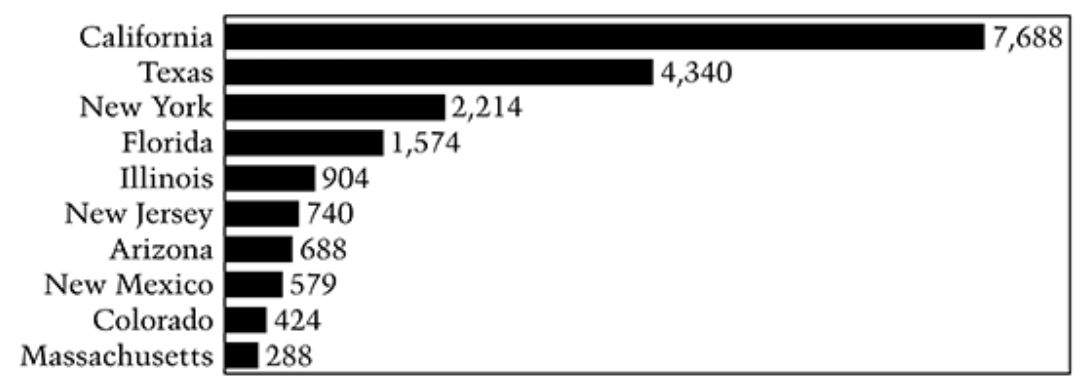
a. Cuba
b. Puerto Rico
c. Mexico
d. Dominican Republic 
2. How were the great lakes formed?

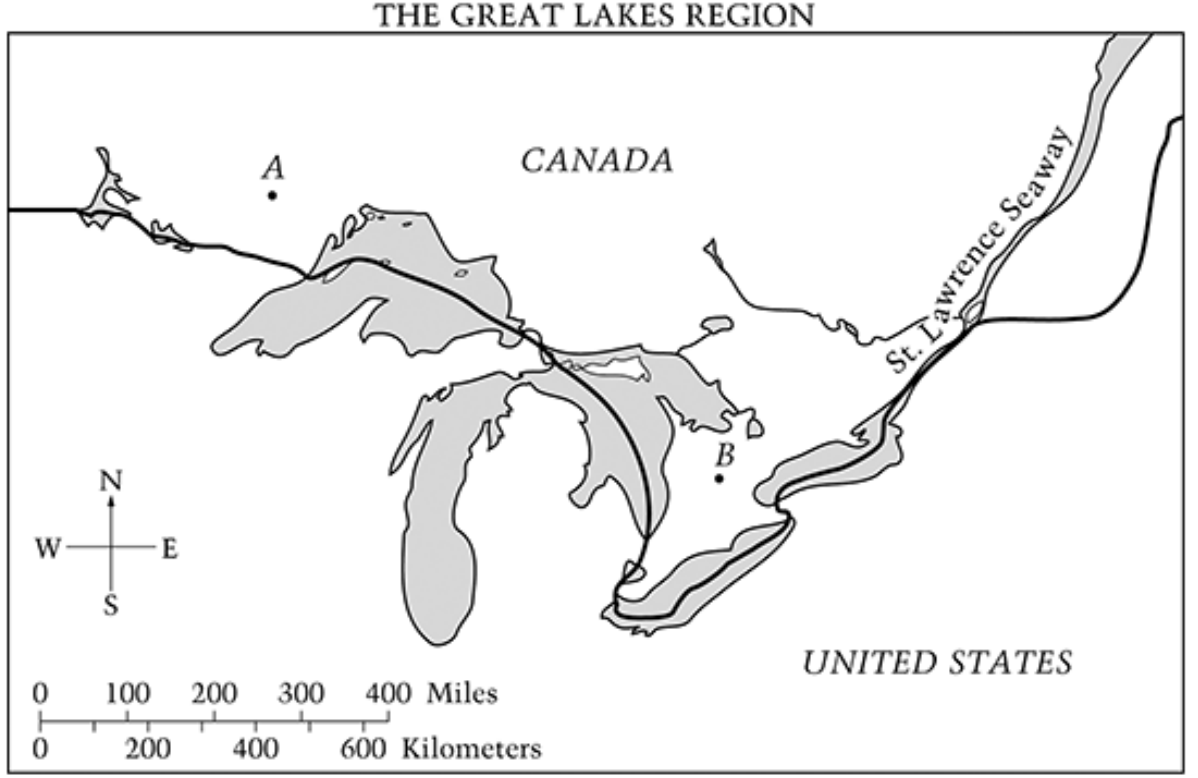
a. Glaciation
b. Volcanic Activity
c. Soil Deposition
d. Erosion

3. Look at the outline maps of the four imaginary countries below. Which country's shape was probably most heavily influenced by physical or natural boundaries?

A

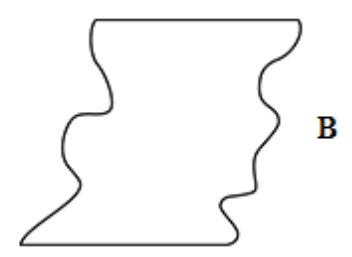

C

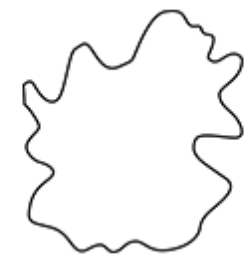

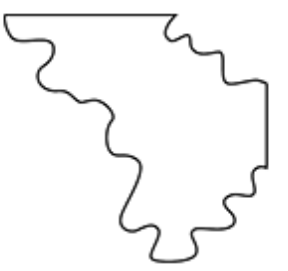

D

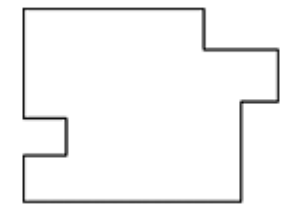
a. A
b. $\mathrm{B}$
c. $\mathrm{C}$
d. D 


\section{Which two of the following are shown on the map below?}

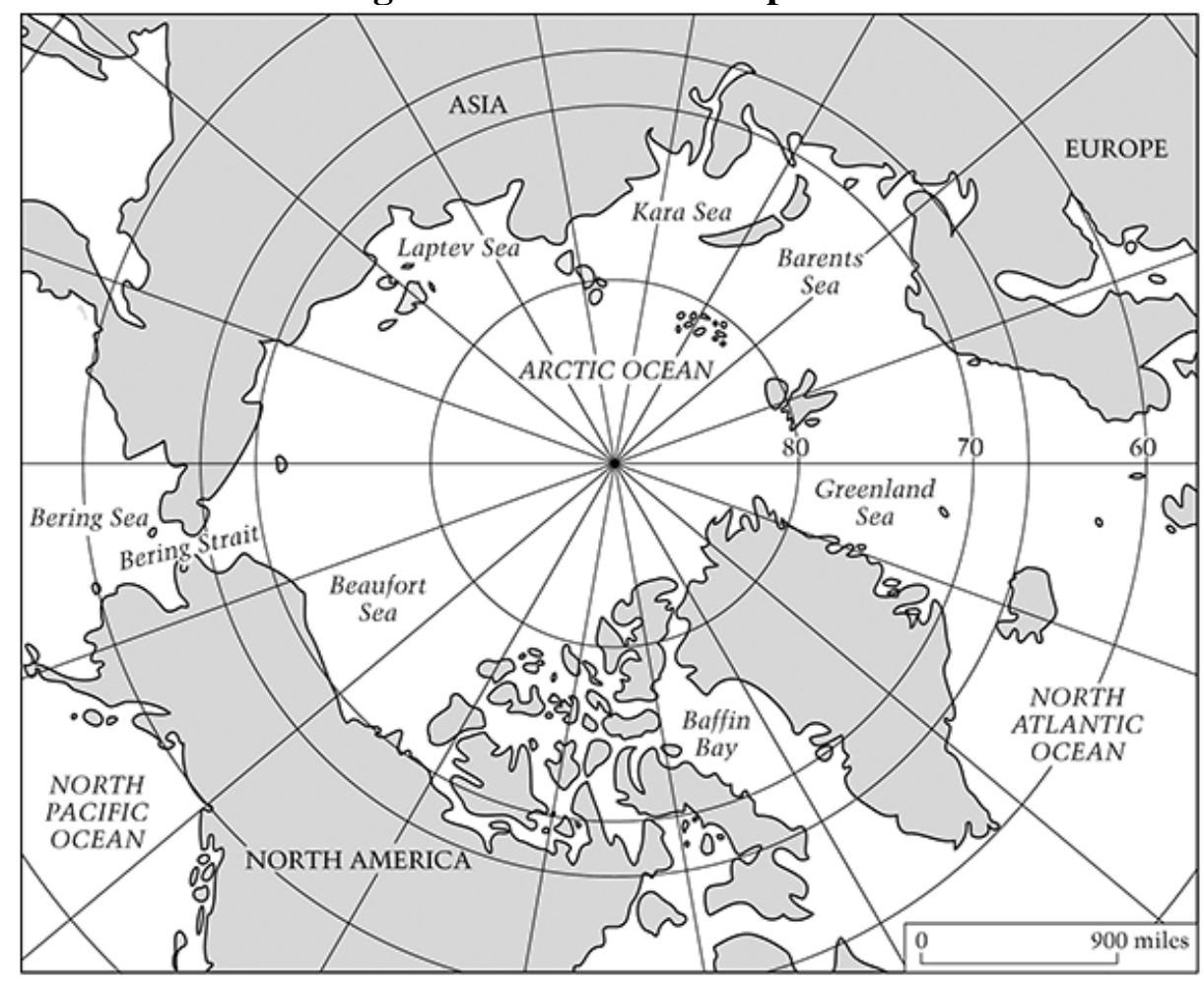

a. The equator and the international date line

b. The Arctic Circle and the prime meridian

c. The Tropic of Capricorn and the Tropic of Cancer

d. The Great Divide and the Antarctic Circle

\section{Which statement is true about the economies of most developing countries?}

a. Their exports are often limited to a few agricultural products or raw materials.

b. They produce a wide variety of high-technology goods.

c. Their imports are often limited to manufactured goods

d. Their manufacturing sectors are usually well developed. 
6. What explains why the official language in many African countries is different from the African language group native to that area?

THE LANGUAGES OF AFRICA

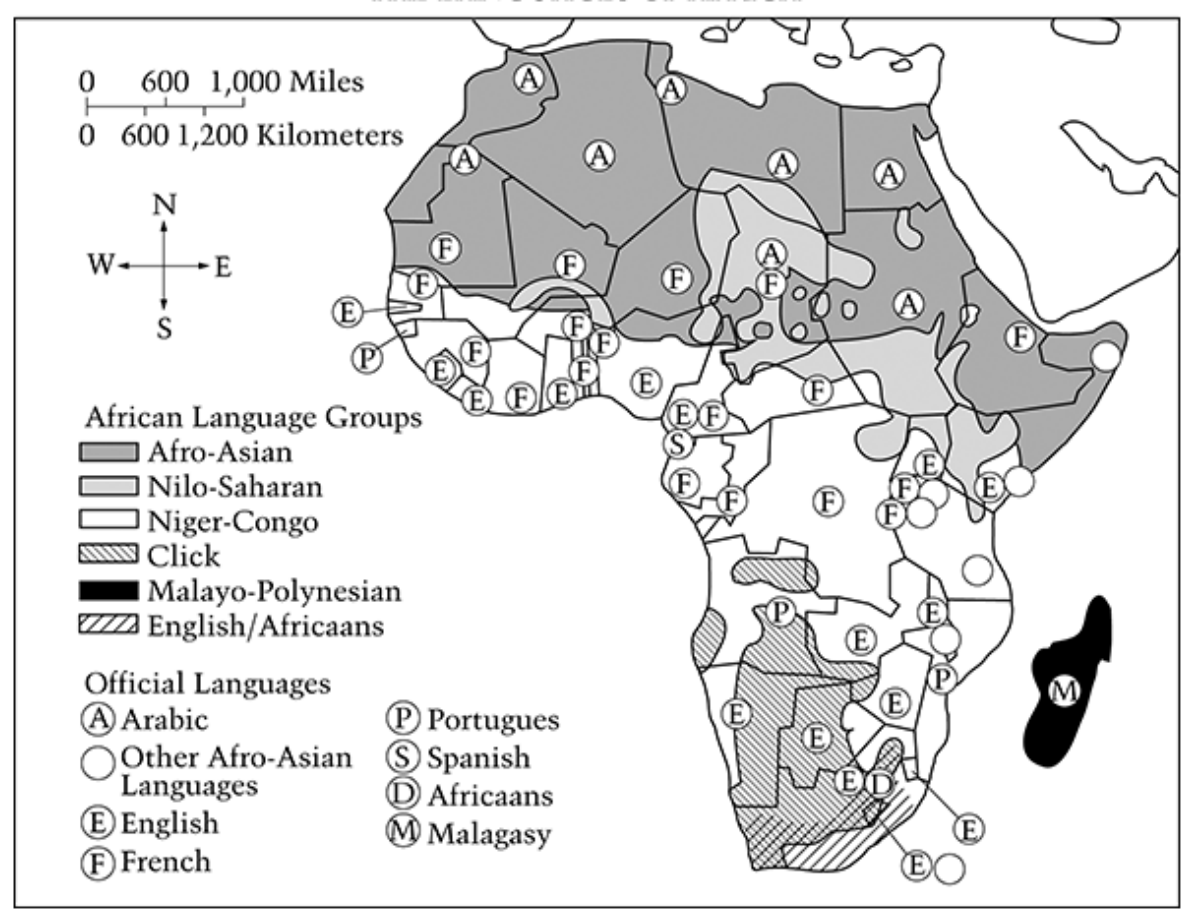

a. The influence of Chinese and Indian immigrants

b. The influence of European colonization

c. The political dominance of North Africa

d. The differences in physical landscape

7. Where is the Mississippi River on the cross section of the United States shown below?

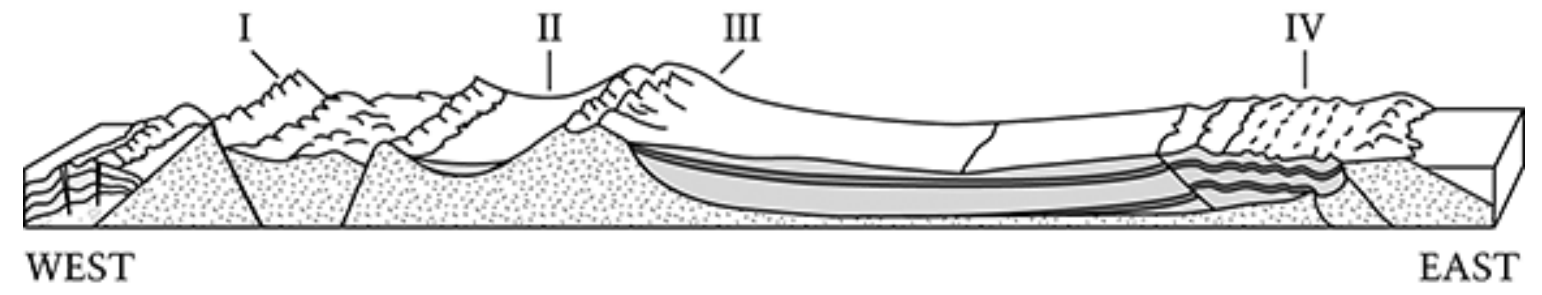
a. Between I and II
b. Between II and III
c. Between III and IV
d. East of IV 


\section{The numbered/shaded areas on the map represent}

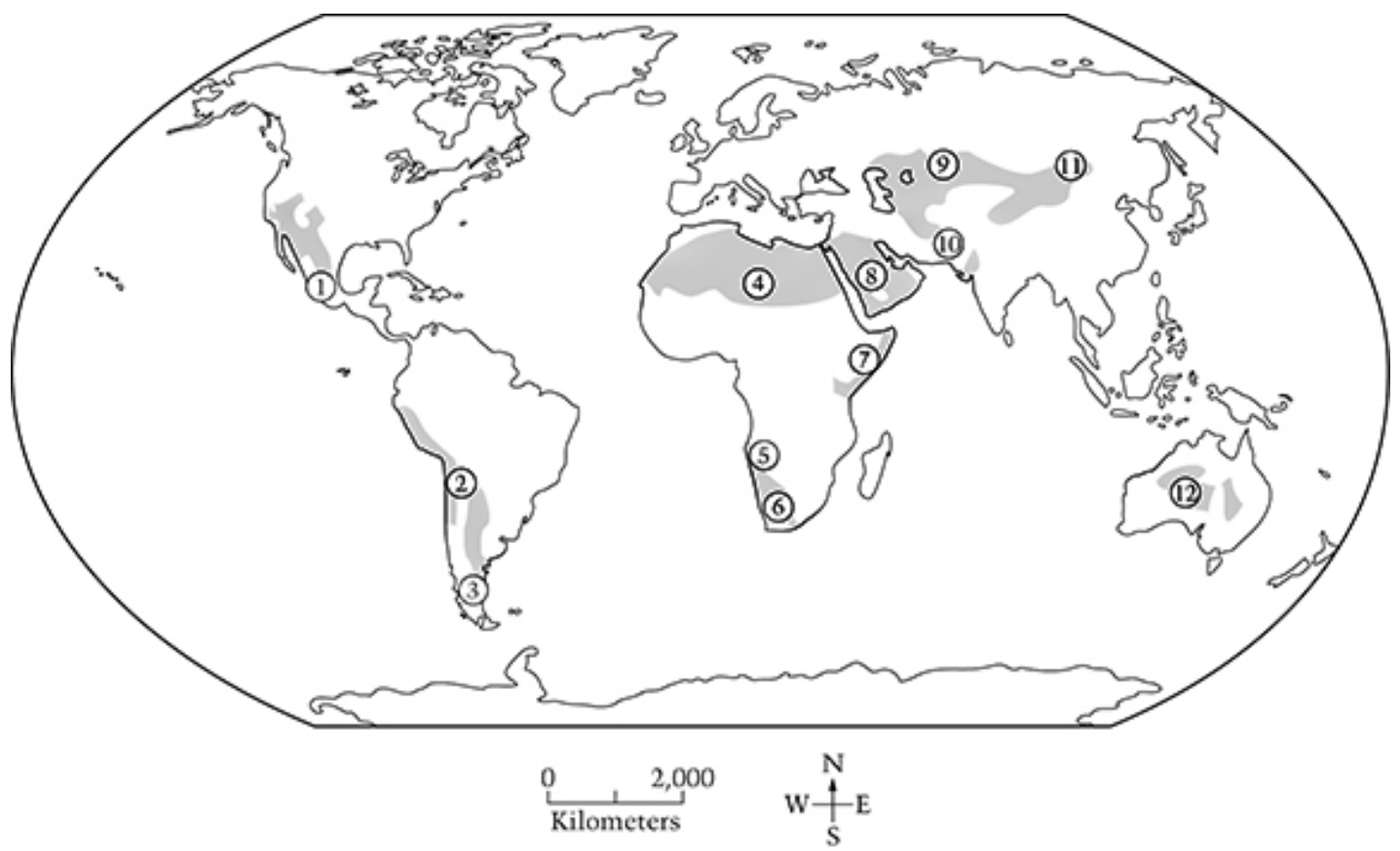
a. grasslands
b. deserts
c. rain forests
d. mountains

9. In East Africa the process of desertification causes greater hardship for women that for men mostly because
a. women consume more water than do men
b. women are primarily responsible for collecting the fuelwood and water for their families
c. in times of drought family size usually increases
d. there are proportionately more women than men in this area

10. Worldwide, the greatest number of people who emigrate from one country to another today do so because they
a. believe that moving will help them economically
b. believe that moving will give them greater religious freedom
c. like the climate better in their new country
d. have been expelled from their native countries 


\section{SECTION B: BACKGROUND INFORMATION}

11. What is your sex?
a. male
b. female
c. other

12. What is your race? (circle all that apply)
a. American Indian or Alaska Native
b. Asian
c. Black or African American
d. Native Hawaiian or Other Pacific Islander
e. White
f. Multiracial
g. Other

13. What is your ethnicity?
a. Hispanic or Latino
b. Not Hispanic or Latino

14. Which is your school/college? (circle all that apply)
a. Architecture and the Arts
b. Arts and Sciences
c. Business Administration
d. Education
e. Engineering \& Computing
f. Honors College
g. Hospitality and Tourism Management
h. Journalism and Mass Communication
i. Nursing and Health Sciences
j. Public Health and Social Work
k. Undecided/Exploratory 
15. How many languages do you speak with ease?
a. 1
b. 2
c. 3
d. more than 3

16. How many classes do you think you took in your K-12 education in which you used geographic knowledge and/or skills?
a. $0-1$
b. 2
c. 3
d. more than 3

17. Did you complete more than half of your K-12 education in the United States?
a. Yes
b. No

18. How do you perceive your geographical abilities and skills?
a. Very Poor
b. Poor
c. Good
d. Very Good

19. Which of the following social studies subjects is your favorite?
a. Civics/Government
b. Economics
c. Geography
d. History

20. How often do you read, listen, and/or watch international news?
a. Never
b. Once a week
c. Twice a week
d. More than twice a week 
21. How many times have you traveled abroad*?
a. 0
b. 1-3
c. 4-6
d. More than 6

22. How many years have you lived abroad*?
b. $1-3$
c. 4-6
d. More than 6

23. How many times have you done a semester (or more) of a study abroad* program?
a. 0
b. 1-3
C. 4-6
d. More than 6

*outside of the U.S. 


\section{Appendix C}

\section{INTERVIEW GUIDE}

Geographical Literacy, Attitudes, and Experiences of Freshman Students:

A Qualitative Study at Florida International University.

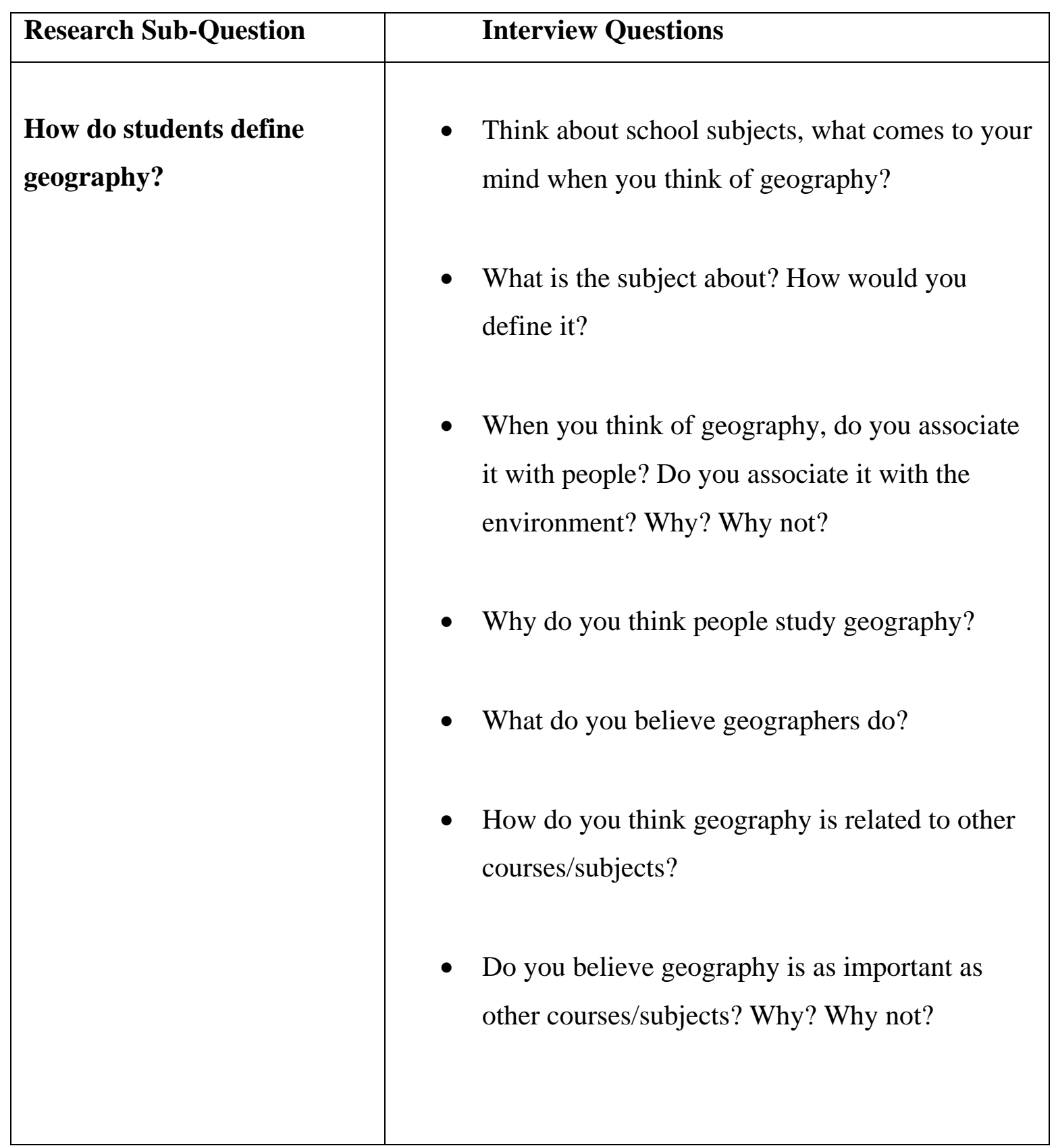


- Do you believe it is necessary for people to have map skills? Why? Why not?

- What types of experiences have you had with Google Earth, Google Maps, and/or GPS Navigators?

- Do you believe it is necessary for people to learn about foreign countries and foreign languages? Please explain.

- How has it helped you to be bilingual/speak several languages?

- Do you think geography might help you in understanding this country and our world better? Please elaborate.

- How can geographical knowledge help you understand floods, hurricanes, and other natural disasters?

\begin{tabular}{|l|}
\hline Research Sub-Question \\
\hline How do students describe \\
their in and out of school
\end{tabular}

\section{Interview Questions}

- What are some courses related to geography that you have taken in the past (whether at 


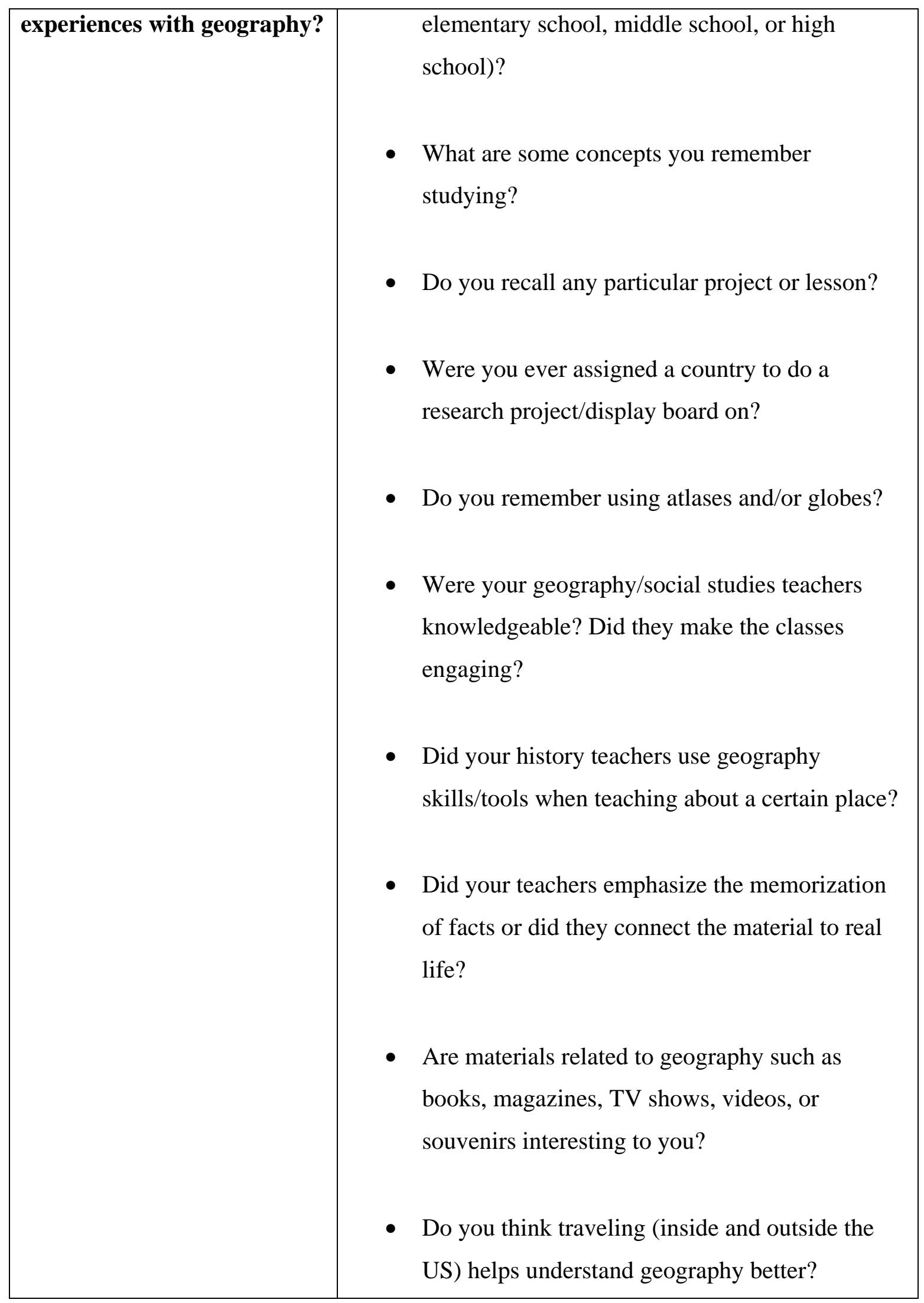


- Do you enjoy meeting/talking to people from other places?

- Do you enjoy taking or looking at pictures of national or international landmarks and landscapes?

- Do you seek more information about places you listen about on the news?

\begin{tabular}{|l|}
\hline Research Sub-Question \\
\hline How do students describe \\
the value of geography to \\
their lives, fields of study \\
and careers?
\end{tabular}

\section{Interview Questions}

- Based on your school years, if you had to rank history, geography, economics, and government from more to least useful, how would you rank them? Why?

- Were geography lessons or exams difficult to you?

- Was geography a boring, exciting or just a regular subject?

- Do you believe people would benefit from taking a geography course? 
- Was the geography information you were taught in school useful to you?

- Does geographical thinking/skills/knowledge play a useful role in everyday life?

- What is the relevance of learning geography to your field of study?

- Do you have difficulty seeing how geography relates to your field of study?

- Do you feel that geographical knowledge will be useful to you in your future job?

- If a course that tied geography and your field of study was developed, would you consider taking it or be willing to look at its course description?

- How is it important for individuals to have knowledge of geography when discussing current events?

- Geographers believe knowing geography is beneficial to society. Do you agree with this statement? Why or why not? 


\begin{tabular}{|l|l|}
\hline & $\begin{array}{l}\text { Will geography knowledge one day be as } \\
\text { necessary for efficient citizenship as the ability to } \\
\text { read and write? }\end{array}$ \\
\hline
\end{tabular}




\section{Appendix D}

\section{SAMPLE INTERVIEW}

\begin{tabular}{|c|c|}
\hline RESEARCHER & $\begin{array}{l}\text { PARTICIPANT } \\
\text { “Naomi" }\end{array}$ \\
\hline $\begin{array}{l}\text { Tell me a little bit about your } \\
\text { background... }\end{array}$ & $\begin{array}{l}\text { Right now I'm a freshman; I just started now for the } \\
\text { fall semester. For middle school, like first for my } \\
\text { elementary I went to a small privately-owned school } \\
\text { in the Okeechobee area and then they had it closed } \\
\text { down or what not because like the owner couldn't do } \\
\text { it anymore and then from there I went to Divine } \\
\text { Savior for two years, so then from there I went to } \\
\text { Saint Agatha and that's like where I got more or } \\
\text { less... this is all here in Miami. Well, from then } \\
\text { though, my high school was Lourdes, the one in } \\
\text { Kendall. I was born here, my mom was raised here, } \\
\text { but she was born in Costa Rica so like that's more or } \\
\text { less my background like I grew up like being raised } \\
\text { by my stepdad now and he is...he was born here and } \\
\text { his family background is Cuban, but my biological } \\
\text { dad like we had roots in Israel, so Jewish... I speak } \\
\text { English, Spanish, and little bit of Portuguese. }\end{array}$ \\
\hline $\begin{array}{l}\text { Think about school subjects, } \\
\text { what comes to your mind } \\
\text { when you think of } \\
\text { geography? }\end{array}$ & $\begin{array}{l}\text { Maps [pauses] I just think about the regions like as } \\
\text { far as mountains, their structure... }\end{array}$ \\
\hline What is the subject about? & $\begin{array}{l}\text { You are basically gonna be studying about like } \\
\text { different regions, more the less like locating them, the }\end{array}$ \\
\hline
\end{tabular}




\begin{tabular}{|c|c|}
\hline How would you define it? & land itself... \\
\hline $\begin{array}{l}\text { When you think of } \\
\text { geography, do you associate } \\
\text { it with people? The } \\
\text { environment? }\end{array}$ & $\begin{array}{l}\text { I mean I do associate people with it because like the } \\
\text { people are the ones living there so I guess in a way } \\
\text { they will be shaping the land, but yeah, I usually } \\
\text { associate it more with like the land itself . }\end{array}$ \\
\hline $\begin{array}{l}\text { Why do you think people } \\
\text { study geography? }\end{array}$ & n like hov \\
\hline $\begin{array}{l}\text { How do you think geography } \\
\text { is related to other } \\
\text { courses/subjects? }\end{array}$ & $\begin{array}{l}\text { [long pause] somewhat, I mean the sciences, it's } \\
\text { important in daily life, I mean you can ask someone } \\
\text { “oh what's the capital of this state?” and they have } \\
\text { no idea or you ask them this country and they would } \\
\text { be “what is that? Asia or Africa?” [laughs] they are } \\
\text { really confused so I think it's kinda important to } \\
\text { know about like the world. }\end{array}$ \\
\hline $\begin{array}{l}\text { In what ways do you see the } \\
\text { connection between } \\
\text { geography and science? }\end{array}$ & $\begin{array}{l}\text { Like how you will be using your land, I mean } \\
\text { geography will change over time and I think that } \\
\text { overlaps with science, erosion, biology and maybe } \\
\text { environmental. }\end{array}$ \\
\hline $\begin{array}{l}\text { Do you believe geography is } \\
\text { as important as other } \\
\text { courses/subjects? }\end{array}$ & $\begin{array}{l}\text { Definitely just because it's gonna help a lot like I said, } \\
\text { just knowing about news events today so... }\end{array}$ \\
\hline $\begin{array}{l}\text { When you listen to a country } \\
\text { on the news you are not } \\
\text { familiar with, do you usually } \\
\text { look up the information? }\end{array}$ & $\begin{array}{l}\text { Ok, really yeah, but in middle school they had us } \\
\text { learn all the countries in the world and we had to } \\
\text { locate them on the map and we were tested on that all } \\
\text { year so I know surprisingly a lot of countries so I can } \\
\text { more or less locate them on the map. }\end{array}$ \\
\hline
\end{tabular}




\begin{tabular}{|c|c|}
\hline $\begin{array}{l}\text { Do you believe it is necessary } \\
\text { for people to have map } \\
\text { skills? }\end{array}$ & $\begin{array}{l}\text { Yes because sometimes you can't always rely on } \\
\text { technology. That happens, that happened to me the } \\
\text { other day. I was with one of my sisters from my } \\
\text { sorority and she didn't know at all where she was } \\
\text { going and we got lost three times because the GPS, } \\
\text { each time she plugged in the direction would say } \\
\text { something else, it would say new address, completely, } \\
\text { so then I was like “do you want me to help you?” and } \\
\text { then when I finally helped her we got to where it was } \\
\text { because she had no idea how to actually...I mean I } \\
\text { gave her the address she had no idea. }\end{array}$ \\
\hline $\begin{array}{l}\text { Do you use Google Earth, } \\
\text { Google Maps? }\end{array}$ & $\begin{array}{l}\text { No, I mean, if I see like a map or something that I am } \\
\text { usually not familiar with I would probably ask just } \\
\text { my mom or like my dad and I would be like “oh, } \\
\text { what's around this area?” and they might tell me, } \\
\text { “there's a McDonald's.” }\end{array}$ \\
\hline $\begin{array}{l}\text { Do you believe it is necessary } \\
\text { for people to learn about } \\
\text { foreign countries and foreign } \\
\text { languages? }\end{array}$ & $\begin{array}{l}\text { I think it can be useful for many reasons especially } \\
\text { for jobs or just you never know when you are out } \\
\text { somewhere and can use the language. }\end{array}$ \\
\hline $\begin{array}{l}\text { How has it been beneficial to } \\
\text { you to speak English, } \\
\text { Spanish and a little of } \\
\text { Portuguese? }\end{array}$ & $\begin{array}{l}\text { It just expands your horizons so much more, I think } \\
\text { so ‘cause you can be speaking to someone in English } \\
\text { and you can go somewhere else in just your city and } \\
\text { you will notice the change of environment and there's } \\
\text { different people everywhere, it’s not “oh, we are all in } \\
\text { Miami, you know we are in the United States, } \\
\text { English.” In Miami there's a lot of Spanish speakers, } \\
\text { there's a fair share of Brazilians too, I have a lot of } \\
\text { friends, that's when I started learning Portuguese. }\end{array}$ \\
\hline
\end{tabular}




\begin{tabular}{|c|c|}
\hline $\begin{array}{l}\text { Are you planning on adding } \\
\text { more languages? }\end{array}$ & $\begin{array}{l}\text { Definitely, yeah, it's just right now I started college, } \\
\text { so it's a little much [laughs]. Definitely I think I } \\
\text { would try to pick up either like French or Italian. }\end{array}$ \\
\hline $\begin{array}{l}\text { Do you think geography } \\
\text { might help you in } \\
\text { understanding this country? }\end{array}$ & $\begin{array}{l}\text { Well, I mean literally like I said it depends on where } \\
\text { you go, I mean for one minute you will be here in } \\
\text { Miami and it will seem like a completely different } \\
\text { place and for example if you go to Boston, there's } \\
\text { totally different, from the people, to seasons, the } \\
\text { languages, the land itself, you know, you would } \\
\text { suddenly step in Washington, DC the area, and you } \\
\text { will see mountains, and you know it's like oh [laughs] }\end{array}$ \\
\hline $\begin{array}{l}\text { Can geographical knowledge } \\
\text { help you understand floods, } \\
\text { hurricanes, and other natural } \\
\text { disasters? }\end{array}$ & $\begin{array}{l}\text { I guess it would help you more or less to be aware of } \\
\text { what's occurring and why so you should be able to } \\
\text { recognize that Florida really won't have an } \\
\text { earthquake while California is more prone to the } \\
\text { earthquakes because of the tectonic plates while you } \\
\text { know Kansas isn't gonna get a hurricane, more than } \\
\text { likely they shouldn't, but you know it will give you } \\
\text { more or less a perspective of what to be prepared for, } \\
\text { you can also see the housing structures are different, } \\
\text { like my dad is into developing and construction so } \\
\text { ever since I was little he would tell me “OK, Florida } \\
\text { area is more concerned with houses, you know, to be } \\
\text { built for tsunamis, or hurricanes,” that kind of } \\
\text { structure, while in Kansas and the whole sunbelt area } \\
\text { they are all prepared for twisters and that kind of } \\
\text { stuff so... }\end{array}$ \\
\hline $\begin{array}{l}\text { What are some courses } \\
\text { related to geography that you }\end{array}$ & $\begin{array}{l}\text { I had middle school geography. In high school not } \\
\text { really, it was a little bit just in history class, but we } \\
\text { never really focused... In elementary definitely, we }\end{array}$ \\
\hline
\end{tabular}




\begin{tabular}{|c|c|}
\hline $\begin{array}{l}\text { have taken in the past } \\
\text { (whether at elementary } \\
\text { school, middle school, or } \\
\text { high school)? }\end{array}$ & $\begin{array}{l}\text { had our little notebooks and we would learn about a } \\
\text { new country or we'd have, every week we'd be } \\
\text { assigned a different country so like every time I think } \\
\text { of geography I usually think of Uzbekistan because it } \\
\text { was usually my assigned country all the time for some } \\
\text { reason and I would be like “yeah, I know all about it! } \\
\text { I know this, this and this.” I felt like accomplished } \\
\text { when I was little so... }\end{array}$ \\
\hline $\begin{array}{l}\text { And what about the middle } \\
\text { school geography class? }\end{array}$ & $\begin{array}{l}\text { It was mainly just memorizing, but I didn't really like } \\
\text { liked doing that. When I do something, I think I } \\
\text { might as well learn it if I'm going through the effort } \\
\text { so I would go ahead take a little extra time, like OK, } \\
\text { this is here and then I tried to connect it to like a fun } \\
\text { fact or something going on in the news. }\end{array}$ \\
\hline $\begin{array}{l}\text { Was that class boring, } \\
\text { exciting or just another class? }\end{array}$ & $\begin{array}{l}\text { I fairly liked it just because it was different and it } \\
\text { wasn't, oh, it's just another class, it was something } \\
\text { that I was like, OK, I'd actually be able to use this } \\
\text { like in the future, it's not gonna be like one of these } \\
\text { classes that if I go you know into English, I'm not } \\
\text { gonna necessarily be using heavy math and biology } \\
\text { you know so it was one of those that I said, OK, I'll } \\
\text { still use it for you know just conversations or news or } \\
\text { something like that. }\end{array}$ \\
\hline Was the teacher prepared? & $\begin{array}{l}\text { He did fairly fine, he knew what he was talking } \\
\text { about, but not enough people in the class cared about } \\
\text { it so he rushed through it. They [the students] really } \\
\text { didn't care. They didn't have the interest. It was sixth } \\
\text { grade so no one really cared [laughs]. }\end{array}$ \\
\hline Do you remember using & I had one globe at home and I would look at places. \\
\hline
\end{tabular}




\begin{tabular}{|c|c|}
\hline ? & \\
\hline $\begin{array}{l}\text { Are materials related to } \\
\text { geography such as books, } \\
\text { magazines, TV shows, videos } \\
\text { interesting to you? }\end{array}$ & $\begin{array}{l}\text { Yes, like I still do that on occasion, I have like a few } \\
\text { Instagram accounts that I follow like of different } \\
\text { places around the world and it would be a really } \\
\text { pretty place and I would also be like “uuuhh, where's } \\
\text { that?” I would start looking it up and I would be like } \\
\text { “Oh, OK.” Where's that? Where's this? I would just } \\
\text { compare them... I won't sit there and watch travel } \\
\text { things, but if I see something that I'm interested in } \\
\text { then I'll watch it... }\end{array}$ \\
\hline $\begin{array}{l}\text { Do you think traveling } \\
\text { (inside and outside the US) } \\
\text { helps understand geography } \\
\text { better? }\end{array}$ & $\begin{array}{l}\text { Yeah, I mean just traveling like a few hours north } \\
\text { you will see you know there's a lot more trees, a lot } \\
\text { more nature, for example just even an hour off you } \\
\text { go into the Everglades and that's a completely } \\
\text { different ecosystem from here and you would just } \\
\text { learn so much more. It's like about how much could } \\
\text { there actually be in one small region. }\end{array}$ \\
\hline $\begin{array}{l}\text { If you meet someone here in } \\
\text { Miami and they are from a } \\
\text { different nationality, would } \\
\text { you be interested in talking to } \\
\text { them and asking them about } \\
\text { their nation? }\end{array}$ & $\begin{array}{l}\text { Well I mean I went to Lourdes and it was an all-girls } \\
\text { Catholic high school. Most of the girls were of } \\
\text { Cuban-descent so I was always used to just that one } \\
\text { particular group. And then coming here now in the } \\
\text { fall there are people in my classes who were like “oh } \\
\text { yeah, I'm Lebanese,” “I'm already married,” “I'm } \\
\text { this,” “I'm that,” and I would be like “What? Like } \\
\text { you are 18?” and here I am just like I live with my } \\
\text { family, do cheerleading, I do all my own little } \\
\text { activities and this people like have their lives together } \\
\text { already, they are already married, they have their } \\
\text { homes, they are stabilizing themselves, just the } \\
\text { cultures themselves are so different and I find it like I }\end{array}$ \\
\hline
\end{tabular}




\begin{tabular}{|c|c|}
\hline & $\begin{array}{l}\text { definitely find it interesting just because it's very } \\
\text { different from what I'm used to especially since all } \\
\text { the girls were very similar in my high school, which is } \\
\text { just completely different, when I got here, I felt like I } \\
\text { had left just because it's so variated that I was “oh, } \\
\text { OK.” }\end{array}$ \\
\hline $\begin{array}{l}\text { Do you have that curiosity } \\
\text { with people from all over the } \\
\text { globe or more with people of } \\
\text { a certain region/continent? }\end{array}$ & $\begin{array}{l}\text { No, yeah, like I have a friend now that I made from I } \\
\text { think she is colombiana and she was like “oh, yeah, } \\
\text { like I did tennis professionally over there” but we } \\
\text { were all like, all my friends we were asking her like so } \\
\text { like “do you use Instagram?” and she was like “yeah” } \\
\text { she said “do you guys use it?” and we were like } \\
\text { “yeah” [laughs]. You expect something so different, } \\
\text { but at the same time like they are not that different in } \\
\text { their own culture. }\end{array}$ \\
\hline $\begin{array}{l}\text { Based on your school years, } \\
\text { if you had to rank history, } \\
\text { geography, economics, and } \\
\text { government from more to } \\
\text { least useful, how would you } \\
\text { rank them? Why? }\end{array}$ & $\begin{array}{l}\text { I think economics would have to be the first one only } \\
\text { because I personally feel that there's lot of people } \\
\text { that don't know how to manage their money, they } \\
\text { don't know how to manage their accounts, they go } \\
\text { into debt very fast, we have thousands of people going } \\
\text { in debt, countries are also going to be in problems so } \\
\text { I think that's something that has to start at home. } \\
\text { Ever since I was little too my parents would tell me } \\
\text { "this is how you use your credit card," “this is how } \\
\text { you save it, this kind of account, that kind of } \\
\text { account," you know, I definitely feel that's crucial to } \\
\text { society. Second, government because there's a lot of } \\
\text { people that might go out there and they go voting and } \\
\text { they don't know what they're doing, you can say “oh, } \\
\text { hey there's the district at large voting coming now," }\end{array}$ \\
\hline
\end{tabular}




\begin{tabular}{|l|l|}
\hline & $\begin{array}{l}\text { and they would be like “what is that?" and like you } \\
\text { don't know what it is, but you are going to go ahead } \\
\text { and vote for these people. It was my government class } \\
\text { that my teacher had for extra credit to write down } \\
\text { the name of two of the state senators, and none of the } \\
\text { girls in the class except for me and like two others } \\
\text { wrote that down and it was a problem because no one } \\
\text { had any idea what they were talking about and they } \\
\text { were just like “oh, it doesn't even matter to me” yet } \\
\text { they were all 19 or 18 and when he asked who's } \\
\text { voting, they all raised their hands. And I just found } \\
\text { that really disturbing that they didn't know at all } \\
\text { what was going on. They didn't even know you know } \\
\text { any of the simple terms and they were like “yeah, I'm } \\
\text { gonna go vote!” I just find that very problematic so... } \\
\text { third I would say geography so you can more or less } \\
\text { locate the issues that are going on so you are not like } \\
\text { “oh, this is going on in Africa” or “uh, that's } \\
\text { happening here” more so you can know where it's } \\
\text { going on. And I mean last is history, I mean just } \\
\text { because I think history is important, but it's not as } \\
\text { important as something you will be using right there } \\
\text { in the spot. I think economics and government have a } \\
\text { place in modern society that you're gonna have } \\
\text { hands on activities every day. History, not so much } \\
\text { so... }\end{array}$ \\
\hline Do you think students will & $\begin{array}{l}\text { Not really } \\
\text { exams difficult to you? }\end{array}$ \\
\hline Definitely yeah, I mean, at least one course, but \\
\hline
\end{tabular}




\begin{tabular}{|c|c|}
\hline $\begin{array}{l}\text { benefit from at least taking } \\
\text { one geography course in K- } \\
12 \text { ? }\end{array}$ & $\begin{array}{l}\text { personally I think maybe instead if they have to } \\
\text { choose one class I would say that across the country } \\
\text { they should have a personal financial management } \\
\text { course just because sometimes I for example wanted } \\
\text { to take that course and I couldn't because I had all } \\
\text { my other APs and all my classes to take, so I feel that } \\
\text { would be a good requirement to graduate just } \\
\text { because it's something that at the end of the day you } \\
\text { are going to use it. It's not one of those classes that } \\
\text { “OK, it was AP Music Theory.” Unless you are going } \\
\text { into music, you're not really gonna use it so... }\end{array}$ \\
\hline $\begin{array}{l}\text { Was the geography } \\
\text { information you learned } \\
\text { useful to you? }\end{array}$ & $\begin{array}{l}\text { We could have expanded a lot more on it, but it } \\
\text { wasn't a waste of time because I mean I did learn } \\
\text { from it, I did take something away from it at the end } \\
\text { of the day. }\end{array}$ \\
\hline $\begin{array}{l}\text { Do you think it had to do } \\
\text { with the extra effort you put } \\
\text { in to make it more } \\
\text { meaningful? }\end{array}$ & $\begin{array}{l}\text { Yeah, definitely, if I would have treated it like “oh, } \\
\text { it's just another class” memorizing information right } \\
\text { now that I will forget at the end of the semester then I } \\
\text { think I would have definitely wasted my time and I } \\
\text { wouldn't really have cared, but the fact that today } \\
\text { they can say a country and I can more or less -I } \\
\text { might not be able to exactly point at it on the map- } \\
\text { but I might be one or two countries away from it, I } \\
\text { would be pretty close by. }\end{array}$ \\
\hline What is you field of study? & Hos \\
\hline $\begin{array}{l}\text { Do you see any relation } \\
\text { between hospitality and } \\
\text { geography? }\end{array}$ & $\begin{array}{l}\text { Definitely, hospitality I think is very open, you are } \\
\text { gonna be dealing with a lot of internationals, there is } \\
\text { for example, over the summer I worked a lot, I had } \\
\text { an internship, it was dealing with event planning and }\end{array}$ \\
\hline
\end{tabular}




\begin{tabular}{|c|c|}
\hline & $\begin{array}{l}\text { event décor so I dealt sometimes with people who } \\
\text { wanted to do destination weddings so there were } \\
\text { people you know from California, there was another } \\
\text { girl from New York and they were all like, we want to } \\
\text { come and do it at Miami, Eden Roc, or we are going } \\
\text { to go to the InterContinental and you just have to be } \\
\text { prepared to work with different kinds of people, not } \\
\text { “oh, we are only going to work with these,” there's a } \\
\text { lot of people that are going to be involved, you know, } \\
\text { there's so many different things in that field... }\end{array}$ \\
\hline $\begin{array}{l}\text { If a course that tied } \\
\text { geography and your field of } \\
\text { study was developed, would } \\
\text { you consider taking it or be } \\
\text { willing to look at its course } \\
\text { description? }\end{array}$ & Definitely, yes. \\
\hline $\begin{array}{l}\text { How important is having } \\
\text { geography knowledge when } \\
\text { discussing current events? }\end{array}$ & $\begin{array}{l}\text { I definitely think it's important 'cause sometimes you } \\
\text { might be talking and they would tell you all about it } \\
\text { and “oh my God, this issue is going on and it's so } \\
\text { important and I feel so strongly about it” and then } \\
\text { you might ask them a question like “OK, what's } \\
\text { happening around it that you think may be } \\
\text { influencing that?” and they are like “oh, I don't } \\
\text { know!” I think it just makes them sound a little bit } \\
\text { ignorant just because they don't take the extra step of } \\
\text { trying to find out more or less what exactly is going } \\
\text { on so they might think oh yes this is terrible and this } \\
\text { is happening, but you don't know what's going on }\end{array}$ \\
\hline
\end{tabular}




\begin{tabular}{|c|c|}
\hline & $\begin{array}{l}\text { around it, the circumstances, you don't know what's } \\
\text { influencing so... }\end{array}$ \\
\hline $\begin{array}{l}\text { Geographers believe } \\
\text { geography is beneficial to all } \\
\text { society. Do you agree of } \\
\text { disagree with this statement? }\end{array}$ & $\begin{array}{l}\text { Yeah, because I mean, like I said you are going to } \\
\text { meet all kinds of people wherever you go or even if } \\
\text { you know example science, there's going to be } \\
\text { researchers everywhere and say you choose a } \\
\text { particular species there can be that kind of species } \\
\text { across the world, you don't know that, hospitality, } \\
\text { you are going to be dealing with different clients, } \\
\text { engineering, there's different types of architecture, } \\
\text { things you need to take into perspective such as the } \\
\text { natural disasters in the area, it's just something that } \\
\text { wherever you go you should know more or less the } \\
\text { land 'cause at the end of the day it's definitely gonna } \\
\text { influence how you live. }\end{array}$ \\
\hline $\begin{array}{l}\text { And what about for daily-life } \\
\text { applications like deciding } \\
\text { where to buy a house or } \\
\text { where to go to school? Do } \\
\text { you think people associate } \\
\text { geography to some of our } \\
\text { basic decision-making? }\end{array}$ & $\begin{array}{l}\text { Sometimes, I mean, I had a lot of friends that they } \\
\text { would decide like their college “oh, just because I } \\
\text { want to go there.” I for example I applied to three } \\
\text { schools only because I think it's important for me to } \\
\text { build a networking in hospitality because I'm not } \\
\text { going to go study hospitality you know in the middle } \\
\text { of Kansas or you know Ohio, I'm not gonna go over } \\
\text { there. I'm in Miami, I'm in a perfect place for } \\
\text { hospitality and networking so I definitely think where } \\
\text { you go, where you study it's going to have an impact } \\
\text { with what you do. }\end{array}$ \\
\hline $\begin{array}{l}\text { Will geography knowledge } \\
\text { one day be as necessary for } \\
\text { efficient citizenship as the }\end{array}$ & $\begin{array}{l}\text { It should just 'cause it is important, but I feel like } \\
\text { there's a lot of people that are way too caught up in } \\
\text { technology and think “oh, I can just Google it” so it } \\
\text { doesn't really matter to them “oh, I have Google }\end{array}$ \\
\hline
\end{tabular}




\begin{tabular}{|c|c|}
\hline ability to read and write? & $\begin{array}{l}\text { maps.” I asked my friend the other day, “you have } \\
\text { been driving for all these years and you still can’t go } \\
\text { to an address without a GPS?” And she was like “no, } \\
\text { it doesn't really matter 'cause I always have my GPS } \\
\text { on my phone” so I was like... I feel we are dependent } \\
\text { on our technology so I definitely think that's not a } \\
\text { good thing, I mean, it should be more important. }\end{array}$ \\
\hline $\begin{array}{l}\text { Student reacts to essential } \\
\text { elements... }\end{array}$ & $\begin{array}{l}\text { \#1 [How to use maps and other geographic } \\
\text { representations, tools, and technologies to acquire, } \\
\text { process, and report information] alright, that one I } \\
\text { would have to say I learned from my parents, just } \\
\text { you know if they give me an address I'm able to } \\
\text { recognize where to go. } \\
\text { \#2 [How to use mental maps to organize } \\
\text { information about people, places, and } \\
\text { environments] OK, yeah, just again in my family if I } \\
\text { call my mom “oh, is there a Taco Bell in the area?” } \\
\text { or “is there this?” or I have some family members in } \\
\text { Aventura and you will see a few more synagogues } \\
\text { because of the Jewish people in the area so I mean it } \\
\text { all depends where you are at and were people gather, } \\
\text { in Doral there are more Venezuelans and little } \\
\text { Venezuelan shops or coffee shops so... } \\
\text { people, places, and environments on Earth's } \\
\text { \#3 [How to analyze the spatial organization of } \\
\text { surface] Yeah. }\end{array}$ \\
\hline & \#4 [The physical and human characteristics of \\
\hline
\end{tabular}




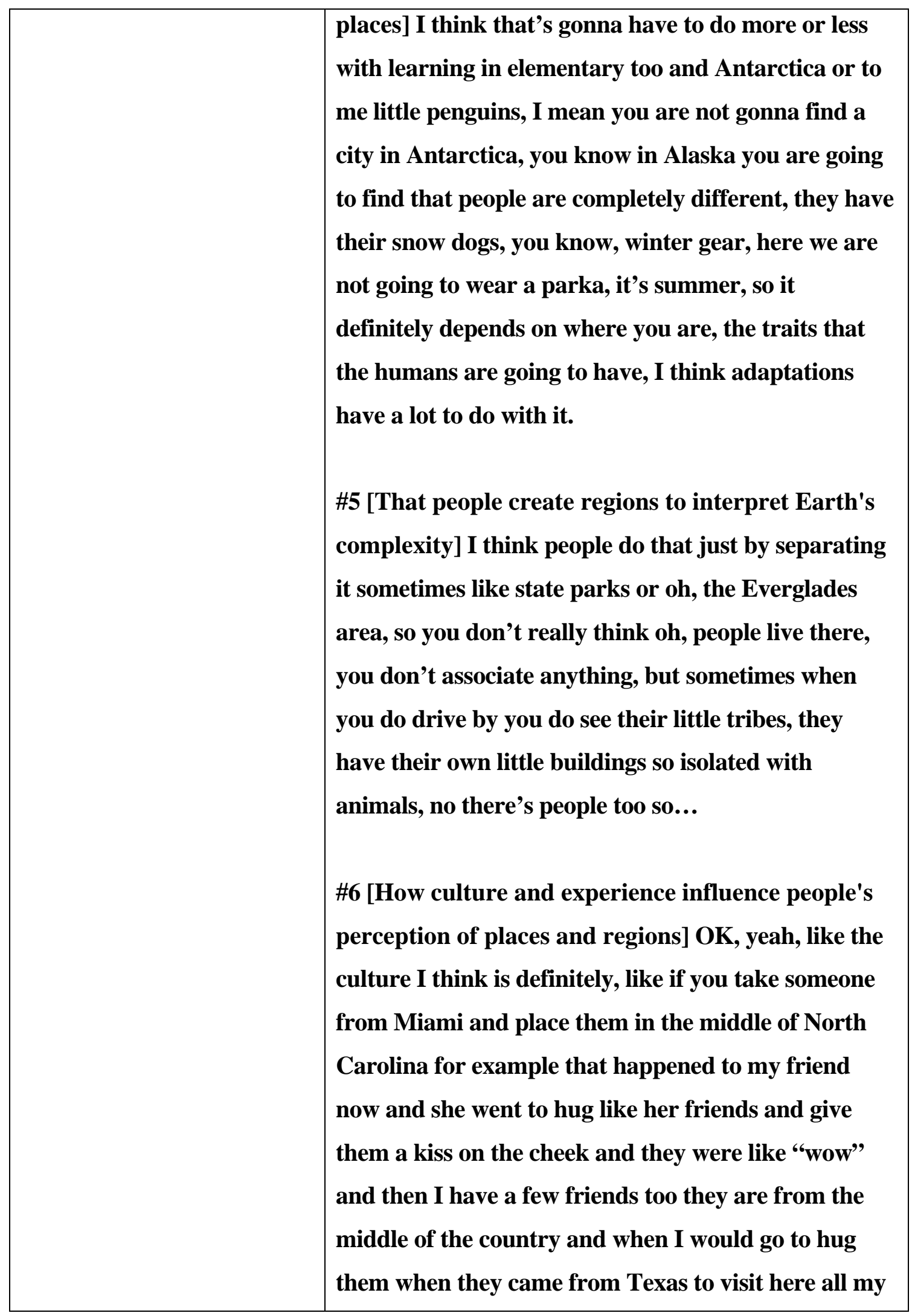




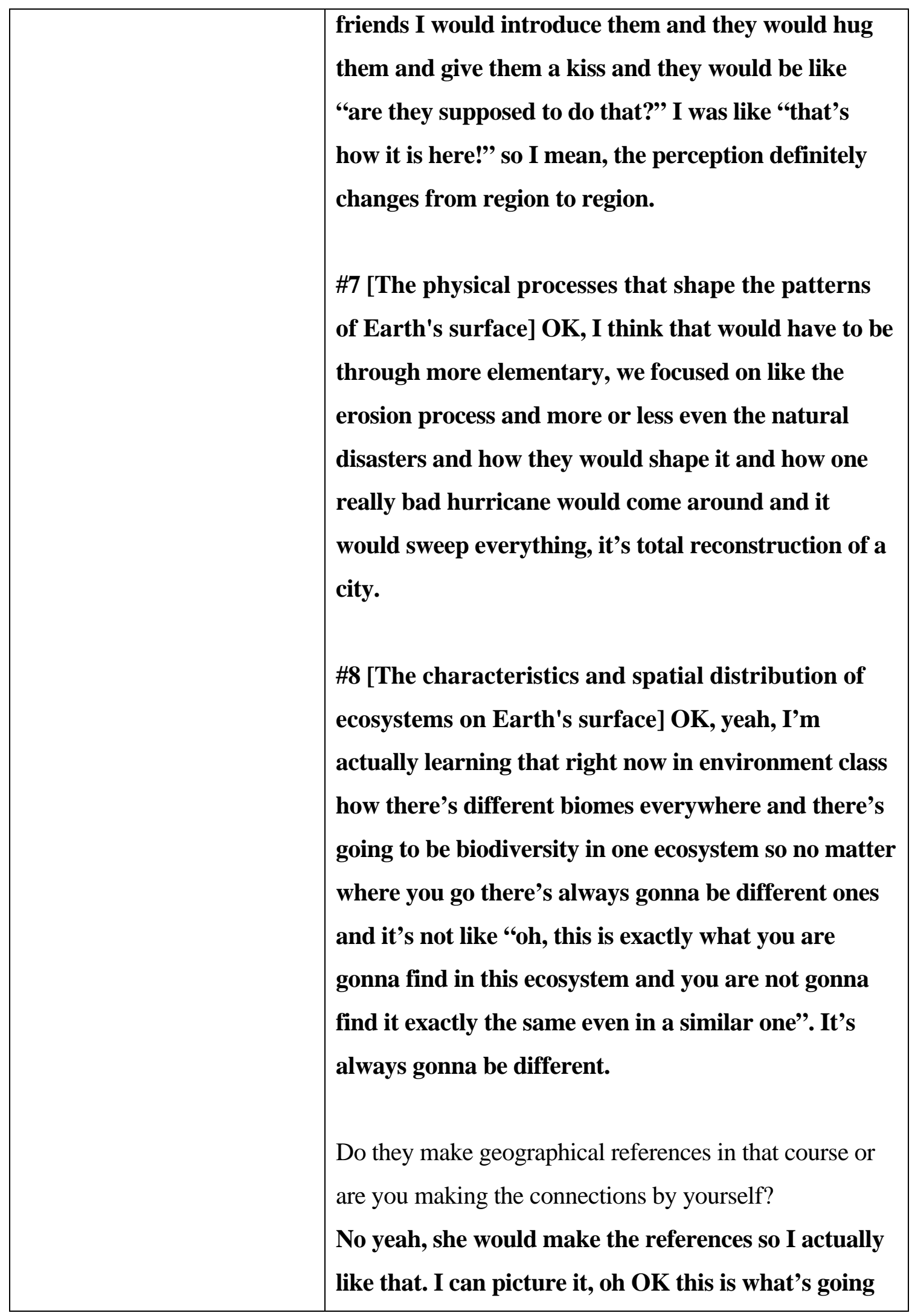




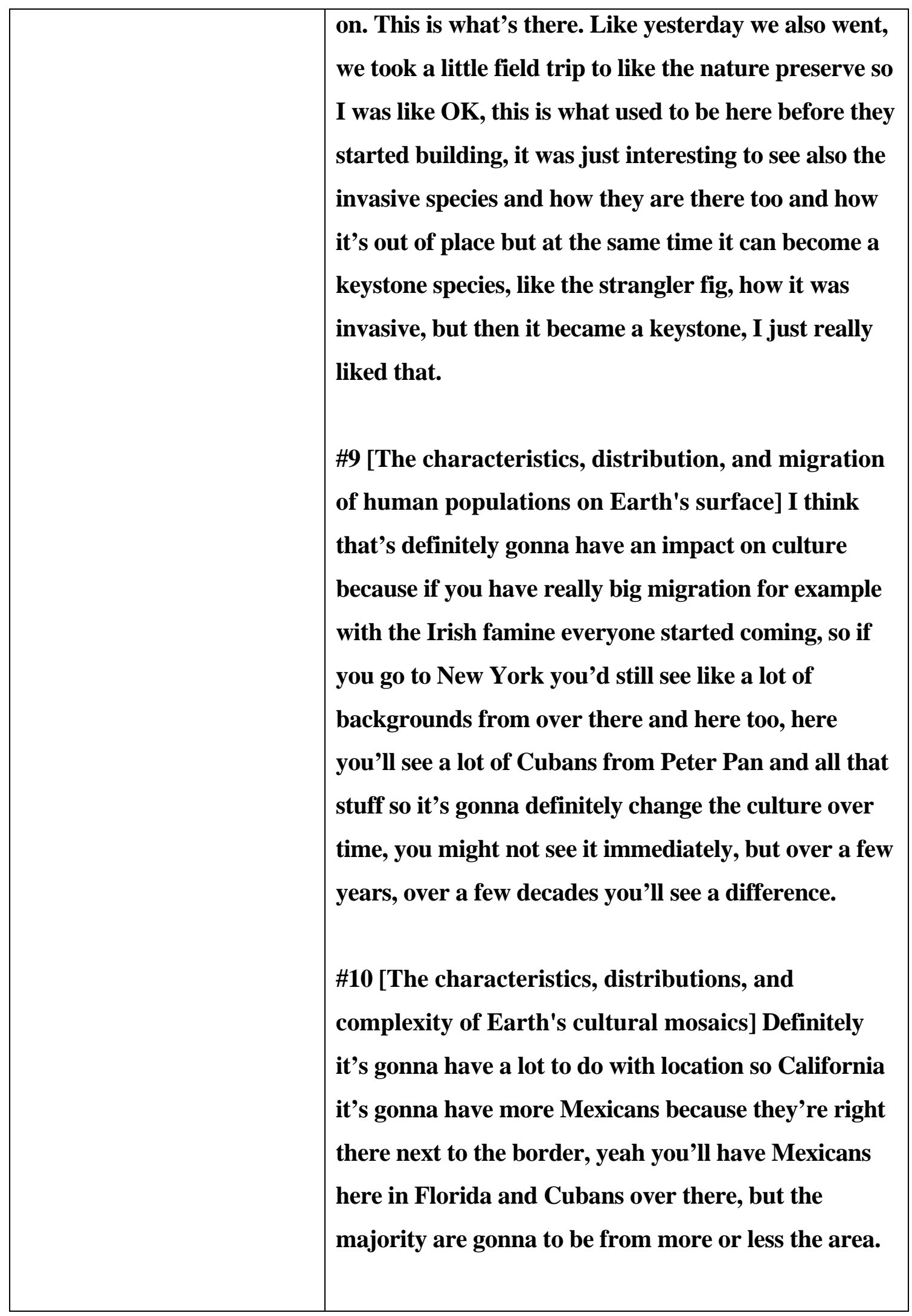




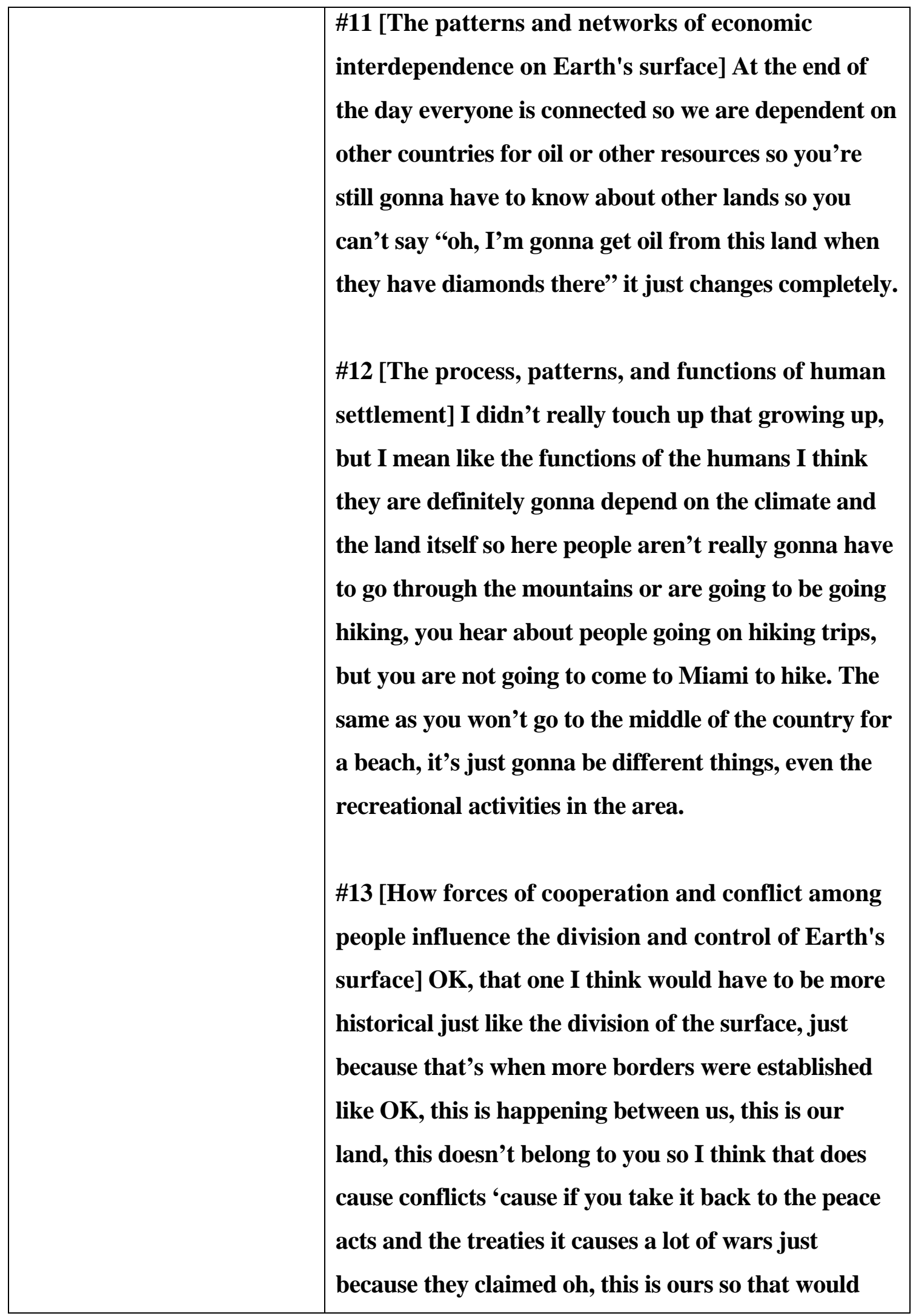




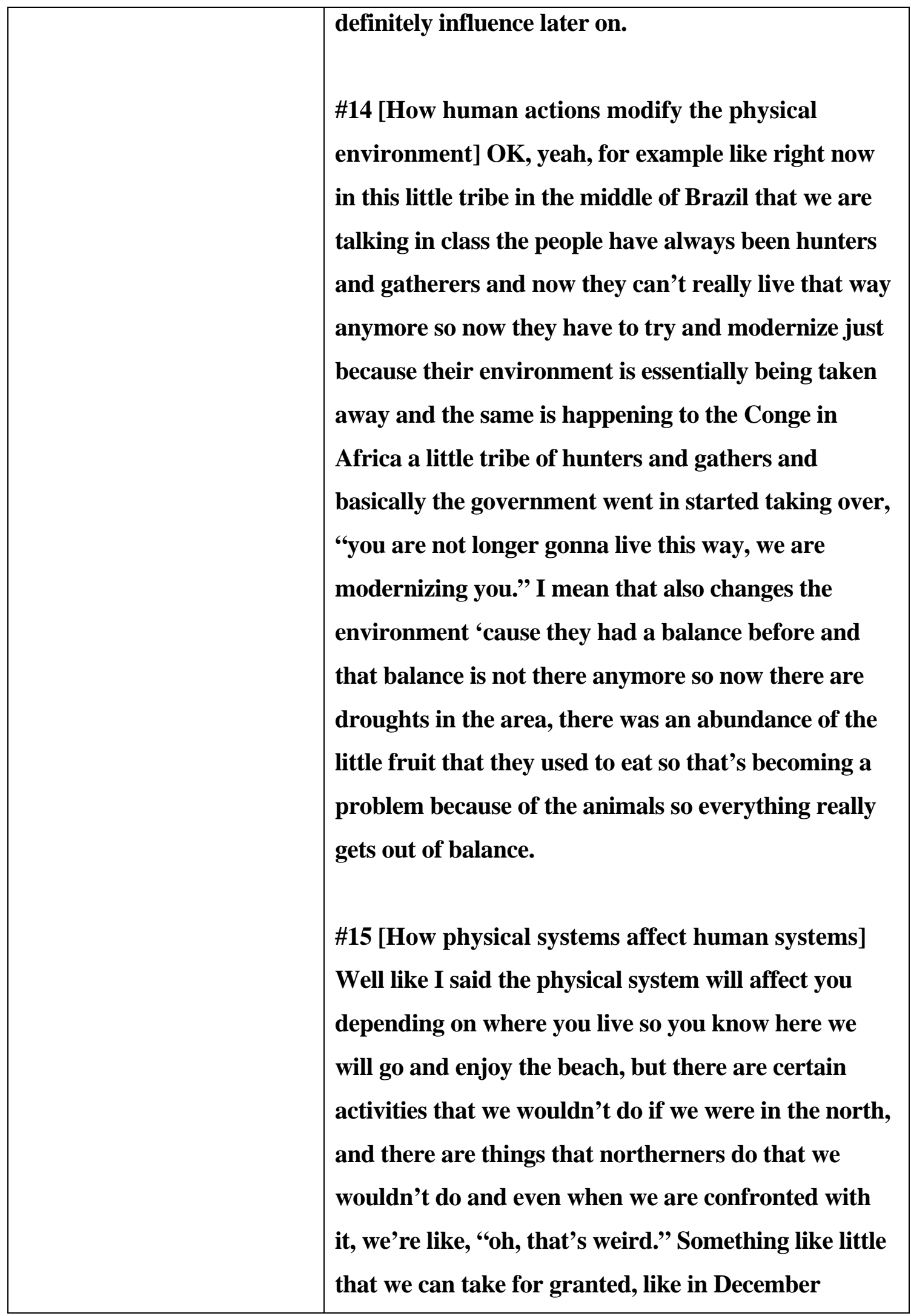




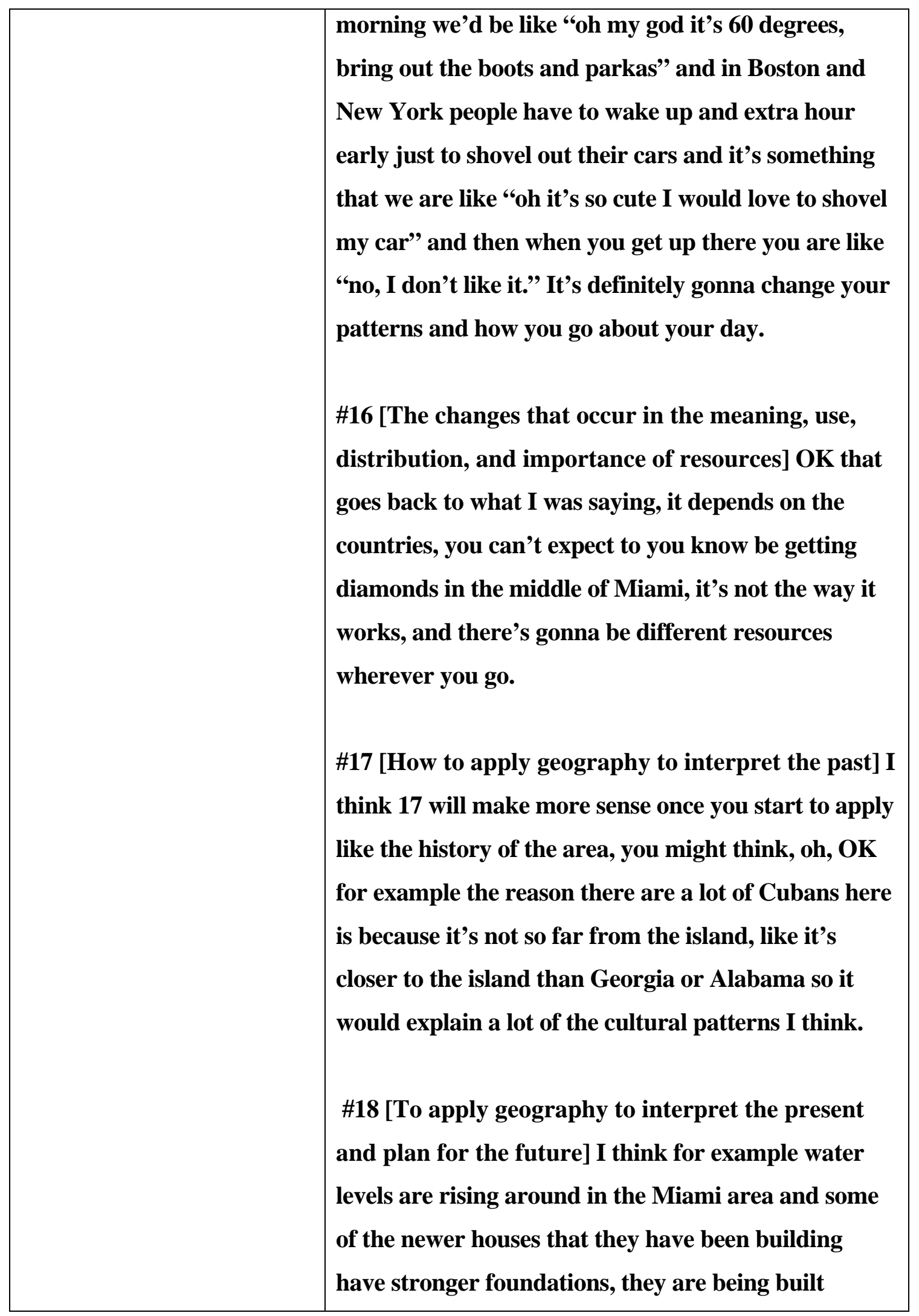




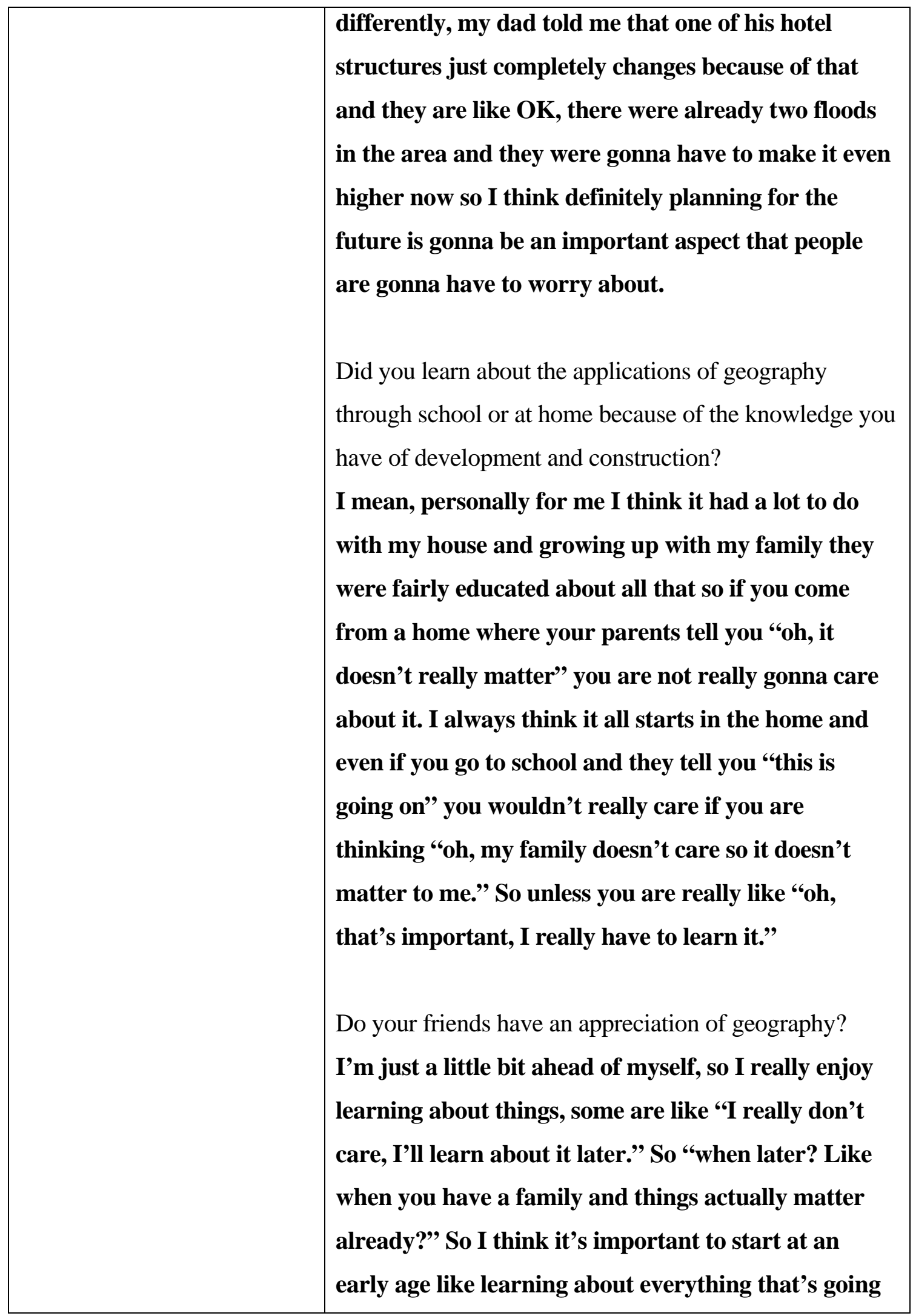


on around you just because then you are already into the habit of doing it when you are older. 
VITA

DANIELA FABIANA OTTATI REPERGER

Born, Montevideo, Uruguay

2005-2009

B.S., Elementary Education with ESOL Certificate, Honors College Certificate, European Studies Minor, Advertising

Florida International University

Miami, FL

2009-2010

M.S., Mass Communication

Florida International University

North Miami, FL

2010-2013

Teacher, Fourth Grade Dual Language Teacher, Fourth Grade Aventura Waterways K-8 Center Miami, FL

2011-2015

Ed.S., Curriculum \& Instruction Ph.D Candidate, Curriculum \& Instruction Adjunct Professor, Communication Arts Worlds Ahead Graduate Florida International University Miami, FL 